\title{
The Association between Suicidality and Treatment with Selective Serotonin Reuptake Inhibitors in Older People with Major Depression: a Systematic Review
}

\author{
Dr Edward KoKoAung \\ Master of Clinical Science \\ School of Translational Science \\ Faculty of Health Sciences \\ The University of Adelaide \\ South Australia.
}

$25^{\text {th }}$ August 2014 


\section{ACKNOWLEDGEMENTS}

It would not have been possible for me to complete this thesis without the support of a number of significant people whom I would like to acknowledge and thank.

Firstly, I would like to thank my supervisors Associate Professor Edoardo Aromataris and Ms Alexa McArthur for their ongoing advice and guidance. I would particularly like to thank Associate Professor Edoardo Aromataris for his time, patience and encouragement which enabled me to go beyond my comfort zone. I would also like to thank Ms Sally Cavenett, my secondary reviewer, for her help and support. To complete this thesis, I required a great deal of help from the academic and office staff at the Joanna Briggs Institute, librarians at the Noarlunga Hospital, Flinders Medical Centre and Barr Smith Library. This would not have been possible without their direct support to complete this systematic review.

To my wife and daughter I thank you for supporting me during this challenging time. I realise many things in our household became 'topsy-turvy' in order to me to complete this task. Finally, my thanks go to the older patients who were involved in the studies, carers and the investigators who proved their dedication to improving safety and patient care. 


\section{DECLARATION}

I, Edward KoKoAung, certify that this work contains no material that has been accepted for the award of any other tertiary institution, and, to the best to my knowledge and belief, contains no material previously published or written by any other person, except where due reference has been made in the text. In addition, I certify that no part of this work will, in the future, be used in a submission for any other degree or diploma in any university or other tertiary institution without the prior approval of the University of Adelaide and where applicable, any partner institution responsible for the joint award of this degree.

I give consent to this copy of my thesis, when deposited in the University Library, being made available for loan and photocopying, subject to the provisions of the Copyright Act 1968.

I also give permission for the digital version of my thesis to be made available on the web, via the University's digital research repository, the Library catalogue, and also through web search engines, unless permission has been granted by The University to restrict access for a period of time.

\section{Edward KoKoAung}

$25^{\text {th }}$ August 2014 


\begin{abstract}
Suicide is a leading cause of death in Australia, most notably amongst elderly men over the age of 75. Currently, treatment with Selective Serotonin Reuptake Inhibitors (SSRI) is regarded as preventive against suicidality in late life depression. The aim of this systematic review was to synthesise the best available evidence, including both experimental and observational data, on the association between treatment with SSRIs and suicidality in older people over the age of 60 . A comprehensive literature search was conducted to locate relevant studies. Methodological quality of eligible studies was assessed using Joanna Briggs Institute (JBI) critical appraisal checklists and the McMaster Quality Assessment Scale for Harms (McHarm). Research data was extracted using the JBI data extraction tool for experimental and observational studies. Eight randomised controlled trials on short-term SSRI treatment and five observational studies investigating longer term SSRI exposure in the geriatric population were included. The overall methodological quality of RCTs and observational studies was high. Separate meta-analyses were conducted for the experimental and observational studies. Analysis of experimental studies revealed no difference in the risk of suicide attempt in elderly participants treated with SSRIs compared to Tricyclic Antidepressants with OR 1.0 ( $95 \% \mathrm{Cl} 0.14,7.10)$ and showed no statistically significant heterogeneity $\mathrm{Chi}^{2} 3.88, \mathrm{I}^{2} 23 \%, \mathrm{P}=1.00$. Synthesis of observational studies however, suggested an $18 \%$ increased risk of attempting suicide with long-term SSRI treatment compared to no treatment in elderly patients with major depression OR 1.18 (95\% Cl 1.10, 1.27), $\mathrm{Chi}^{2} 34.81, \mathrm{I}^{2} 94 \%, \mathrm{P}<0.00001$. In contrast to the experimental studies, the presence of statistically significant heterogeneity in the included observational studies may predispose them to bias in their meta-analysis. Nevertheless, the results of this systematic review highlight the important clinical implications of the need to systematically monitor the risk of suicide in elderly patients on long-term SSRI treatment.
\end{abstract}




\section{TABLE OF CONTENTS}

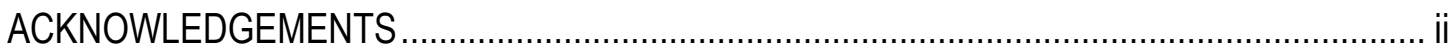

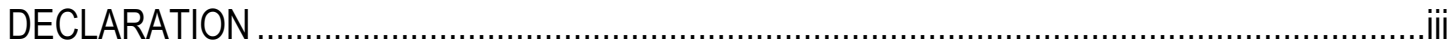

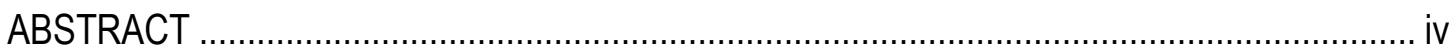

1 CHAPTER ONE: GENERAL INTRODUCTION .......................................................... 1

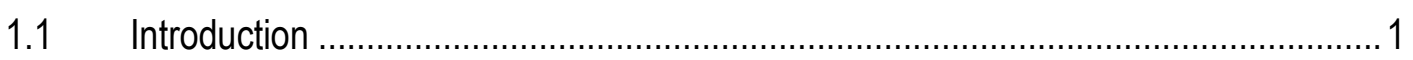

1.1.1 Suicide among elderly people in Australia .................................................. 1

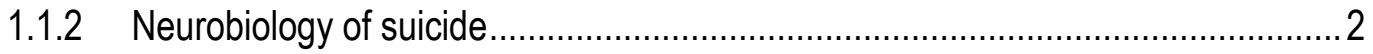

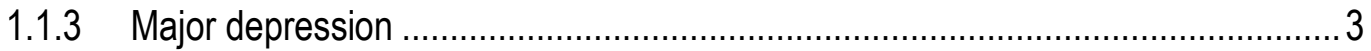

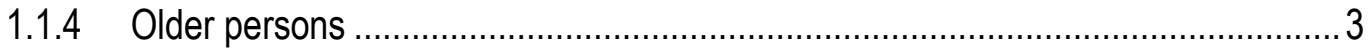

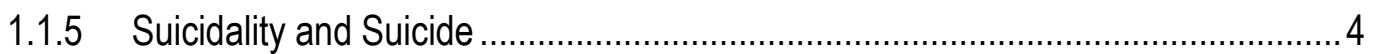

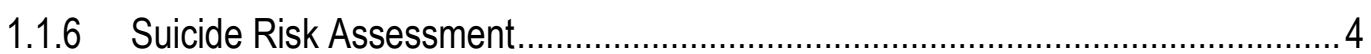

1.1.7 Prevalence of suicide in major depression.................................................... 4

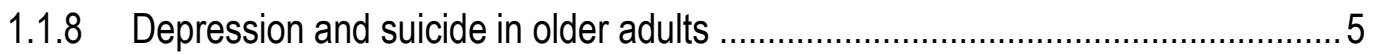

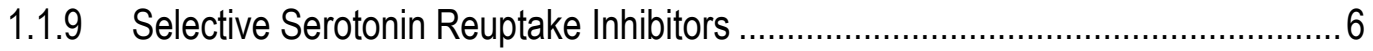

1.1.10 Selective Serotonin Reuptake Inhibitors and treatment for major depression in

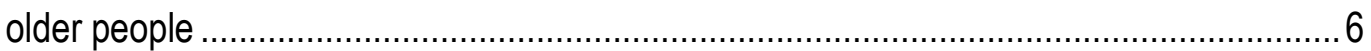

1.1.11 Suicide harms associated with antidepressant treatment .................................. 7

1.1.12 The US Food and Drugs Administration (FDA) black box warning on Selective Serotonin Reuptake Inhibitors ............................................................................ 7

1.1.13 Evidence against the Food and Drugs Administration Black box warning............ 8

1.1.14 Investigating harms and adverse consequences of a treatment ........................ 9

1.1.15 Measurement of suicide/suicidality as an outcome in clinical studies ................10

1.1.16 Methodological and ethical limitations suicide research in the elderly................11

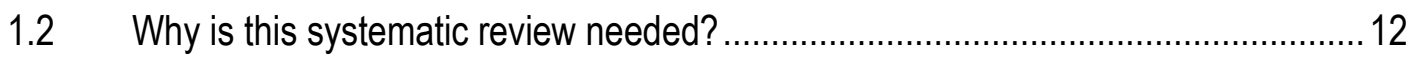

1.2.1 Current evidence for a relationship between SSRI treatment and risk of suicide/suicidality in late life depression.................................................................... 12

1.3 Combining the results of experimental and observational studies .......................... 14

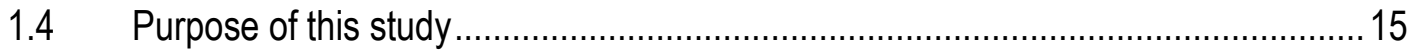

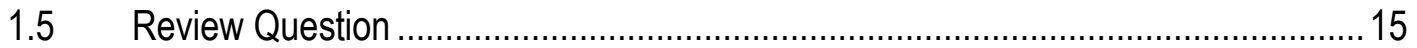

2 CHAPTER TWO: SYSTEMATIC REVIEW methods................ Error! Bookmark not defined.

2.1 Type of participants ................................................... Error! Bookmark not defined.

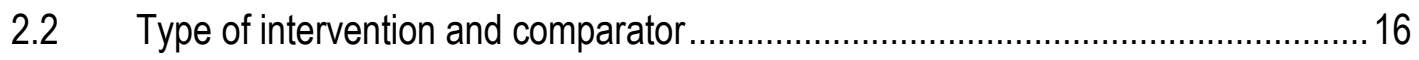




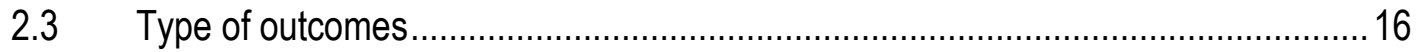

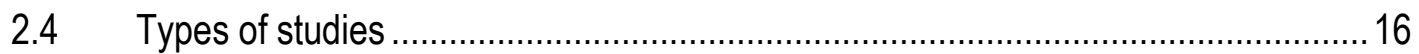

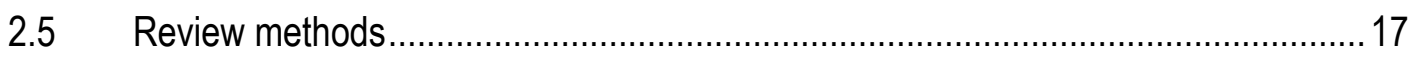

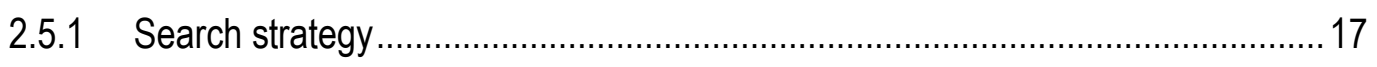

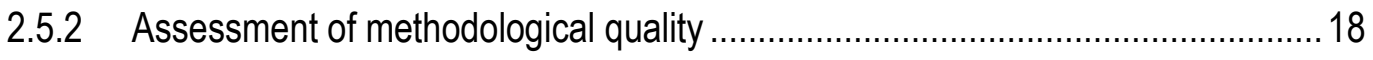

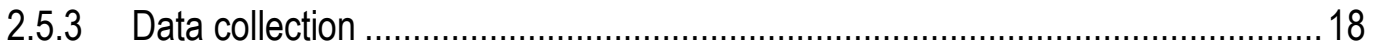

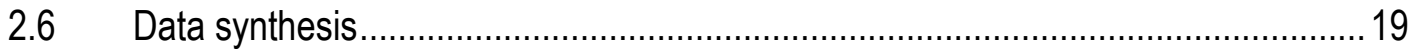

3 CHAPTER THREE: RESULTS ............................................ Error! Bookmark not defined.

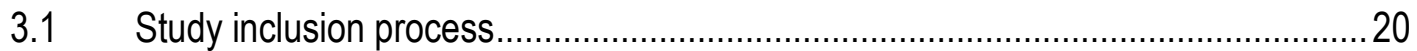

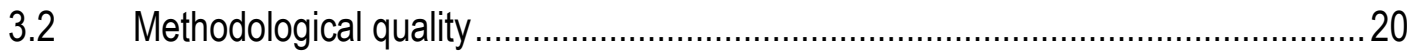

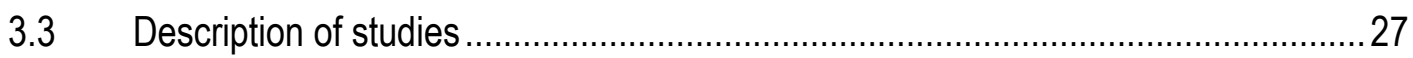

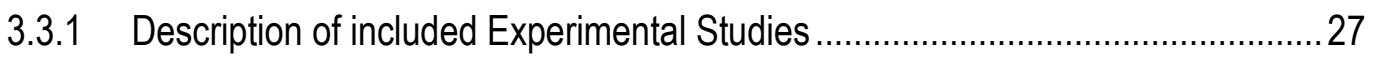

3.3.2 Description of included Observational studies ….................................................

3.4 The rate of emergent suicidal ideation, suicide and suicide attempt with Selective

Serotonin Reuptake Inhibitors .................................................... 38

3.4.1 Emergence of suicidal ideation with Selective Serotonin Reuptake Inhibitors in

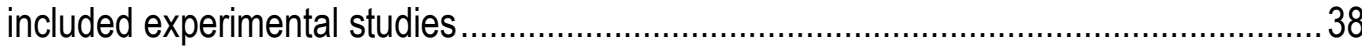

3.4.2 Suicide attempts with Selective Serotonin Reuptake Inhibitors in included experimental studies

3.4.3 Suicide and suicide attempt with Selective Serotonin Reuptake Inhibitors in included observational studies ........................................................ 40

4 CHAPTER FOUR: DISCUSSION

4.1 Major findings from the Systematic Review......................................................... 43

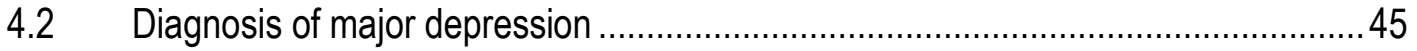

4.3 Comparison with findings from wider literature review .......................................... 46

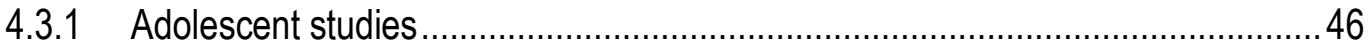

4.3.2 Evidence from wider studies involving adult and older people ..........................4 47

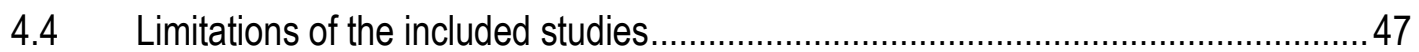

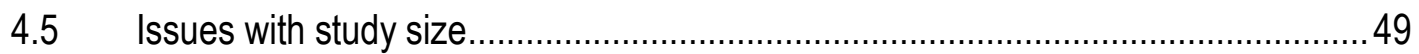

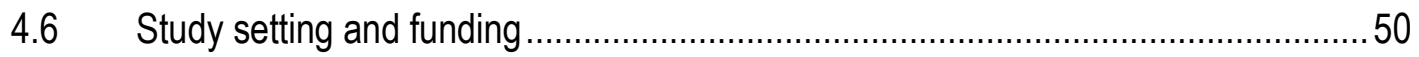

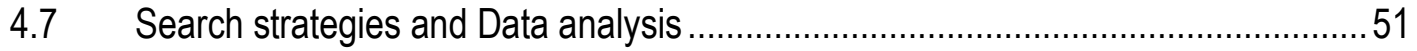

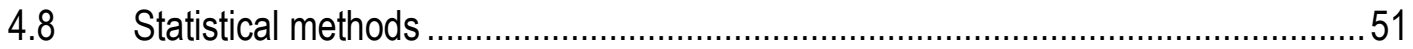




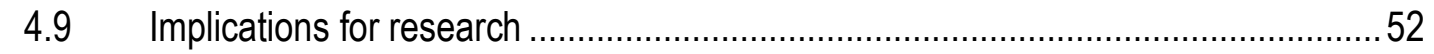

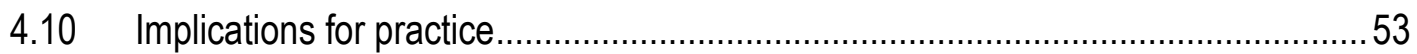

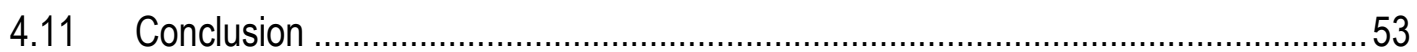

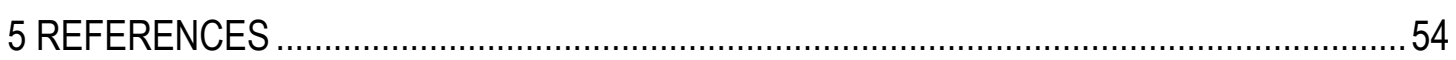

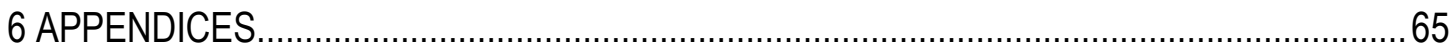

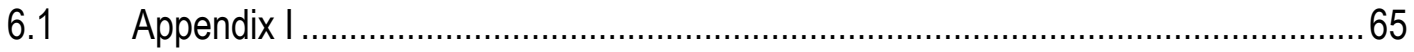

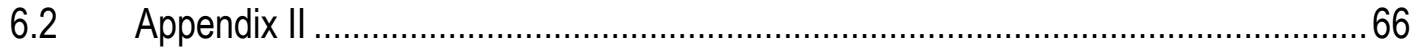

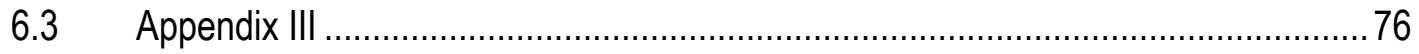

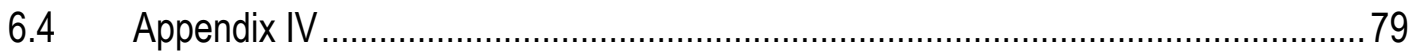




\section{LIST OF TABLES}

Table 2.1 Databases and grey literature sites searched and the date when each search was performed

Table 3.1 Critical appraisal scores of the included experimental studies

Table 3.2 Critical appraisal scores of the included observational studies

Table 3.3 McHarm critical appraisal Score for Included Studies

Table 3.4 Study characteristics of the Included Experimental Studies 31

Table 3.5 Study characteristics of Included Observational Studies

Table 3.6 Rate of emergent suicidal ideation for different SSRIs 39

Table 3.7 Rate of suicide attempt for different SSRIs 40

Table 3.8 Suicide-related events in observational studies

\section{LIST OF FIGURES}

Figure 3.1 Outline of the study inclusion process 21

Figure 3.2 Meta-Analysis of Risk of Emergent Suicidal Ideation with SSRI 38 versus Placebo Treatment in Experimental Studies

Figure 3.3 Meta-Analysis of Risk of Suicide Attempt with SSRI versus other Antidepressant Treatment in experimental studies

Figure 3.4 Meta-Analysis of Risk of suicide with SSRI in Observational Studies 42

Figure 3.5 Meta-Analysis of Risk of Suicide attempt with SSRI Treatment in Observational Studies 


\section{CHAPTER ONE: GENERAL INTRODUCTION}

\subsection{Introduction}

\subsubsection{Suicide among elderly people in Australia}

The number of elderly people in Australia is steadily rising. The Australian Bureau of Statistics (ABS, 2012) reports that between 30 June 1992 and 30 June 2012, the proportion of the Australian population aged 65 years and over, increased from $11.5 \%$ to $14.2 \%$. (1) Similarly, in the 12 months to 30 June 2012, the number of people aged 85 years and over increased by 20,400 people (5.1\%) to reach 423,700 . Thus, over the past two decades the number of people over the age of 85 increased by $160 \%$ compared to a total population growth of $30 \%$ over the same period.(1) It is not known how many people among this elderly population experienced a mental disorder for the first time in their late life. Analyses of similar health data estimated that $45 \%$ of all Australians have experienced a mental disorder at some point in their lifetime.(2) About three quarters of the adult population who seriously thought about committing suicide had a mental disorder (72\%); of these, $77 \%$ had an anxiety disorder, $63 \%$ had a mood disorder and $34 \%$ had some substance use disorder.(1)

Suicide is the 15th leading cause of death in Australia with a rate of 1 per 100,000 people per year.(1) In 2008, the reported age-specific mean death rate for suicide in males over the age of 65 years was $23.5 / 100,000$ and for females, $4.4 / 100,000$.(1) In the 30-45 year age group, the rate was marginally higher, with $27.7 / 100,000$ for males and $6.4 / 100,000$ for females.(1) Raymond(3) suggests that suicide rates are too high among Australia's elderly compared to other age groups. The rate of suicide in males over the age of 75 was 25.8/100,000 per year compared to $4.7 / 100,000$ for females. (1) Research conducted in the Australian Capital Territory suggests the most common methods of choice for elderly suicide cases were hanging $(30 \%)$, gas (18\%) and using a firearm (12\%). ${ }^{(4)}$

These numbers clearly indicate suicide is a significant public health issue. (5) Knox et al. (6) looked at suicide as a preventable public health concern not confined only to the emergency mental health service. (6) This source stated that although suicide is not a disease, it is a tragic endpoint of complex aetiology and a leading cause of death worldwide. Suicide prevention is now viewed as both a clinical and public health concern which requires coordinated multidisciplinary clinical intervention and public health response.

Suicide may not always be pathological and caused by identifiable depression or psychiatric pathology driven by psychosis. For example, Pridmore and Walter ${ }^{(7)}$ highlighted that culturebound personal decisions may be involved in some suicide cases such as self-immolation in 
Tibet. Many elderly patients suffer from dementia and other medical conditions and as a result their quality of life is severely reduced. These patients often live in nursing homes with minimal social support or contact. This living environment may contribute to clinical depression and suicidal ideation.

Kleepsies et al.(8) reported concepts of rational suicide and assisted suicide in certain circumstances in older people suffering from a terminal illness. Similarly, Ginn et al.(9) reported that $72 \%$ of senior doctors in England and Wales agreed with the possibility of rational suicide, a considered suicide act made by a sound mind, a precondition of assisted dying legislation. In 2013, the New South Wales state parliament proposed the legalisation of euthanasia, however, The Rights of the Terminally III bill was defeated.(9) In the developed world, the occurrence of indirect self-destructive behaviour (ISDB), which often leads to premature death among nursing home residents, is reported as silent suicide, or sub-intentional suicide.(10) Such events or rational suicide in palliative care patients may not be included in the ABS national figures. The review by Szanto et al ${ }^{11}$ reported that antidepressant treatment may be associated with decreased suicide risk in elderly depressed patients.

\subsubsection{Neurobiology of suicide}

The search for biological markers for suicide is continuing. Carballo et al.(12) hypothesize that genetics and early environmental challenges influence Hypothalamic-Pituitary Adrenal (HPA) axis function, which in turn interacts with brain neurochemistry. The authors suggested this HPA effect on neurochemistry may relate to several clinical endophenotypes relevant to suicidal behaviour including impulsivity, aggression, pessimism and hopelessness. ${ }^{(12)}$ The same authors also reported that a higher level of hopelessness was reported in suicide attempters compared to normal controls. Hypothalamic-Pituitary Adrenal hyperactivity observed in suicide may also be responsible for some of the serotonin abnormalities associated with suicide.(13) These authors suggested that corticosteroid modulation of $5 \mathrm{HT}$ receptors (5hydroxytryptamine receptors are cellular binding sites for serotonin) may have important implications for pathophysiology and treatment of both mood disorders and suicide. Low cerebrospinal fluid serotonin level has also been linked to suicide attempts in people.(14) Similarly, studies by Arango et al. (15) in 1990 and Hrdina et al.(16) in 2003 reported increased prefrontal cortical 5HT2A binding in the brain of suicide victims. Furthermore, Slater et al. ${ }^{17}$ ) proposed that malfunctions in serotonergic, dopaminergic and noradrenergic neuropathways were involved in the pathophysiology of suicide. Recently, Brent et al.(18) reported the potential role of genetic polymorphisms involved in transcription (CREB1), neuroprotection (BDNF and 
NTRK2), glutamatergic and noradrenergic neurotransmission (GRIA3, GRIK2 and ADRA2A), the stress and inflammatory responses (FKBP5 and IL28RA), and the synthesis of glycoproteins (PAPLN) in antidepressant treatment-emergent suicidal events.

\subsubsection{Major depression}

Depression among the elderly population is heterogeneous in nature and clinically complicated by factors such as the presence of co-occurring medical conditions. To meet the diagnosis of major depressive disorder, the Diagnostic and Statistical Manual of Mental Disorders Fourth Edition (DSM IV)(19) requires five out of the following nine symptoms to be present almost daily over the preceding two week period: 1) Depressed mood most of the day, nearly every day. 2) Markedly diminished interest in pleasure in all, or almost all, activities most of the day, nearly every day as indicated by either subjective account or observation made by others. 3) Significant weight loss when not dieting or weight gain or decrease or increase in appetite nearly every day. 4) Insomnia or hypersomnia nearly every day. 5) Psychomotor agitation or retardation nearly every day observable by others. 6) Fatigue or loss of energy nearly every day. 7) Feelings of worthlessness or excessive or inappropriate guilt nearly every day. 8) Diminished ability to think or concentrate, or indecisiveness, nearly every day. 9) Recurrent thoughts of death (not just fear of dying), recurrent suicidal ideation without a specific plan, or a suicide attempt or a specific plan for committing suicide.(19) Of the identified diagnostic symptoms, loss of pleasure in life, excessive guilt and recurrent suicidal ideations are stronger indicators of major depression in older people who have medical co-morbidities.

The severity of major depression is graded as mild, moderate and severe in DSM IV. (19) For a major depression a mild episode needs to fulfil four out of nine diagnostic criteria and functioning impairment must also be mild. For moderate severity, the episode needs to fulfil more than five diagnostic criteria with a moderate degree of functional impairment. Severe major depression is associated with psychotic features which can cause serious functioning impairment.(19)

\subsubsection{Older persons}

Older people are described in the literature using the terms elderly, geriatric, senior or older adults. In Australia, the USA, Canada and the UK, the age at which an individual may be referred to as an 'older person' varies. The age commonly used to denote an older person by mental health services in Australia is 65 years. Many SSRI clinical trials in geriatric settings, however, use 60 years as the age cut-off point to define their sample.(20) This systematic review 
considered persons aged 60 years and over as participants in order to include the maximum number of relevant geriatric SSRI trials.

\subsubsection{Suicidality and Suicide}

The term suicidality is criticised due to its vagueness on clinical application and potential for misinterpretation or misuse of the term. In suicide research, suicidality is often used to cover all behaviour related to suicide risk. For the purposes of this review, suicidality is conceptualised as a composite outcome that includes suicide ideas, preparatory acts, suicide attempts and death by suicide.(21) Suicide is defined as the act of taking one's own life on purpose.(22) Suicide is a complex, multi-causal human behaviour related to several psychiatric-medical, psychosocial and demographic risk factors. ${ }^{20)}$ Suicide risk is seen as a continuum between suicidal ideation and completed suicide. Suicidal behaviour is any action that could cause a person to die from suicide, for example taking a drug overdose.(22) Similar to suicidality, suicidal behaviour encompasses completed suicide, attempted suicide and any preparatory act of suicide. Stone et al. (23) used the term suicidality to cover suicidal behaviour and suicidal ideations. The relationship between suicidal ideation and completed suicide is not linear. Furthermore, identification of attempted suicide is complicated by the presence of deliberate self-harm acts without suicidal thoughts or intent. In the community, people may have suicidal ideation at some stage of their life with no intention to act on it. In a survey of a random sample of the South Australian adult general population including persons aged 55 and over, $5.6 \%$ of men and $5.3 \%$ of women had suicidal ideation.(24)

\subsubsection{Suicide Risk Assessment}

Beck et al.(25) developed a rating scale for suicide ideation. In practice, rating scales are not routinely used in emergency clinical settings as a substitute for a good clinical assessment and judgement. The US Food and Drug Administration (FDA) used the following classification in the analysis of suicide risk in clinical trials of antidepressants.(22) They classified outcomes relevant to suicide risk into seven mutually exclusive categories as follows: 1) completed suicide, 2) suicide attempt 3) preparatory acts towards imminent suicidal behaviour, 4) suicidal ideation, 5) self-injurious behaviour, intent unknown, 6) not enough information (fatal) and, 7) not enough information (non-fatal). 


\subsubsection{Prevalence of suicide in major depression}

Blair-West et al.(26) estimated the lifetime suicide risks for adult men and women with major depression were $7 \%$ and $1 \%$ respectively, while the combined risk was reported as $3.4 \%$. According to Coryell et al. (27) the suicide rate in major depression was $4.2 \%$ based on an analysis of data concerning 785 adults with a major depressive disorder between 1976 and 1990 in Michigan, USA. In comparison, the 10 year risk of suicide after schizophrenia had been diagnosed was 4.0\%.(28) Unutzer et al. (29) identified $13-15 \%$ of older depressed community patients who reported having suicidal ideation. Similarly, Cattell (30) reported that males aged 75 and over had the highest rates of suicide in nearly all industrialised countries, and among many of these nations suicide rates rose with age. This author $(30)$ indicates there is evidence to suggest that suicide rates among older people are among the highest, and are in turn more closely related to serious mental illness (especially major depressive illness) and significant physical health problems than in any other group. Fiske et al.(31) noted that physical illness such as cancer, congestive heart failure or Parkinson's disease increases the risk of suicide late in life. Despite these figures, however, most older adults with a chronic health problem or terminal illness do not die by suicide.(8) Fiske et al.(31) argued that depression outweighs physical illness as a risk factor for suicide in later life. Furthermore clinical attention and assessment of depression as a suicide risk in physically ill older adults are necessary to avoid two things: firstly, failed recognition; and secondly, failed treatment of those elderly who come into contact with health services.

\subsubsection{Depression and suicide in older adults}

Depression is one of the leading causes of suicide in older people. Crumpacker et al.(32) point out that clinical depression is never a normal part of aging and warrants aggressive treatment. Up to $75 \%$ of older people who died by suicide reportedly visit a physician within a month before their death. ${ }^{(33)}$ This is further supported by the results of one clinical study indicating that a prior depressive episode is present in $90 \%$ of older adults who commit suicide.(20) Elderly patients who took their own life were more likely to have been inpatients and to have had a history of suicide attempts, felt more hopeless and had higher ratings of suicidal tendency at the time of baseline assessment.(27) The interplay between impulsivity, psychological pain and mental illness such as depression may influence the likelihood of death by suicide in elderly patients.(34) Isacsson et al.(35) noted other potential contributors to suicide such as alcohol intoxication, acute interpersonal conflicts, unemployment and the possibility of suicide being 
triggered by antidepressant withdrawal that may not have been detected in toxicological studies. Wessely et al.(36) reported that depression is unequivocally and substantially associated with suicide and self-harm and the prescription of antidepressants. Selective serotonin reuptake inhibitors (SSRIs) can cause agitation and activation, particularly at the start of the treatment and may increase the risk of suicide. (37)

Following their intensive investigation, Healy et al. (38) concluded that antidepressant treatment can be implicated in some cases of suicide. They proposed five different mechanisms whereby antidepressant treatment might lead to suicide: 1) ameliorating depression rapidly by alleviating depressive psychomotor retardation more rapidly than suicidal ideation; 2) an action intrinsic to the specific antidepressant effects; 3) toxicity in overdose; 4) by side-effects of specific antidepressants; and 5) by virtue of treatment inefficacy.

\subsubsection{Selective Serotonin Reuptake Inhibitors}

Selective Serotonin Reuptake Inhibitors are a relatively new class of antidepressant medication, which inhibits reuptake of serotonin in the central nervous system. The first SSRI Fluoxetine - was introduced to the market in the United States in 1988. This class of drugs is used to treat multiple psychiatric conditions including major depression. Selective Serotonin Reuptake Inhibitors include Fluoxetine, Sertraline, Paroxetine, Citalopram, Escitalopram and Fluvoxamine.

1.1.10 Selective Serotonin Reuptake Inhibitors and treatment for major depression in older people

As a first line treatment, SSRIs are generally considered to constitute effective and safe pharmacological antidepressant therapy in the management of depression in adults. (39) Tricyclic antidepressants (TCAs) such as Amitriptyline and Monoamine Oxidase Inhibitors (MAOIs) such as Phenelzine have a higher side effect profile with higher risk of death from overdose. ${ }^{(40)}$ Other antidepressants commonly used in major depression are newer dual action antidepressants such as Venlafaxine, Desvenlafaxine, Mirtazapine and Duloxetine, which target both serotonin and noradrenalin neurotransmitters. Due to a comparatively favourable side effect profile, SSRIs are most commonly used in older people experiencing major depression.

A number of studies have been conducted investigating the safety, efficacy and effectiveness of pharmacological agents used to treat depression in older people. One study reported both TCAs and SSRIs showed greater efficacy than placebo in the treatment of older people with depression.(41) Schneider et al. (42) reported improvement in symptoms of depression with 
antidepressant treatment in $60-70 \%$ of elderly patients while symptoms improved in $30-40 \%$ with placebo treatment. Selective serotonin reuptake inhibitors may reduce suicidal ideations by improving overall depressive symptoms. An ecological study conducted by Hall et al. (43) reported an association between increased antidepressant prescription and reduced suicide trends in Australia from 1991 to 2000 . However, no causal link was established between the decline in suicide rate and antidepressant treatment. In contrast to this, however, in a metaanalysis of 74 clinical trials investigating the efficacy of antidepressants for late-life depression, these drugs were not found to be efficacious in the subset of studies using an age threshold of 65 years. ${ }^{(44)}$

\subsubsection{Suicide harms associated with antidepressant treatment}

Idiosyncratic reaction to SSRIs may precipitate suicidal behaviour and increase suicide risk in a subgroup of older people with depression.(45) It emerged that nearly $15 \%$ of outpatients without suicidal ideation at baseline experienced the emergence of passive or active suicidal ideation in an open trial using Fluoxetine. The rate of emergent suicidal ideation varies between $8-15 \%$.(46) Among older inpatients and outpatients treated for depression, nearly $8 \%$ reported emergent suicidality during a 12 week course of Paroxetine or Nortriptyline.(47) Similarly, in patients discharged from hospital, Gaudiano et al. (48) reported that $27 \%$ of patients developed suicidal ideation during the first 6 months of their outpatient treatment period. A nested case-control study involving 146,095 individuals with a first prescription of an antidepressant for depression, found some weak evidence for an increased risk of non-fatal self-harm for current SSRI use among those aged 18 or younger. There was, however, no evidence to suggest that the risk of suicide or non-fatal self-harm in adults who were prescribed SSRIs was greater than in those prescribed TCAs. ${ }^{(49)}$ Conversely, in a meta-analysis of observational studies including participants with over 10 years of SSRI exposure, Barbui et al.(50) reported that SSRIs had a protective effect against suicide in older people with depression. Schneeweiss et al.(51) observed no clinically meaningful variation in the risk of suicide and suicide attempt in adult patients treated with SSRIs, Serotonin Noradrenalin Reuptake Inhibitors (SNRIs), TCAs and MAOls with most events occurring in the first 6 months.

\subsubsection{The US FDA black box warning on Selective Serotonin Reuptake Inhibitors}

Case reports in the 1980s have suggested that akathesia, a motor restlessness side effect of SSRIs, can be associated with the emergence of suicidal thinking and behaviour. (52) Similarly,

Teicher et al.(53) reported the emergence of intense suicidal preoccupation during Fluoxetine 
treatment in 1990. Later in 2004, Jick et al. ${ }^{(54)}$ concluded that the risk of suicide behaviour rose in the first month after starting antidepressants, especially during the first 1-9 days. A 'black box' warning is a consumer alert added to the drug label about its potentially serious adverse effects. The US FDA issued a black box warning of increased suicidal ideation and suicidal behaviour in short-term use of all antidepressants in children and young adults in October 2004. (54) Two years after the issue of the US FDA's black box warning, Hall and Lucke(56) reported in their meta-analysis of Randomised Controlled Trials (RCTs) that SSRIs increased suicide ideation compared to placebo in the adult population. The same authors in their systematic review on observational studies reported that SSRIs do not increase suicide risk more than older antidepressants in adults.

At the same time, Moller(57) conducted a systematic review of randomised controlled trials and epidemiological and cohort studies on adult population, finding no evidence to indicate that all antidepressants, not only SSRIs, might induce, aggravate or increase the risk of suicidal ideation and suicide attempts or cause actual suicide. After the US FDA black box warning in 2007, Gibbons et al.(58) reported the rate of prescription for antidepressants as first line treatment in young suicidal patients with depression significantly decreased. Moller(57) argued the ongoing discussion about suicidality-inducing effects should not prevent physicians from prescribing SSRIs and other antidepressants to their patients if they are clinically indicated. However, clinicians should take into account potential risks and manage them through good clinical practice.

Studies investigating the association between drug treatment and suicidality are not restricted to antidepressant treatment and major depression. Carlsten et al.(59) reported an association between sedatives (Diazepam, Alprazolam, Buspirone) and hypnotics (Nitrazepam, Oxazepam, Zolpidem) with increased risk of suicide in the elderly. The same authors reported that having a current prescription for a hypnotic was associated with a four-fold increase in suicide risk in the adjusted model. (58) Other drugs such as Varenicline (nicotinic agent for smoking cessation), Accutane (vitamin A derivative for acne treatment) and Montelukast (leukotriene receptor antagonist for hay fever) have all been linked to increases in the number of spontaneous reports on suicidality.(60) The US FDA issued an alert regarding increased suicidal thoughts and behaviour with antiepileptic drugs in 2008.

\subsubsection{Evidence against the US FDA Black box warning}

In contrast to the black box warning issued by the US FDA, Beasley et al (61) reported that the emergence of substantial suicidal ideation was significantly less in patients taking Fluoxetine 
(1.2\%) compared to placebo (2.6\%). Similarly, Tollefson et al.(62) detected no significant differences among Fluoxetine, TCAs or placebo when suicidal ideation emerged. Healy and Whitaker(63) proposed further studies be undertaken to establish the magnitude of excess of suicide acts on SSRIs compared with placebo and the characteristics of most vulnerable patients. The antidepressant discontinuation rate of $28 \%$ in the first month, and $44 \%$ in the first three months, may relate to the emergence of adverse events such as weakness, fatigue, strange feelings and restlessness. All may influence lack of improvement or worsening of depression, and hence the risk of developing a suicidal idea or suicide attempt.(64) The US FDA ignored the report by Lapierre (65) in 2003 that the available evidence does not support the hypothesis that antidepressants or, more specifically, SSRIs caused increased suicidality in patients with depression, nor do they appear to do so in patients treated with these drugs for other reasons.

Contrary to the black box warning, Barak et al. (66) concluded that elderly depressed patients treated with antidepressants may be at reduced risk of attempting suicide. A meta-analysis conducted by Beasley et al. (67) including clinical trials with Fluoxetine concluded this treatment was associated with greater improvement and faster resolution of suicide ideation. Similarly, Gartlehner et al. (68) conducted a comparative benefit and harm review of second generation antidepressants, concluding that no particular antidepressant had an excess risk compared with any other drug in this class. ${ }^{(67)}$ Furthermore, the study by Isacsson et al.(69) including 16,937 suicides and 33,426 controls in Sweden from 1995-2005, suggested that the increased use of antidepressants had substantially contributed to the decline in suicide.

\subsubsection{Investigating harms and adverse consequences of a treatment}

Chou et al.(70) proposed the following clarification on harm-related terms: Harms could be defined as the totality of all possible adverse consequences of an intervention. Adverse consequences include the following commonly used terms: side effect, adverse effect, adverse event, serious adverse event, severe adverse event and adverse reaction. These terms are often used interchangeably in clinical studies reporting safety or harms. Side effects refer to unintended drug effects (benefit or harmful) given at doses usually used for therapeutic effects. An adverse effect is defined as a harmful or undesirable outcome that occurs during or after the use of a drug or intervention for which there is at least a reasonable possibility of a causal relationship. An adverse event refers to a harmful or undesirable outcome that occurs during or after the use of a drug or intervention but is not necessarily caused by it. Chou et al.(70) recommended that when causality is uncertain, "adverse event" should generally be the default 
term rather than "adverse effect". An adverse reaction/adverse drug reaction is an adverse effect specifically associated with a drug.

Antidepressant clinical trials seldom use both active and passive surveillance of harms; creating high risk of bias in detecting serious harms or reporting them. In active surveillance, participants are asked about the occurrence of specific adverse events in structured questionnaires or interviews, or predefined laboratory or other diagnostic tests are performed at pre-specified time intervals in order to detect adverse events. In passive surveillance, participants are not specifically asked about or tested for the occurrence of adverse events; rather, adverse events are identified based on patients' reports made by their own initiative. (71) The McMaster University Quality Assessment Scale for Harms (McHarm)(72) was developed specifically for evaluating how harms are investigated in primary efficacy studies of drugs and clinical interventions. The use of such a tool to appraise the quality of harm investigation in primary clinical trials is proposed to reduce bias in harm reports. Utilising quality appraisal tools such as McHarm on the harm reports in drug trials may add a new dimension to systematic reviews of harms derived from drugs. McHarm (Appendix I) is a 15-item rating scale that assesses the use of precise harm definitions in research, including pre-defined precise definition on harms (items 1-3), report on death (item 4), the process of harm assessment and status of the collector (items 5-11), the number of drop outs, number of participants affected by harms and statistical analyses used (items 11-15). The McHarm rating scale applies to all general drugs or treatment-related harms including death, but it does not specifically focus on detecting suicide-related harms linked to a medication treatment. (72)

\subsubsection{Measurement of suicide/suicidality as an outcome in clinical studies}

Research on antidepressant treatment and suicide risk in experimental clinical trials has several methodological limitations. Firstly, RCTs investigating the efficacy of SSRIs for depression usually exclude patients at significant risk of committing suicide. Generally, the primary outcomes measured by antidepressant efficacy studies are changes in the total score of scales used to measure depression before and after the drug treatment intervention. Such trials do not usually report changes in the score of a suicidality sub-scale, nor commonly utilise a standardised suicide-related harm assessment for their safety and tolerability report. Current measurement of suicide rate in clinical trials is commonly derived from spontaneous safety reports (Passive Surveillance), which count the number of suicide cases or attempted cases in each study. The American College of Neuropharmacology (ACNP) for example, investigated the rate of suicide in clinical trials conducted by drug manufacturers using these two outcome 
measures. ${ }^{(73)}$ Paroxetine manufacturer Smithkline-Beecham provided safety information from 6 week, double-blind RCTs involving a total of 4668 patients randomised to Paroxetine ( $n=2963)$, placebo $(n=544)$ and other antidepressants $(n=1151)$. There were five completed suicides in the Paroxetine arm (0.17\%), two in the placebo group (0.37\%) and three suicide cases in the other antidepressant groups (0.26\%). Similarly, Sertraline manufacturer Pfizer provided safety information from 8 week, double-blind RCTs involving 3902 patients who were randomised to Sertraline $(n=1938)$, placebo $(n=1042)$, and other antidepressants $(n=922)$. There were six suicide attempts in the Sertraline group $(0.3 \%)$, three suicide attempts in the placebo group $(0.3 \%)$ and two such attempts in the other antidepressant groups $(0.2 \%) .{ }^{(73)}$ There is a higher rate of completed suicide in the SSRI group compared to Placebo or other antidepressants in these reports provided by antidepressant manufacturers. This outcome highlighted the potential risk of suicide associated with SSRI treatment.

\subsubsection{Methodological and ethical limitations of suicide research in the elderly}

Goldney(74) identified the limitations of RCTs in demonstrating the effectiveness of antidepressants in reducing suicide rates for both adult and old age populations. The fact that suicide is a rare event and the risk of suicide is not constant over the course of the illness impacts on the RCTs' ability to adequately measure the rate of suicide. To illustrate these limitations, Gunnell et al. (75) estimated a RCT would need 1.9 million subjects to detect an effect on suicide mortality of $20 \%$, or a clinical trial would need to enroll around 30 million patients to detect an impact of $5 \%$ of suicide mortality risk. Fergusson et al.(76) pointed out many methodological limitations in published clinical trials and the lack of disclosing all events in full. To illustrate this further, there was no report of a suicide attempt in 329 TCA clinical trials and one suicide in 337 SSRI clinical trials. ${ }^{(76)}$ A further methodological limitation hindering the investigation of the adverse effects of a treatment with experimental studies is the high dropout rate in clinical trials. If the dropout rate is too large, it may not be possible to detect a true suicide rate. Furthermore, there are clear ethical limitations such as the use of placebo in patients at risk of suicide and the ethics and practicality of recruiting a large enough number of patients at such risk. ${ }^{(74)}$ There has been some debate on the inevitability of suicide as an outcome of depression as well as antidepressant treatment. Maris et al.(77) in 2007 asserted that suicide is an inevitable risk of antidepressant treatment for depressive disorders. However, Goldney(78) at the same time, suggested that suicide appears to be a risk that is inevitable and part of the natural recovery from depression rather than being associated with a specific treatment. 
Pragmatic clinical trials may overcome some of these aforementioned methodological and ethical limitations. Nallamothu et al.(79) provide insights into the major advantages and limitations of such pragmatic clinical trials. The advantages identified by these authors ${ }^{(79)}$ are clinically relevant active controls, a larger population from diverse environments, evaluation of strategies for treatment, and measurement of multiple outcomes such as symptoms and quality of life. The limitations identified include longer trial duration and the cost for such trials. ${ }^{(79)}$ For example, the landmark Antihypertensive and Lipid Lowering treatment to prevent Heart Attack Trial (ALLHAT), which evaluated multiple anti-hypertensive drugs, required an enormous amount of resources and time; it involved 600 American clinical sites and took 8 years to complete. (79) Considering these limitations of RCTs in providing information about the harmful outcomes of treatment, observational studies provide an alternative and necessary research method to measure such an adverse outcome as suicide.

\subsection{Why is this systematic review needed?}

1.2.1 Current evidence for a relationship between Selective Serotonin Reuptake Inhibitor (SSRI) treatment and risk of suicide/suicidality in late life depression

\subsubsection{Selective Serotonin Reuptake Inhibitor (SSRI) treatment increases risk of suicide}

Many studies have been published that point towards an association between SSRI treatment and suicidality. Hall and Lucke ${ }^{(56)}$ reported an increased risk of completed suicide and suicide attempt in the first 9 days of placebo controlled RCTs and observational studies in adults with a reported odds ratio $(\mathrm{OR})$ of $4.07,(95 \% \mathrm{Cl} 2.89-5.74)$ in their systematic review and metaanalysis. Similarly, in a retrospective case control study, Juurlink et al.(45) reported that SSRI treatment was associated with a nearly five-fold higher risk of completed suicide than treatment with other antidepressants in the elderly during the first month of therapy. Didham et al. (80) also noted an association between SSRI treatment and self-harm with a reported OR of 1.66 (95\% $\mathrm{Cl}$ 1.23-2.23), but not for suicide, OR 1.28 (Cl 0.38-4.35) after correction for the confounding effects of age and gender. Recently, a population cohort study in the UK found increased attempted suicide/self-harm rates linked to Mirtazapine, Venlafaxine and Trazodone compared to SSRIs. ${ }^{(81)}$ 


\subsubsection{SSRI treatment reduces risk of suicide}

Kalmar et al.(82) compared suicide rates amongst older people with the antidepressant prescription rate; the results suggested that antidepressants have a primarily age dependent effect on completed suicide. The protective effect was most evident in the 70 and older age group. In general, the greater the use of antidepressants by older people, then the greater the decrease observed in their suicide rate.(82) Similarly, Stone et al. (23) reported the OR for suicidal behaviour or ideation was $1.62(95 \% \mathrm{Cl} 0.97$ to 2.71$)$ for participants aged less than 25 , for those aged $25-64$ an $\mathrm{OR}$ of 0.79 (95\% $\mathrm{Cl} 0.64$ to 0.98$)$, and for participants aged 65 or older the OR for suicidal behaviour or ideation was $0.37(95 \% \mathrm{Cl} 0.18$ to 0.76$)$. Barbui et al.(83) systematically reviewed eight observational studies of both adult and older people on SSRI treatment and the risk of suicide and their review reported that exposure to SSRIs had a significant protective effect against suicide in elderly people. Furthermore, in a recent reanalysis of the short-term risk of suicide with use of antidepressants in youth, adult and geriatric populations, it emerged that Fluoxetine and Venlafaxine decrease suicidal thoughts and behaviour in both adult and geriatric patients. ${ }^{(84)}$

\subsubsection{No difference in the risk of suicide with SSRIs}

Beyond the controversial evidence that points towards the beneficial and harmful effects of SSRIs when considering suicide, further research has indicated that there is no difference between antidepressants and placebo. Hammad et al. (85) reported that in placebo-controlled major depression trials including those assessing SSRIs, the rate ratio of suicide in the combined antidepressant groups compared to placebo was 1.07 (95\% Cl 0.1-63). Neither use of placebo nor of antidepressants including SSRIs in short-term RCTs was associated with an increased risk of completed suicide among patients suffering from major depression and anxiety disorders. ${ }^{(85)}$

\subsubsection{Current evidence hierarchy}

As outlined above, there is considerable controversy surrounding the relationship between SSRI treatment and risk of suicidality; furthermore, the evidence surrounding the risk of suicidality in older people with depression has not been adequately assessed. With reference to this issue, Healy (86) concluded that given the small numbers of suicides in the RCTs and subsequent lack of statistical power, this does not rule out the increased risk of completed suicide in association with either drug or placebo treatment in depressed patients. 
The evidence derived from a meta-analysis of RCTs is ranked as level 1a, at the top of the evidence hierarchy, while evidence from a meta-analysis of observational studies is ranked at level 3a according to the Joanna Briggs Institute (JBI).(87) The US FDA's black box warning was based on a meta-analysis of safety data from RCTs; however, these studies were specifically designed to assess antidepressant efficacy and tolerability. A preliminary search of the JBI Library of Systematic Reviews and the Cochrane Library located no systematic reviews of RCTs and observational studies with SSRIs specifically focused on older people with major depression. This systematic review set out to explore the best available evidence concerning suicide risk in elderly depressed patients by combining data from RCTs and observational studies.

\subsection{Combining the results of experimental and observational studies}

Golder et al.(88) suggest that systematic reviews of the adverse effects of drugs should not be restricted to specific experimental or observational study types. As mentioned previously, RCTs are designed to explore clinical efficacy and are not designed to detect rare adverse effects such as suicide; RCTs may not be large enough, long enough or may miss capturing adverse events after discontinuation of treatment and follow up period. In contrast, observational study designs represent a feasible alternative in the study of suicide with the advantage of being more naturalistic and longer term, despite their decreased ability to establish causation due to bias and the impact of confounding factors. These authors further highlight the need for more observational and pragmatic studies to assist research on the clinical topics such as reduced risk of suicide in elderly depressed patients.(88) Multiple challenges associated with conducting a systematic review on drug-related harms such as issues with internal validity, presence of heterogeneity and lack of consistent definitions on suicidality are detailed by Chou et al.(70)

Randomised controlled trials and observational studies may be complementary in answering certain research questions such as suicide. For instance, observational studies are more likely to produce homogenous results since they include a broad spectrum of the population at risk.(89)The advantages of short-term RCTs over longer term observational studies include active intervention and repeatability. However, recently reported observational studies show a degree of consistency in their reported results. Concato et al.(90) commended taking a more balanced and scientifically justified approach to evaluate the strengths and limitations of welldone experimental and observational studies, recognizing the attributes of each type of study design. These authors caution not to take sides on methodological authority between experimental and observational studies that have been criticised by proponents of evidence- 
based medicine.(90) It is important for systematic reviews to assess included studies' methodological qualities, explore the differences that typically emerge in study results, and quantitatively synthesise these results.(91) Systematic reviews are open to systematic errors or bias and confounding, and therefore as a result, to accurately inform the effectiveness of an intervention it is necessary to combine benefits and harms. It is also critical to incorporate and integrate best available information from both randomised trials and observational studies. ${ }^{\left({ }^{92}\right)}$

\subsection{Purpose of this study}

Selective serotonin reuptake inhibitors constitute the first line antidepressant medication for older depressed and suicidal patients. This systematic review focuses specifically on the geriatric population over 60 years of age to provide a high quality systematic review combining best available evidence, including both experimental and observational data, on the association between treatment with SSRIs and suicide/ suicidality in older people. The aim of this study was to inform clinicians on the risk of suicide from SSRI treatment in older people aged 60 years and over with major depression. The protocol for the research conducted in this thesis is published and available in the online journal The JBI Database of Systematic Reviews and Implementation Reports. ${ }^{(93)}$

\subsection{Review Question}

Does treatment with SSRIs increase the risk of suicide in older people over the age of 60 years who suffer from major depression? 


\section{CHAPTER TWO: SYSTEMATIC REVIEW METHODS}

\subsection{Type of participants}

Consideration was given to studies that included older people aged 60 years and over, regardless of gender or ethnic background with DSM IV or equivalent diagnostic criteria for Major Depressive disorder without psychotic features. The review considered both community and hospitalised older patients with stable medical co-morbidities.

\subsection{Type of intervention and comparator}

The review considered treatments using any SSRI medication including oral Fluoxetine, Sertraline, Paroxetine, Citalopram, Escitalopram and Fluvoxamine with a clinically effective dose recommended by the manufacturer for older people for a minimum duration of treatment of four weeks. Comparators included placebo or a different class of antidepressants including MAOls or TCAs.

\subsection{Type of outcomes}

The primary outcome measures of interest in this systematic review were worsening or emergent suicidal ideation, attempted suicide and completed suicide. For this systematic review, the term 'suicide attempt' refers to potentially self-injurious behaviour with a non-fatal outcome, for which there is evidence (either implicit or explicit) that the person intended at some (non-zero) level to kill himself or herself.(29) This included incidents such as intentional drug overdose. Suicide ideation can be measured by Scale for Suicidal Ideation, Hamilton Rating Scale for Depression (HAM-D), Montgomery-Asberg Depression Rating Scale (MADRS) and/or Beck's Depression Inventory (BDI).

\subsection{Types of studies}

This review considered both experimental and observational study designs including RCTs, non-randomised controlled trials, quasi-experimental, before and after studies, prospective and retrospective cohort studies and case control studies. Randomised controlled trials (8), cohort studies (4) and retrospective case control study (1) designs were included in this systematic review. 


\subsection{Review methods}

\subsubsection{Search strategy}

The search for studies employed in this systematic review followed the JBI standard methods. Before developing the search strategy for this systematic review, an initial scoping search of the Cochrane Database of Systematic Reviews, Database of Abstracts of Reviews of Effects and JBI Database of Systematic Reviews was conducted to ascertain the suitability of the proposed review topic and determine if this or a similar systematic review had already been undertaken.

The search strategy aimed to locate both published and unpublished studies in the English language. The search employed a three-step search strategy. An initial search in PubMed was undertaken using initial key words in various combinations. Initial key words or terms employed included older people, old age, geriatric patients, major depression, depression, late-life depression, depression outcome, suicide ideation, change in suicidal ideation, completed suicide, attempted suicide, suicide outcome, randomised double-blind placebo controlled trials, randomised controlled trials, placebo controlled trials, clinical trial, experimental study, SSRIs and dual action antidepressants. This was followed by analysis of the text words contained in the title, abstract and the index terms used to describe the most relevant articles. Then a second search was undertaken using all identified keywords and index terms across all databases and grey literature sites listed in Table 2.1. Finally, the reference list of all identified reports and articles were searched for additional studies. EndNote X6 software(94) served to manage the results of the literature search and facilitate study selection. Details on search strategies are reported in Appendix II.

Table 2.1 Databases and grey literature sites searched and the date when each search was performed

\begin{tabular}{|l|l|}
\hline Database & Date searched \\
\hline PubMed & $27 / 11 / 2012$ \\
\hline CINAHL & $28 / 11 / 2012$ \\
\hline Embase & $27 / 11 / 2012$ \\
\hline ScienceDirect & $04 / 10 / 2012$ \\
\hline PsychARTICLES & $28 / 11 / 2012$ \\
\hline Cochrane Central Trials Register & $04 / 10 / 2012$ \\
\hline Cochrane adverse effects methods group & $04 / 10 / 2012$ \\
\hline
\end{tabular}




\begin{tabular}{|l|l|}
\hline Cochrane health care of older people field & $04 / 10 / 2012$ \\
\hline Australian New Zealand Clinical Trials Registry & $04 / 10 / 2012$ \\
\hline EU Clinical Trials Register Current Controlled Trials & $04 / 10 / 2012$ \\
\hline United States Clinical Trials Register-Clinicaltrials.gov & $04 / 10 / 2012$ \\
\hline World Health Organization international clinical trials registry & $04 / 10 / 2012$ \\
\hline ISRCTN Register & $04 / 10 / 2012$ \\
\hline ProQuest Dissertations and Theses Database (PQDT) & $08 / 12 / 2012$ \\
\hline $\begin{array}{l}\text { Mednar and Journal of Negative Results in Biomedicine for } \\
\text { unpublished data }\end{array}$ & $08 / 12 / 2012$ \\
\hline
\end{tabular}

\subsubsection{Assessment of methodological quality}

The methodological quality of papers selected for retrieval was assessed by two independent reviewers prior to inclusion in the review using standardised critical appraisal instruments from the JBI Meta-Analysis of Statistics Assessment and Review Instrument (JBI-MAStARI; see Appendix III).(87) A critical appraisal score of less than four out of ten for experimental studies and four out of nine in observational studies was considered to represent high risk of bias and hence not suitable for inclusion in this systematic review. The McMaster Quality Assessment Scale for Harms (McHarm; Appendix I) is an appraisal tool that specifically evaluates the assessment of harms in primary studies. Considering a systematic review of adverse effects of a drug treatment, Chou (92) recommended that all studies be assessed for their methodological quality based both on study design and using the McHarm tool. This systematic review used $\mathrm{McHarm}$ as the quality assessment tool for suicide-related harm report in RCTs and observational studies. Minimal differences were found between individual appraisal answers allocated by the primary and secondary reviewers that did not require the introduction of a third assessor.

\subsubsection{Data collection}

Descriptive and outcome data from included studies were extracted using the standardised data extraction tool from JBI-MAStARI (Appendix III). The primary data on the number of completed suicides, suicide attempts and emergent or worsening of suicidal ideation in both arms of RCTs and observational studies was extracted. Baseline demographic data on each study was collected for presentation in tabular format. Where necessary, further information to confirm there was no additional suicide-related outcome information from included RCTs was 
sought by contacting corresponding authors. A list of 32 excluded RCTs that matched the inclusion criteria for the review aside from the relevant outcome data prior to critical analysis (i.e. during study selection) are shown in Appendix IV for reference. Fourteen primary authors of 32 excluded RCTs were available by email contact. Out of 14 email enquiries, only two authors responded and provided no additional information on suicide risk.

\subsection{Data synthesis}

Data on the suicide-related events in RCTs and observational studies were ultimately divided into four groups based on the comparisons identified in the included RCTs and the outcomes reported by the included observational studies. The first was the incidence of emergent suicidal ideation in included RCTs comparing SSRIs versus placebo; the second was the rate of suicide attempt with SSRIs versus other antidepressants in RCTs. There was no data available from any of the eligible studies on completed suicide in RCTs during the study period. The third group was SSRI exposure and the rate of completed suicide in observational studies. The final group was the rate of suicide attempt with SSRI exposure in observational studies. There was no data available on emergent suicidal ideation from any included observational studies. The data from RCTs and observational studies was pooled separately in a statistical meta-analysis using RevMan v5.1 software (The Cochrane Collaboration). (95) The statistical analyses in this systematic review employed the Peto fixed effect model to allow for low event rates and zero cell events encountered in experimental studies.

The Peto method is the most suitable for rare event studies such as suicide.(96) The effect sizes expressed as OR and their 95\% confidence intervals were calculated for data derived from RCTs. The risk ratios (RR) for suicide death and suicide attempt during exposure to SSRI treatment was calculated using the inverse variance method with statistical combination of original adjusted hazard ratios extracted from the three included observational studies. ${ }^{(104,105,106)}$ Heterogeneity was assessed statistically using the standard $\mathrm{Chi}^{2}$ and $\mathrm{I}^{2}$. Despite the recommendation for distinction between the different study designs included in this review by subgroup analysis in the a priori protocol (93), due to the nature of the data extracted and the different major clinical and methodological heterogeneities evident in the studies, combining the experimental and observational studies into a single meta-analysis was not performed in this systematic review. A brief description of included studies has been presented in the narrative. 


\section{CHAPTER THREE: RESULTS}

\subsection{Study inclusion process}

A total of 1904 potentially relevant citations were identified using the search strategies developed specifically for each database (Appendix II). Of these, 259 articles were duplicate citations and a further 1258 citations were excluded after screening of titles, resulting in 387 articles for review of the abstract. Forty-nine studies were retrieved for full-text examination following the exclusion of 338 articles when their abstracts were examined in detail. After full text examination, a total of 32 SSRI RCTs were excluded due to the lack of reporting on suicide-related events (see Appendix IV). Eight RCTs with data on suicide-related events and five observational studies (i.e. population cohort and retrospective case control studies) were selected for critical appraisal. Finally, all 13 papers were included in the systematic review following critical appraisal. Figure 3.1 outlines the study inclusion process.

\subsection{Methodological quality}

The included RCTs were generally of good quality with a clear description of study design and statistical analysis methods used. All of the eight included RCTs scored a minimum of six against the ten critical appraisal questions. However, many of the studies scored "Unclear" on question three and five which assess the allocation concealment process and blinding respectively. Lack of allocation concealment may lead to selection bias and performance bias in efficacy studies. However, it should not have a significant impact on the general quality of safety data including suicide risk. The dropout rate in the SSRI group during the RCTs was $24 \%$ which may create potential attrition bias in the results. Table 3.1 outlines the scores of experimental studies following their critical appraisal. 


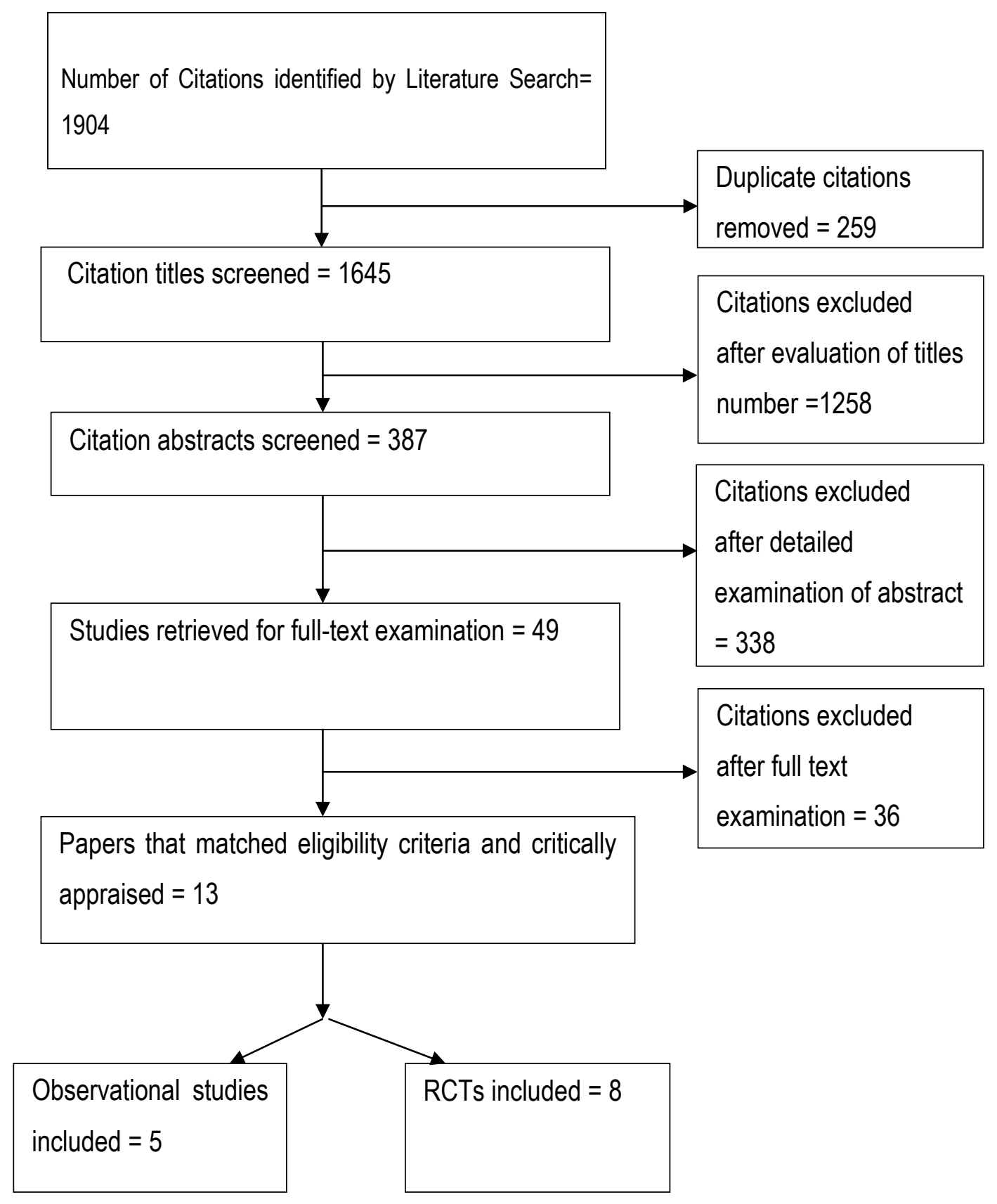

Figure 3.1 Outline of the study inclusion process 
Table 3.1 Critical appraisal scores of the included experimental studies

\begin{tabular}{|l|l|l|l|l|l|l|l|l|l|l|l|}
\hline Paper & Q1 & Q2 & Q3 & Q4 & Q5 & Q6 & Q7 & Q8 & Q9 & Q10 & Total \\
\hline $\begin{array}{l}\text { Guillibert et al. } \\
\text { 1989(101) }\end{array}$ & N & Y & U & Y & U & Y & Y & Y & Y & Y & 7 \\
\hline $\begin{array}{l}\text { Geretseger et } \\
\text { al. 1994(100) }\end{array}$ & Y & U & U & Y & U & Y & Y & Y & Y & Y & 7 \\
\hline $\begin{array}{l}\text { Rouillon et al. } \\
\text { 1991(102) }\end{array}$ & Y & U & U & Y & U & Y & U & Y & Y & Y & 6 \\
\hline $\begin{array}{l}\text { Nelson et al. } \\
\text { 2007(108) }\end{array}$ & Y & Y & U & Y & U & Y & U & Y & Y & Y & 7 \\
\hline $\begin{array}{l}\text { Kasper et al. } \\
\text { 2005(98) }\end{array}$ & Y & U & U & Y & Y & Y & Y & Y & Y & Y & 8 \\
\hline $\begin{array}{l}\text { Kyle et al. } \\
\text { 1998(99) }\end{array}$ & Y & Y & Y & Y & U & Y & Y & Y & Y & Y & 9 \\
\hline $\begin{array}{l}\text { Dorman et al. } \\
\text { 1992(103) }\end{array}$ & Y & Y & U & Y & U & U & Y & Y & Y & Y & 7 \\
\hline $\begin{array}{l}\text { Tollefson et } \\
\text { al. Y } \\
\text { 1995(97) }\end{array}$ & Y & U & Y & U & Y & Y & Y & Y & Y & 8 \\
\hline
\end{tabular}

The appraisal tool is available in Appendix III. $Y=Y e s$, indicates a score of 1 ; $U=U n c l e a r$ 
Table 3.2 Critical appraisal scores of the included observational studies

\begin{tabular}{|l|l|l|l|l|l|l|l|l|l|l|}
\hline $\begin{array}{l}\text { Citation and } \\
\text { Type of Study }\end{array}$ & Q1 & Q2 & Q3 & Q4 & Q5 & Q6 & Q7 & Q8 & Q9 & Total \\
\hline $\begin{array}{l}\text { Rahme et al. } \\
\text { 2008(105) } \\
\text { Cohort Study }\end{array}$ & $\mathrm{Y}$ & $\mathrm{U}$ & $\mathrm{U}$ & $\mathrm{Y}$ & $\mathrm{Y}$ & $\mathrm{Y}$ & $\mathrm{NA}$ & $\mathrm{Y}$ & $\mathrm{Y}$ & 6 \\
\hline $\begin{array}{l}\text { Coupland et al. } \\
\text { 2011(106) } \\
\text { Cohort Study }\end{array}$ & $\mathrm{Y}$ & $\mathrm{Y}$ & $\mathrm{Y}$ & $\mathrm{Y}$ & $\mathrm{Y}$ & $\mathrm{U}$ & $\mathrm{Y}$ & $\mathrm{Y}$ & 8 \\
\hline $\begin{array}{l}\text { Gibbons et al. } \\
\text { 2007(104) } \\
\text { Cohort Study }\end{array}$ & $\mathrm{Y}$ & $\mathrm{Y}$ & $\mathrm{U}$ & $\mathrm{U}$ & $\mathrm{Y}$ & $\mathrm{Y}$ & $\mathrm{U}$ & $\mathrm{Y}$ & $\mathrm{Y}$ & 6 \\
\hline $\begin{array}{l}\text { Juurlink et al. } \\
\text { 2006(107) } \\
\begin{array}{l}\text { Population- } \\
\text { based Case } \\
\text { Control Study }\end{array}\end{array}$ & $\mathrm{Y}$ & $\mathrm{U}$ & $\mathrm{Y}$ & $\mathrm{Y}$ & $\mathrm{Y}$ & $\mathrm{NA}$ & $\mathrm{NA}$ & $\mathrm{Y}$ & $\mathrm{Y}$ & 6 \\
\hline $\begin{array}{l}\text { Barak et al. } \\
\text { 2006(66) } \\
\text { Case Control } \\
\text { Study }\end{array}$ & $\mathrm{Y}$ & $\mathrm{U}$ & $\mathrm{U}$ & $\mathrm{N}$ & $\mathrm{Y}$ & $\mathrm{NA}$ & $\mathrm{U}$ & $\mathrm{Y}$ & $\mathrm{Y}$ & 4 \\
\hline
\end{tabular}

The appraisal tool is available in Appendix III. $Y=Y$ es indicates a score of $1 ; \mathrm{N}=\mathrm{No}$; $U=$ Unclear; NA=Not Applicable

All five observational studies in this review generally scored high using the JBI MAStARI critical appraisal tool (see Appendix III). The study by Coupland et al. (106) scored 8 out of a maximum of 9 and three other studies by Gibbons et al. (104), Rahme et al. (105) and Juurlink et al. (107) scored six out of nine (see Table 3.2). All of the observational studies utilised objective criteria for suicide and suicide attempt assessment. However, only two $(106,107)$ out of five observational studies scored 'yes' on question number three which assesses the presence of selection bias. Question number 7 was not applicable in two observational studies (105, 107); the remaining three studies $(66,104,106)$ did not provide reasons for patients dropping out. Overall, observational 
studies demonstrated good quality of outcome measurement, management on confounding factors and the use of appropriate statistical analysis.

All 13 included studies were also appraised using the McHarm critical analysis tool (see Section 2.5.2; Appendix I) and each study scored between one and ten out of a maximum score of 15. Appraisal with the McHarm tool suggested that the selected experimental studies were at risk of bias for detection and reporting the risk of suicide-related harm. Table 3.3 outlines the McHarm appraisal scores for the included studies.

The McHarm score for experimental studies ranged from five to nine out of 15 (see Table 3.3). This is likely due to the fact that the primary outcome of experimental studies was not harm but the efficacy of the drug treatments investigated. The study by Guillibert et al.(101) scored highest on McHarm with nine out of 15 . The lowest score was five out of 15 in the studies by Kyle et al. (99) , Geretseger et al. (100) and Dorman et al. (103) Many of the experimental studies did not score for questions one, two, three and eight. Question one focused on the use of a predefined standardised definition of suicide-related harm in the RCT safety analysis. All RCTs investigating SSRI efficacy did not use a precise definition of suicide-related harm in their safety report. Question two focused on the severity rating of the harm events; all of the included RCTs did not utilise severity rating. It is clinically important to assess and report the severity of suicidal ideation associated with antidepressant treatment in the safety report. Question eight focused on whether the safety data was collected by a specifically trained data collector. All RCTs did not provide information on the background and training of safety data collector.

Despite their primary outcome of interest being suicide or suicide attempt, the scores regarding McHarm appraisals in the included observational studies were low. The observational studies with low McHarm scores may carry the risk of reporting bias by under-detection of treatmentrelated harms. For example, Juurlink et al. (107) scored only one out of 15 on the McHarm scale. The reason for this may be linked to the study design which was based on retrospective population data on SSRI use and suicide rate; this same study scored six out of nine using the JBI critical appraisal tool (Table 3.2). The difference between higher scores on the JBI critical appraisal tool and lower McHarm score in the included studies is likely due to the McHarm tool focusing on the domain of treatment-related harms. In practice, despite recommendations (72), it may be that the McHarm scales are not directly applicable to studies such as population-based retrospective case control studies. Despite this, the overall McHarm appraisal finding in this systematic review is significant; it questions the quality of recording and reporting of harms in 
studies and clearly highlights the need for appropriate consideration of treatment-related harms when designing and conducting studies investigating treatment benefits. 
Table 3.3 McHarm critical appraisal Score for Included Studies

\begin{tabular}{|l|l|l|l|l|l|l|l|l|l|l|l|l|l|l|l|l|}
\hline Citation & Q1 & Q2 & Q3 & Q4 & Q5 & Q6 & Q7 & Q8 & Q9 & Q10 & Q11 & Q12 & Q13 & Q14 & Q15 & Total \\
\hline Rahme 2008(105) & U & Y & U & U & Y & N & U & U & Y & N & N & U & U & Y & Y & 5 \\
\hline $\begin{array}{l}\text { Coupland } \\
\text { 2011(106) }\end{array}$ & Y & Y & Y & U & U & U & U & U & U & N & Y & U & NA & NA & Y & 5 \\
\hline Gibbons 2007(104) & Y & Y & Y & U & Y & Y & N & N & Y & Y & U & U & Y & Y & Y & 10 \\
\hline Juurlink 2006(107) & N & N & N & N & Y & N & N & N & U & U & N & U & U & U & U & 1 \\
\hline Barak 2005(65) & $\mathrm{N}$ & $\mathrm{N}$ & $\mathrm{N}$ & $\mathrm{U}$ & $\mathrm{Y}$ & $\mathrm{N}$ & $\mathrm{N}$ & $\mathrm{N}$ & $\mathrm{N}$ & $\mathrm{N}$ & $\mathrm{N}$ & $\mathrm{U}$ & $\mathrm{Y}$ & $\mathrm{Y}$ & $\mathrm{Y}$ & 4 \\
\hline Guillibert 1989(96) & $\mathrm{N}$ & $\mathrm{N}$ & $\mathrm{Y}$ & $\mathrm{U}$ & $\mathrm{Y}$ & $\mathrm{Y}$ & $\mathrm{N}$ & $\mathrm{N}$ & $\mathrm{Y}$ & $\mathrm{Y}$ & $\mathrm{Y}$ & $\mathrm{Y}$ & $\mathrm{U}$ & $\mathrm{Y}$ & $\mathrm{Y}$ & 9 \\
\hline $\begin{array}{l}\text { Geretseger } \\
\text { 1994(100) }\end{array}$ & $\mathrm{N}$ & $\mathrm{N}$ & $\mathrm{N}$ & $\mathrm{U}$ & $\mathrm{N}$ & $\mathrm{N}$ & $\mathrm{N}$ & $\mathrm{N}$ & $\mathrm{Y}$ & $\mathrm{Y}$ & $\mathrm{Y}$ & $\mathrm{Y}$ & $\mathrm{Y}$ & $\mathrm{U}$ & $\mathrm{N}$ & 5 \\
\hline Rouillon 1991(102) & $\mathrm{N}$ & $\mathrm{U}$ & $\mathrm{U}$ & $\mathrm{Y}$ & $\mathrm{U}$ & $\mathrm{U}$ & $\mathrm{N}$ & $\mathrm{N}$ & $\mathrm{Y}$ & $\mathrm{N}$ & $\mathrm{Y}$ & $\mathrm{Y}$ & $\mathrm{Y}$ & $\mathrm{Y}$ & $\mathrm{N}$ & 6 \\
\hline Tollefson 2005(103) & $\mathrm{N}$ & $\mathrm{N}$ & $\mathrm{N}$ & $\mathrm{U}$ & $\mathrm{Y}$ & $\mathrm{Y}$ & $\mathrm{N}$ & $\mathrm{N}$ & $\mathrm{Y}$ & $\mathrm{N}$ & $\mathrm{Y}$ & $\mathrm{Y}$ & $\mathrm{Y}$ & $\mathrm{Y}$ & $\mathrm{Y}$ & 8 \\
\hline Kasper, 2005(97) & $\mathrm{N}$ & $\mathrm{N}$ & $\mathrm{N}$ & $\mathrm{U}$ & $\mathrm{Y}$ & $\mathrm{Y}$ & $\mathrm{Y}$ & $\mathrm{N}$ & $\mathrm{N}$ & $\mathrm{N}$ & $\mathrm{Y}$ & $\mathrm{Y}$ & $\mathrm{Y}$ & $\mathrm{Y}$ & $\mathrm{Y}$ & 8 \\
\hline Kyle 1998(101) & $\mathrm{N}$ & $\mathrm{N}$ & $\mathrm{N}$ & $\mathrm{U}$ & $\mathrm{N}$ & $\mathrm{N}$ & $\mathrm{N}$ & $\mathrm{N}$ & $\mathrm{Y}$ & $\mathrm{N}$ & $\mathrm{U}$ & $\mathrm{Y}$ & $\mathrm{Y}$ & $\mathrm{Y}$ & $\mathrm{Y}$ & 5 \\
\hline Dorman 1992(103) & $\mathrm{N}$ & $\mathrm{N}$ & $\mathrm{N}$ & $\mathrm{U}$ & $\mathrm{U}$ & $\mathrm{U}$ & $\mathrm{N}$ & $\mathrm{N}$ & $\mathrm{N}$ & $\mathrm{Y}$ & $\mathrm{N}$ & $\mathrm{Y}$ & $\mathrm{Y}$ & $\mathrm{Y}$ & $\mathrm{Y}$ & 5 \\
\hline Nelson 2007(108) & $\mathrm{U}$ & $\mathrm{U}$ & $\mathrm{U}$ & $\mathrm{U}$ & $\mathrm{Y}$ & $\mathrm{Y}$ & $\mathrm{Y}$ & $\mathrm{N}$ & $\mathrm{Y}$ & $\mathrm{N}$ & $\mathrm{U}$ & $\mathrm{Y}$ & $\mathrm{Y}$ & $\mathrm{Y}$ & $\mathrm{Y}$ & 8 \\
\hline
\end{tabular}

The McHarm tool is available in Appendix I. Y=Yes indicates a score of $1 ; \mathrm{U}=$ Unclear; $\mathrm{N}=\mathrm{No}$; NA=Not Applicable 


\subsection{Description of studies}

\subsubsection{Description of included Experimental Studies}

The primary outcomes of interest in the eight included RCTs conducted between 1989 and 2005 were clinical efficacy and tolerability of SSRI treatment in older people with major depression. Three RCTs (97,98,108) compared SSRI and placebo. The study by Kasper et al. (98) reported one suicide each on SSRI and placebo arms but these incidents occurred well over one week after the RCT ended. The remaining studies by Nelson et al. (108) and Tollefson et al. (97) reported emergent suicidal ideation. These two placebo controlled RCTs $(97,98)$ used a fixed dose of SSRI. Five RCTs (99-103) comparing SSRI and other antidepressants reported on the number of suicide attempts in their analyses. These RCTs used a SSRI dose escalation method (99-103). The average dose of SSRI and TCA used in RCTs were Fluoxetine $30 \mathrm{mg}$ equivalent and Amitriptyline $100 \mathrm{mg}$ equivalent. There appeared to be no relationship between the dose escalation and number of suicide-related events in this systematic review. Descriptive details of the included studies incorporating the age of participants, male to female ratio, baseline depression score and treatment settings are reported in Table 3.4.

Further descriptive details of each included RCT are presented in the following paragraphs. Tollefson et al. (97) studied the effectiveness of Fluoxetine for elderly depressed outpatients in a six week placebo controlled RCT. A total of 671 elderly patients were randomised, 335 to the Fluoxetine group and 336 to the placebo group. The study reported 95 percent of the patients in the Fluoxetine arm and 94 percent in the placebo arm were Caucasian. Male to female ratio was low in both Fluoxetine and placebo groups with $86 \%$ or $155 / 180$ in the treatment group and $80 \%$ or $150 / 186$ in the placebo group. Average age of the participants was 67.4 years and the baseline 17 HAM-D score was 22 indicating major depression, moderate severity. The dose of Fluoxetine was fixed to $20 \mathrm{mg}$ per day. Only 534 patients or $79.6 \%$ completed the study, with 72 dropouts in the Fluoxetine group (21\%) and 65 in the placebo group (19\%). There was no conflict of interest statement.

Kasper et al. (98) compared the effectiveness of Escitalopram with Fluoxetine or placebo in an eight week RCT involving a total of 518 elderly patients. All participants were recruited from general practices or specialist centres in 11 European countries. Male to female ratio was $38 / 126(30 \%)$ in the Fluoxetine group, 44/130 (34\%) in the Escitalopram group and 43/137 $(31 \%)$ in the placebo group. The participants' average age was 75 years in all three groups with the average base-line MADRS score being 28.5. The study fixed the dose of Fluoxetine at 20 
$\mathrm{mg}$ and Escitalopram at $10 \mathrm{mg}$ per day. The dropout rate was 20/180 in the placebo group (11\%), 29/170 in the Escitalopram group (17\%) and 42/164 in the Fluoxetine group (25\%). The safety report included 0/164 in the Fluoxetine group, 1/173 suicide case in the Escitalopram group and 1/180 in the placebo group. Both events occurred after the completion of the study but their relationship to the experiment was not mentioned. The first author reported their involvement with multiple pharmaceutical companies.

Nelson et al. (108) conducted a secondary analysis of original a 2003 eight week $\operatorname{RCT}(110)$ in the United States comparing suicidal ideation in Sertraline and placebo-treated elderly patients with major depression. The study included 747 participants with an average age of 70 years. The male to female ratio was $87 \%$ or $167 / 193$ in the Sertraline group and $71 \%$ or $153 / 215$ in the placebo group; the percentage of Caucasian participants in the study was $93 \%$. The duration of current depressive episodes was 26 and 28 months respectively. A total of 68 patients left the study with a dropout rate of $10 \%-30 \%$. The authors did not report if there was any conflict of interest.

Kyle et al. (99) compared Citalopram to Amitriptyline for treating depression in an eight week RCT involving 365 community patients over the age of 60 . Male to female ratio was $49 / 130$ or $38 \%$ and $48 / 138$ or $35 \%$ respectively. The average age was 73.4 years and baseline MADRS score was 22 , indicative of moderate depression in both groups. The study initially included a total of 408 patients: there were 44/179 drop outs from the Citalopram arm (25\%) and 56/186 dropouts from the Amitriptyline arm (30\%), and 43 withdrew during the placebo washout period. In the Citalopram group, $47 \%$ of patients were sufferers of first episode depression while $53 \%$ suffered from recurrent major depression. Similarly, in the Amitriptyline group, $49 \%$ of depressive patients were first episode. The safety report included one suicide attempt (1/186) in the Amitriptyline group but no suicide attempt $(0 / 179)$ in the Citalopram group. The authors did not report on conflict of interest.

Geretsegger et al. (100) compared antidepressant efficacy between Paroxetine and Fluoxetine in a six week RCT in Germany involving 106 elderly patients aged 61-85 years. The number of male participants in the study was low with only $10 \%$ in the Fluoxetine group. The average age was 74.3 years and baseline HAM-D 21 item score was 18. There were 20 dropouts (18\%), two during the washout phase and nine each during the trial. Most patients had a previous depressive episode (88-94\%), and the average duration of current episode was less than 12 months in more than $70 \%$ of the patients. There was one case where suicide ideation worsened $(1 / 52)$ in the Fluoxetine group requiring urgent admission during the study period but 
no incident was recorded in the Paroxetine group (0/54). The authors did not report on conflict of interest.

Guillibert et al. (101) compared Paroxetine and Clomipramine for the treatment of depression in a six week RCT in France involving 79 patients over the age of 60. The average age was 69 years with a low male-female ratio of $15 / 25(60 \%)$ in the Paroxetine group and $9 / 30(30 \%)$ in the Clomipramine group. The baseline HAM-D score of 20 was in the range of major depression, moderate severity. There were $9 / 40$ (22\%) dropouts from the Paroxetine group and 12/39 (31\%) from the Clomipramine group. The duration of current depressive episodes was 4.4 weeks in the Paroxetine group and two weeks in the Clomipramine group. One suicide was attempted in the Paroxetine group (1/40) and there were no events in the Clomipramine group (0/39). Hospital Necker funded the study and a conflict of interest statement was not reported in the paper.

Rouillon et al. (102) compared Paroxetine and Clomipramine in their nine week multi-centre RCT in France involving 91 patients with a mean age of 71 years. All participants were Caucasian. The male to female patient ratio was low - only every $6^{\text {th }}$ patient was male in the Paroxetine group and only every $10^{\text {th }}$ patient was male in the Clomipramine group. Patients with more severe depression were included in this study with the baseline HAM-D score of 27 . The number of dropouts amounted to $25(27 \%)$. There was no suicide attempt in the Paroxetine group (0/45) but one was attempted in the Clomipramine group (1/46). The funding source or conflict of interest was not reported in this study.

Dorman et al. (103) conducted a double-blind, six week RCT comparing the efficacy, tolerability and effect on sleep of Paroxetine and Mianserin treatment in elderly people with major depression. Their study included 57 patients, 29 in the Paroxetine group and 28 in the Mianserin group. The initial dose was $15 \mathrm{mg}$ Paroxetine and $30 \mathrm{mg}$ Mianserin during the first week and then the dose was increased to $30 \mathrm{mg}$ Paroxetine and $60 \mathrm{mg}$ Mianserin per day for the remaining five weeks. Duration of the current depressive episodes was longer in the Paroxetine group. The baseline HAM-D was 17 in both groups. There were previous depressive episodes in $79 \%$ of patients in the Paroxetine group and $71 \%$ in the Mianserin group. There were nine dropouts during the study (16\%), 6/29 in the Paroxetine group and 3/28 in the Mianserin group. There was one suicide attempt by overdose in Paroxetine-treated patients (1/29) but none in the Mianserin-treated patients (0/28). The funding source of this UK study and conflict of interest were not reported. 
The dropout rate in the included experimental studies ranged from between $9 \%\left({ }^{108)}\right.$ to $35 \%\left({ }^{(99)}\right.$. In the study by Nelson et al. (108), 68 out of 747 patients (9.1\%) discontinued SSRI treatment whereas in the study by Kasper et al. (98), 91 out of 518 patients (17.5\%) dropped out during the 8 weeks of the trial. The relationship between dropout rate and the risk of suicide-related harm in the RCTs is unclear. In the trial conducted by Rouillon et al.(102), 25 out of 91 patients $(27.4 \%)$ dropped out during the 9 week trial period, similar to the numbers reported by Guillibert et al. (101), where 21 out of 79 patients (26.5\%) dropped out. In Kyle et al.'s study(99), 143 patients out of 408 (35\%) dropped out during the 8 week trial period where Citalopram and Amitriptyline were compared, whereas Geretesegger et al.(100), reported that 20 out of 108 (18.5\%) patients dropped out over the 6 week trial that compared Paroxetine and Fluoxetine.

Five $(97,98,99,100,108)$ out of eight RCTs were funded by pharmaceutical companies while two RCTs (102,103) did not disclose their funding sources. In contrast, four (104-107) out of five included observational studies were funded by government health departments (Table 3.4). 
Table 3.4 Study characteristics of the Included Experimental Studies

\begin{tabular}{|c|c|c|c|c|c|c|c|c|c|c|}
\hline Citation & $\begin{array}{l}\text { Country/Set } \\
\text { ting }\end{array}$ & $\begin{array}{l}\text { Patient } \\
\text { No. }\end{array}$ & $\begin{array}{l}\text { Mean } \\
\text { age }\end{array}$ & $\begin{array}{l}\text { Intervention } \\
\text { groups }\end{array}$ & Duration & $\begin{array}{l}\text { Male: } \\
\text { Female } \\
\text { Ratio }\end{array}$ & $\begin{array}{l}\text { Placebo } \\
\text { Run } \\
\text { in } \\
\text { period* }\end{array}$ & $\begin{array}{l}\text { Dropout } \\
\text { Rate }\end{array}$ & $\begin{array}{l}\text { Depression } \\
\text { Scale } \\
\text { used/Base } \\
\text { line score }\end{array}$ & $\begin{array}{l}\text { Funding } \\
\text { Source }\end{array}$ \\
\hline $\begin{array}{l}\text { Tollefson et } \\
\text { al.(97) } \\
1995\end{array}$ & $\begin{array}{l}\text { USA/30 } \\
\text { outpatient } \\
\text { sites }\end{array}$ & $\begin{array}{l}671 \\
335 \\
\text { Fluoxetin } \\
\text { e/336 } \\
\text { Placebo }\end{array}$ & 67.4 & $\begin{array}{l}\text { Fluoxetine } \\
20 \text { mg vs. } \\
\text { Placebo }\end{array}$ & 6 wks. & $\begin{array}{l}\text { Fluoxetine } \\
=155 / 180 \\
0.86: 1.00 \\
\text { Placebo= } \\
150 / 186 \\
0.80: 1.00\end{array}$ & $1 \mathrm{wk}$. & $\begin{array}{l}\text { Fluoxetin } \\
e= \\
21 \%, \\
\text { Placebo= } \\
19 \%\end{array}$ & $\begin{array}{l}\text { HAM-D } \\
22\end{array}$ & Eli Lilly \\
\hline $\begin{array}{l}\text { Kasper et } \\
\text { al.(98) } \\
2005\end{array}$ & $\begin{array}{l}\text { Europe/11 } \\
\text { countries, } \\
\text { Centre } \\
\text { GP, } \\
\text { Specialist }\end{array}$ & $\begin{array}{l}518 \\
173 / 164 / \\
180\end{array}$ & 75 & $\begin{array}{l}\text { Escitalopram } \\
10 \text { mg vs } \\
\text { Fluoxetine } 20 \\
\text { mg vs } \\
\text { Placebo }\end{array}$ & 8 wks. & $\begin{array}{l}\text { Escitalopra } \\
\mathrm{m}=44 / 130 \\
0.34: 1.00 \\
\text { Fluoxetine } \\
= \\
38 / 126 \\
0.30: 1.00 \\
\text { Placebo:= } \\
43 / 137\end{array}$ & 1 wk. & $\begin{array}{l}\text { Escitalop } \\
\text { ram } \\
17 \% \\
\text { Fluoxetin } \\
\text { e } 25 \% \\
\text { Placebo } \\
11 \%\end{array}$ & $\begin{array}{l}\text { MADRS } \\
28.5\end{array}$ & Lundbeck \\
\hline
\end{tabular}




\begin{tabular}{|c|c|c|c|c|c|c|c|c|c|c|}
\hline & & & & & & $0.31: 1$ & & & & \\
\hline $\begin{array}{l}\text { Nelson et } \\
\text { al. }{ }^{(108)} 2007 \\
\text { Schneider et } \\
\text { al. } 2003\end{array}$ & $\begin{array}{l}\text { USA, multi- } \\
\text { centre } \\
\text { outpatients }\end{array}$ & $\begin{array}{l}747 \\
371 / 376\end{array}$ & 70 & $\begin{array}{l}\text { Sertraline 50- } \\
100 \text { mg vs } \\
\text { Placebo }\end{array}$ & 8 wks. & $\begin{array}{l}\text { Sertraline: } \\
\text { 167/193 } \\
0.87: 1.00 \\
\text { Placebo:15 } \\
\text { 3/215 } \\
0.71: 1.00\end{array}$ & 2 wks. & $10 \%$ & $\begin{array}{l}\text { HAM-D } \\
21\end{array}$ & Pfizer \\
\hline $\begin{array}{l}\text { Kyle et al.(99) } \\
1998\end{array}$ & $\begin{array}{l}\text { UK, GP } \\
\text { community- } \\
\text { based }\end{array}$ & $\begin{array}{l}365 \\
179 / 186\end{array}$ & 73.4 & $\begin{array}{l}\text { Citalopram } \\
20-40 \text { mg vs. } \\
\text { Amitriptyline } \\
50-100 \mathrm{mg}\end{array}$ & 8 wks. & $\begin{array}{l}\text { Citalopram } \\
: 49 / 130 \\
0.38: 1.00 \\
\text { Amitriptylin } \\
\text { e: } 48 / 138 \\
0.35: 1.00\end{array}$ & $1 \mathrm{wk}$. & $\begin{array}{l}\text { Citalopra } \\
\mathrm{m}: \\
44 / 179 \\
0.25: 1.00 \\
\text { Amitriptyl } \\
\text { ine:56/18 } \\
6 \\
0.30: 1.00\end{array}$ & $\begin{array}{l}\text { MADRS } \\
22\end{array}$ & Lundbeck \\
\hline $\begin{array}{l}\text { Geretsegger } \\
\text { et al.(100) } \\
1994\end{array}$ & $\begin{array}{l}\text { Germany/ } \\
\text { Inpatients } \\
\text { Outpatients }\end{array}$ & $\begin{array}{l}106 \\
54 / 52\end{array}$ & $\begin{array}{l}61-85 \\
\text { years }\end{array}$ & $\begin{array}{l}\text { Paroxetine } \\
20-40 \mathrm{mg} \text { vs } \\
\text { Fluoxetine 20- } \\
60 \mathrm{mg}\end{array}$ & 6 wks. & $\begin{array}{l}\text { Paroxetine: } \\
\text { 9/45 } \\
0.2: 1.0 \\
\text { Fluoxetine: } \\
5 / 47 \\
0.18: 1.00\end{array}$ & $1 \mathrm{wk}$. & $\begin{array}{l}\text { Total } \\
18 \% \\
\text { dropout }\end{array}$ & $\begin{array}{l}\text { HAM-D } \\
18\end{array}$ & $\begin{array}{l}\text { Smithkline } \\
\text { Beecham }\end{array}$ \\
\hline $\begin{array}{l}\text { Guillibert et } \\
\text { al.(101) }\end{array}$ & $\begin{array}{l}\text { France Multi- } \\
\text { centre }\end{array}$ & $\begin{array}{l}79 \\
40 / 39\end{array}$ & 69 & $\begin{array}{ll}\text { Paroxetine } & 30 \\
\mathrm{mg} & \text { vs }\end{array}$ & 6 wks. & $\begin{array}{l}\text { Paroxetine: } \\
15 / 25\end{array}$ & $1 \mathrm{wk}$. & $\begin{array}{l}\text { Paroxetin } \\
\text { e: } \quad 9 / 40\end{array}$ & $\begin{array}{l}\text { HAM-D } \\
20\end{array}$ & $\begin{array}{l}\text { Hospital } \\
\text { Necker }\end{array}$ \\
\hline
\end{tabular}




\begin{tabular}{|c|c|c|c|c|c|c|c|c|c|c|}
\hline 1989 & & & & $\begin{array}{l}\text { Clomipramine } \\
75 \mathrm{mg}\end{array}$ & & $\begin{array}{l}\text { 0.6:1.0 } \\
\text { Clomiprami } \\
\text { ne:9/30 } \\
\text { 0.3:1.0 }\end{array}$ & & $\begin{array}{l}\text { 0.22:1.00 } \\
\text { Clomipra } \\
\text { mi-ne: } \\
\text { 12/39 } \\
0.31: 1.00\end{array}$ & & \\
\hline $\begin{array}{l}\text { Rouillon et } \\
\text { al. }{ }^{(102)} \\
1991\end{array}$ & $\begin{array}{l}\text { France, } 11 \\
\text { centre }\end{array}$ & $\begin{array}{l}91 \\
45 / 46\end{array}$ & 71 & $\begin{array}{l}\text { Paroxetine } \\
20-50 \mathrm{mg} \text { vs. } \\
\text { Clomipramine } \\
50-150 \mathrm{mg}\end{array}$ & 9 wks. & $\begin{array}{l}\text { Paroxetine: } \\
15 / 25 \\
0.6: 1.00 \\
\text { Clomiprami } \\
\text { ne: } 9 / 30 \\
0.3: 1.0\end{array}$ & $1 \mathrm{wk}$. & $\begin{array}{l}\text { Total } \\
27 \% \\
\text { dropout }\end{array}$ & $\begin{array}{l}\text { HAM-D } \\
27\end{array}$ & $\mathrm{~N} / \mathrm{A}$ \\
\hline $\begin{array}{l}\text { Dorman et } \\
\text { al.(103) } 1992\end{array}$ & $\begin{array}{l}\text { UK, hospital } \\
\text { patients }\end{array}$ & $\begin{array}{l}57 \\
29 / 28\end{array}$ & $\begin{array}{l}\text { Over } \\
65\end{array}$ & $\begin{array}{l}\text { Paroxetine } 30 \\
\mathrm{mg} \quad \text { vs. } \\
\text { Mianserin } \\
60 \mathrm{mg}\end{array}$ & 6 wks. & $\mathrm{N} / \mathrm{A}$ & $1 \mathrm{wk}$. & $\begin{array}{l}\text { Paroxetin } \\
\text { e:5/29, } \\
\text { Mianseri } \\
\text { n: } \quad 3 / 28 \\
\text { Total } \\
16 \% \\
\text { dropout }\end{array}$ & $\begin{array}{l}\text { HAM-D } \\
17\end{array}$ & $\mathrm{~N} / \mathrm{A}$ \\
\hline
\end{tabular}

*Placebo Run in Period is used to detect medication withdrawal symptoms or Placebo responders

HAM-D= Hamilton Rating Scale for Depression, MADRS= Montgomery-Asberg Depression Rating Scale 


\subsubsection{Description of included Observational studies}

This systematic review analysed suicide-related harm data from five observational studies conducted in the USA (104)), Canada (105, 107), UK (106) and Israel (66) on SSRI exposure in elderly patients with major depression. Four of these studies included research participants from the general community, while the retrospective case control study by Barak et al.(66) involved 202 inpatients. Descriptive details of the included observational studies incorporating treatment settings, the age of participants, male to female ratio, duration of illness, medical co-morbidities and concurrent drugs are reported in Table 3.5.

Further descriptive details of each of the included observational studies are presented in the following paragraphs. Coupland et al.(106) studied a cohort of 60,746 elderly participants suffering from depression and who were prescribed antidepressants, including SSRIs, over 11 years from the beginning of 1996 to the end of 2007. The participants were then followed up for a further 12 months. This study focused on the rate of completed suicide or attempted suicide on SSRI treatment compared to no treatment during the observation period. Most patients were aged between 65 and 75 with the mean age of 74.78 years in males and 75.09 years in females. Male to female ratio was $20,230 / 40516$ or $1: 2$. The majority $(51803)$, or $85 \%$, of patients did not have a history of depression before they were 65 years of age. The most common medical co-morbidities were hypertension and coronary heart disease. Out of all antidepressants, SSRIs were prescribed in 29763 patients or $49 \%$ of the total study population. A fifth of all participants or 14391 patients were taking concurrent anxiolytic medications.

Rahme et al.(105) conducted a retrospective cohort study in Quebec, Canada, on SSRI exposure and risk of suicide in elderly depressed patients. The study investigated people over 65 years of age exposed to SSRIs who committed suicide from January 1998 to December 2004. There were 128,229 elderly patients involved in the study who took SSRIs at the index date. Of these, $31.76 \%$ had been diagnosed with depression. Seventy percent of the study population was female. The most common medical co-morbidities were heart failure and cancer. Up to $76 \%$ of the patients were taking anxiolytic medications in the past year. 
Table 3.5 Study characteristics of Included Observational Studies

\begin{tabular}{|c|c|c|c|c|c|c|c|c|c|c|c|}
\hline Citation & $\begin{array}{l}\text { Countryl } \\
\text { Setting }\end{array}$ & $\begin{array}{l}\text { No. of } \\
\text { patients }\end{array}$ & $\begin{array}{l}\text { Mean } \\
\text { age }\end{array}$ & $\begin{array}{l}\text { Intervention } \\
\text { groups }\end{array}$ & Duration & $\begin{array}{l}\text { Male: } \\
\text { Female }\end{array}$ & $\begin{array}{l}\text { Onset } \\
\text { of } \\
\text { Illness }\end{array}$ & $\begin{array}{l}\text { Suicide/ } \\
\text { Suicide } \\
\text { attempt } \\
\text { data source }\end{array}$ & $\begin{array}{l}\text { Most } \\
\text { common } \\
\text { Medical Co- } \\
\text { morbidities }\end{array}$ & $\begin{array}{l}\text { Concur } \\
\text {-rent } \\
\text { drugs }\end{array}$ & $\begin{array}{l}\text { Funding } \\
\text { source }\end{array}$ \\
\hline $\begin{array}{l}\text { Gibbons } \\
\text { et al. }{ }^{(104)} \\
2007\end{array}$ & $\begin{array}{l}\text { US } \\
\text { Veteran } \\
\text { Database }\end{array}$ & $\begin{array}{l}31963 \text { all } \\
\text { depressi } \\
\text { on } \\
\text { 3196- } \\
\text { major } \\
\text { depressi } \\
\text { on }\end{array}$ & $\begin{array}{l}57.4 \\
\text { Data } \\
\text { for } 65 \\
\text { years }\end{array}$ & $\begin{array}{l}\text { Cohort study } \\
\text { SSRI vs No } \\
\text { antidepressa } \\
\text { nt }\end{array}$ & 2 years & $\begin{array}{l}92 \% \\
\text { male }\end{array}$ & $\begin{array}{l}\text { New } \\
\text { onset }\end{array}$ & $\begin{array}{l}\text { The } \\
\text { Veterans } \\
\text { Health } \\
\text { Administratio } \\
\text { n Medical } \\
\text { Data }\end{array}$ & $\mathrm{N} / \mathrm{A}$ & $\mathrm{N} / \mathrm{A}$ & $\begin{array}{l}\text { FDA } \\
\text { USA } \\
\text { Governm } \\
\text { ent }\end{array}$ \\
\hline $\begin{array}{l}\text { Rahme } \\
\text { et al. }{ }^{(105)} \\
2008\end{array}$ & $\begin{array}{l}\text { Canada, } \\
\text { communi } \\
\text { ty }\end{array}$ & $\begin{array}{l}\text { 39597- } \\
\text { all } \\
\text { depressi } \\
\text { on }\end{array}$ & $\begin{array}{l}\text { Over } \\
65\end{array}$ & $\begin{array}{l}\text { Retrospectiv } \\
\text { e Cohort } \\
\text { SSRI } \\
\text { prescription } \\
\text { Suicide rate }\end{array}$ & 7 years & $\begin{array}{l}\text { Female } \\
70 \%\end{array}$ & $\mathrm{n} / \mathrm{a}$ & $\begin{array}{l}\text { Quebec } \\
\text { Coroner's } \\
\text { report }\end{array}$ & $\begin{array}{l}\text { Heart Failure } \\
\text { Cancer }\end{array}$ & $\begin{array}{l}76 \% \text { on } \\
\text { benzodi } \\
\text { - } \\
\text { azepine }\end{array}$ & $\begin{array}{l}\text { Canadian } \\
\text { Health } \\
\text { research }\end{array}$ \\
\hline $\begin{array}{l}\text { Coupland } \\
\text { et al. }{ }^{(106)}\end{array}$ & $\begin{array}{l}\text { UK/GP } \\
\text { outpatien }\end{array}$ & $\begin{array}{l}60746 \\
\text { pts SSRI }\end{array}$ & 74.78 & $\begin{array}{l}\text { Cohort study } \\
\text { SSRI vs No }\end{array}$ & 11 years & $50 \%$ & $\begin{array}{l}\text { New } \\
\text { onset }\end{array}$ & $\begin{array}{l}\text { Death } \\
\text { Certificates }\end{array}$ & $\begin{array}{l}\text { Hypertensio } \\
\mathrm{n}\end{array}$ & $\begin{array}{l}20 \% \text { on } \\
\text { concurr }\end{array}$ & $\begin{array}{l}\text { NIHR } \\
\text { health }\end{array}$ \\
\hline
\end{tabular}




\begin{tabular}{|c|c|c|c|c|c|c|c|c|c|c|c|}
\hline 2011 & ts & $\begin{array}{l}29763 \\
\text { No SSRI } \\
6708\end{array}$ & & $\begin{array}{l}\text { SSRI } \\
\text { prescription }\end{array}$ & & & & $\begin{array}{l}\text { from Primary } \\
\text { Care } \\
\text { Computer } \\
\text { Records }\end{array}$ & $\begin{array}{l}\text { Coronary } \\
\text { Heart } \\
\text { Disease }\end{array}$ & $\begin{array}{l}\text { ent } \\
\text { Anxiolyt } \\
\text { ic } \\
\text { Medicat } \\
\text { ions }\end{array}$ & $\begin{array}{l}\text { technolo } \\
\text { gy } \\
\text { UK }\end{array}$ \\
\hline $\begin{array}{l}\text { Barak et } \\
\text { al.(66) } \\
2005\end{array}$ & $\begin{array}{l}\text { Israel/bot } \\
\mathrm{h} \\
\text { inpatients }\end{array}$ & $\begin{array}{l}50, \quad 21 \\
\text { patients } \\
\text { on SSRI } \\
29 \text { on } \\
\text { control }\end{array}$ & $\begin{array}{l}\text { Mean } \\
\text { age } \\
76.5\end{array}$ & $\begin{array}{l}\text { Retrospectiv } \\
\text { e matched } \\
\text { case control } \\
\text { study } \\
\text { Exposure to } \\
\text { SSRI vs no } \\
\text { exposure }\end{array}$ & 10 years & $\begin{array}{l}42 / 59 \\
0.71: 1.0\end{array}$ & $\mathrm{~N} / \mathrm{A}$ & $\begin{array}{l}\text { Admission } \\
\text { diagnosis } \\
\text { and record }\end{array}$ & $\mathrm{N} / \mathrm{A}$ & $\mathrm{N} / \mathrm{A}$ & $\begin{array}{l}\text { Lundbec } \\
k\end{array}$ \\
\hline $\begin{array}{l}\text { Juurlink } \\
\text { et al.(107) } \\
2006\end{array}$ & $\begin{array}{l}\text { Canada, } \\
\text { Ontario, } \\
\text { communi } \\
\text { ty sample }\end{array}$ & $\begin{array}{l}\text { All- } \\
1,264,68 \\
6 \\
\text { patients } \\
\text { SSRI- } \\
244,749\end{array}$ & 74.9 & $\begin{array}{l}\text { Retrospectiv } \\
\text { e matched } \\
\text { case control } \\
\text { study }\end{array}$ & 9 years & $0.78: 1.0$ & $\mathrm{~N} / \mathrm{A}$ & $\begin{array}{l}\text { Ontario } \\
\text { Chief } \\
\text { Coroner's } \\
\text { record }\end{array}$ & $\mathrm{N} / \mathrm{A}$ & $\mathrm{N} / \mathrm{A}$ & $\begin{array}{l}\text { Canadian } \\
\text { Institutes } \\
\text { of Health } \\
\text { research }\end{array}$ \\
\hline
\end{tabular}


Gibbons et al. (104) conducted a population cohort study in the USA involving 226,866 veterans with a new diagnosis of depression and who had attempted suicide between 2003 and 2004 with six months follow up. The female patient percentage of the veteran population was $8.4 \%$. Twenty-six percent of the study sample was Caucasian and 6.7\% African-American, while the race of the remainder of the sample was unknown. The study included 31963 patients on SSRIs and 18317 patients with no treatment who were 65 years or older. The study investigated suicide attempts that required medical attention and reviewed each participant's antidepressant prescription pharmacy record. The most common method to attempt suicide was hanging followed by poisoning.

Juurlink et al.(107) conducted a retrospective population-based case control study involving a population of 1,264,686 people who were over 66 years of age in Ontario, Canada. The study lasted from the beginning of 1992 to the end of 2000 , examining specifically suicide cases reported to the coroner and involving individuals who were prescribed antidepressants. During the eight year study period, 1354 elderly suicide cases were reported. Each suicide case was compared with four propensity-based matched subjects. After adjustments for propensity scores, 1138 suicide cases were compared with 4552 controls. The mean age of the patients was 74.9 years and in both groups the male percentage was $78 \%$. The number of suicide cases where there was a history of depressive disorders in the preceding year was 361 in index cases and 910 in control cases. This indicated $32 \%$ of cases who committed suicide had been diagnosed with depression prior to suicide compared to $20 \%$ in control subjects. Of these suicide cases, 907 or $68 \%$ had received no antidepressant treatment.

Barak et al. (66) conducted a retrospective case control study on 202 elderly hospitalised patients in Israel. It involved 101 elderly patients with major depression who attempted suicide on admission and 101 control patients without suicide attempt on admission. The study examined the antidepressant prescription rate of these patients over the previous 10 years from 1995 to 2004 . The patients' average age was 76.5 years and the male to female ratio was $42 / 59(71 \%)$ in both index and control cases. Recurrent depression was diagnosed in $67 \%$ of index cases and $73 \%$ of control cases. 


\subsection{The rate of emergent suicidal ideation, suicide and suicide attempt with Selective Serotonin Reuptake Inhibitors}

3.4.1 Emergence of suicidal ideation with Selective Serotonin Reuptake Inhibitors in included experimental studies

The data on the risk of emergent suicidal ideation from two RCTs involving a total of 1281 older people with major depression treated with SSRI compared to placebo was combined in the following meta-analysis to calculate the Peto Odds Ratio (OR). The calculated OR was 0.52 (95\% Cl 0.14-1.94) as seen in Figure 3.2 favoring SSRI treatment. This indicates there is no statistically significant increase in risk of emergent suicidal ideation with SSRI treatment. The two studies in this meta-analysis shared similar features regarding patient demographics and study design and duration despite the differences in dosing regimen and type of SSRI used. All of these factors support the appropriateness of conducting a meta-analysis of two studies that provided data similar enough to combine.

The result of $\mathrm{Chi}^{2}$ in this meta-analysis analysis indicated non-significant statistical heterogeneity, with Chi ${ }^{2}$ result of 0.19 with $\mathrm{I}^{2}$ of 0 . The direction of the study results were similar, both favoring SSRI treatment.

\begin{tabular}{|c|c|c|c|c|c|c|c|c|}
\hline \multirow[b]{2}{*}{ Study or Subgroup } & \multicolumn{2}{|c|}{ SSRI } & \multicolumn{2}{|c|}{ Placebo } & \multicolumn{3}{|c|}{ Peto Odds Ratio } & \multirow{2}{*}{$\begin{array}{l}\text { Peto Odds Ratio } \\
\text { Peto, Fixed, } 95 \% \mathrm{Cl}\end{array}$} \\
\hline & Events & Total & Events & Total & Weight & Peto, Fixed, $95 \% \mathrm{Cl}$ & Year & \\
\hline Tollefson 1995 & 1 & 263 & 3 & 271 & $44.4 \%$ & $0.38[0.05,2.69]$ & 1995 & \\
\hline Nelson 2007 & 2 & 371 & 3 & 376 & $55.6 \%$ & $0.68[0.12,3.93]$ & 2007 & \\
\hline Total $(95 \% \mathrm{Cl})$ & & 634 & & 647 & $100.0 \%$ & $0.52[0.14,1.94]$ & & \\
\hline Total events & 3 & & 6 & & & & & \\
\hline $\begin{array}{l}\text { Heterogeneity: } \mathrm{Chi}^{2}= \\
\text { Test for overall effect }\end{array}$ & $\begin{array}{l}0.19, \mathrm{df}= \\
Z=0.97\end{array}$ & $\begin{array}{l}1(P=0 \\
P=0.3\end{array}$ & $\begin{array}{l}0.66) ;\left.\right|^{2}= \\
\text { 3) }\end{array}$ & $=0 \%$ & & & & 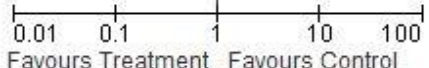 \\
\hline
\end{tabular}

Figure 3.2 Meta-Analysis of Risk of Emergent Suicidal Ideation with SSRI versus Placebo Treatment in Experimental Studies

Further details on the rate of emergent suicidal ideation by each type of SSRI are presented in Table 3.6. 
Table 3.6 Rate of emergent suicidal ideation for different SSRIs

\begin{tabular}{|c|c|c|}
\hline & SSRI Treatment & cebo/TCA Treatment \\
\hline SSRI Drug & $\begin{array}{l}\text { Number of suicide attempts or } \\
\text { emergent suicide ideation }\end{array}$ & $\begin{array}{l}\text { Number of suicide attempts or } \\
\text { emergent suicide ideation }\end{array}$ \\
\hline Fluoxetine & $\begin{array}{l}\text { Emergent Suicidal Ideation } \\
1 / 263 .(97)\end{array}$ & $\begin{array}{l}\text { Emergent Suicidal Ideation 3/271 } \\
\text { (Placebo) }\end{array}$ \\
\hline Sertraline & $\begin{array}{l}\text { Emergent Suicidal Ideation } \\
2 / 371^{(108)}\end{array}$ & $\begin{array}{l}\text { Emergent Suicidal Ideation 3/376 } \\
\text { (Placebo) }\end{array}$ \\
\hline Overall events rate & $3 / 634$ & $6 / 647$ \\
\hline
\end{tabular}

3.4.2 Suicide attempts with Selective Serotonin Reuptake Inhibitors in included experimental studies

The data informing the risk of suicide attempt from four RCTs involving a total of 592 older people with major depression treated with SSRI compared to other antidepressants was combined to calculate Peto Odds Ratio. The calculated OR was 1.00 (95\% Cl 0.14-7.10), as shown in Figure 3.3, indicating no difference between SSRI and other antidepressants in the risk of suicide attempt. The analysis indicated no significant statistical heterogeneity with low values for both $\mathrm{Chi}^{2}$ and an $\mathrm{I}^{2}$ of 3.88 and $23 \%$ respectively. Despite low heterogeneity, combining the results from only 4 studies with very low event counts and the SSRI treated patient population of 293, make it difficult to interpret and draw generalisable conclusions from this data. 


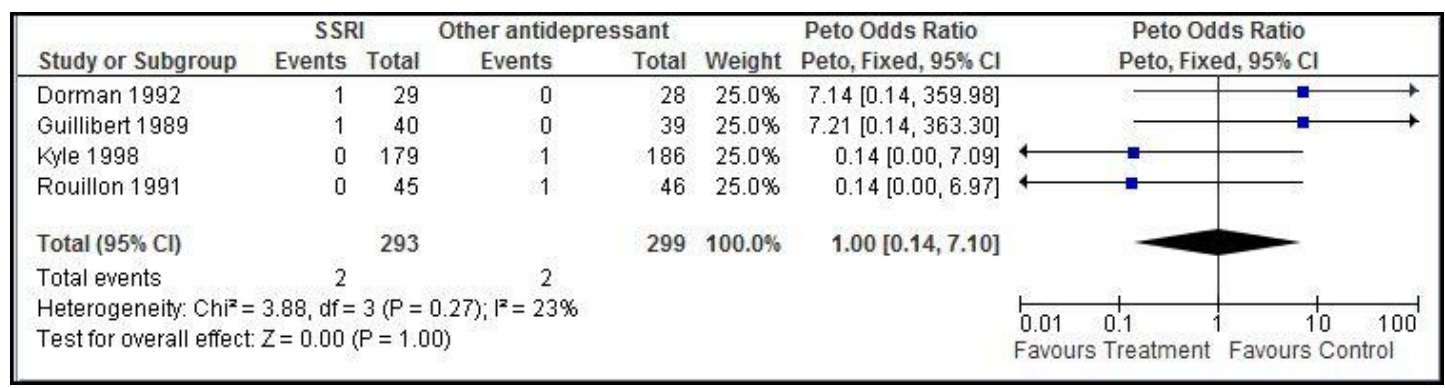

Figure 3.3: Meta-Analysis of Risk of Suicide Attempt with SSRI versus TCAs in experimental studies

Further details on the rate of suicide attempts by each type of SSRI are presented in Table 3.7 below.

Table 3.7 Rate of suicide attempt for different SSRIs

SSRI Treatment TCA Treatment

\begin{tabular}{|l|l|l|}
\hline Citalopram & $\begin{array}{l}\text { Suicide attempt } \\
0 / 179(99)\end{array}$ & $1 / 186$ (Amitriptyline) \\
\hline Paroxetine & Suicide attempt & \\
& $1 / 40{ }^{(101)}$ & $0 / 39$ (Clomipramine) \\
& $0 / 45^{(102)}$ & $1 / 46$ (Clomipramine) \\
& $1 / 29(103)$ & $0 / 28$ (Mianserin) \\
\hline Overall events rate & $2 / 293$ & \\
& & $2 / 299$ \\
\hline
\end{tabular}

3.4.3 Suicide and suicide attempt with Selective Serotonin Reuptake Inhibitors in included observational studies

It was not possible to combine all of the results of suicide-related data from all five observational studies. In this systematic review the number of patients who survived selfpoisoning was categorised under suicide attempt. Gibbon et al. (104) reported only the number of attempted suicides in their cohort study. Two observational studies $(105,106)$ reported the number of completed suicides and suicide attempts in elderly patients exposed to SSRI treatment lasting between 2.5 and 12 years. Two studies $(66,107)$ were case control in design measuring rate of completed suicide (107) and suicide attempts (66). The study by Barak et al. (66) 
did not use statistical analysis while Juurlink et al. (107) used population-based OR. Table 3.8 provides data on different suicide-related events from the observational studies included in this review.

Table 3.8 Suicide-Related Events in Observational Studies

SSRI treatment

No SSRI treatment

\begin{tabular}{|l|l|l|l|l|}
\hline Citation & $\begin{array}{l}\text { Data on Study } \\
\text { Subjects }\end{array}$ & Events & $\begin{array}{l}\text { Data on Study } \\
\text { Subjects }\end{array}$ & Events \\
\hline $\begin{array}{l}\text { Gibbons et al.(104) } \\
2007\end{array}$ & $\begin{array}{l}31963 \text { patients } \\
3196(10 \% \text { MDD })\end{array}$ & 8 suicide attempts & 18317 patients & $\begin{array}{l}12 \text { suicide } \\
\text { attempts }\end{array}$ \\
\hline $\begin{array}{l}\text { Rahme et al.(105) } \\
2008\end{array}$ & $\begin{array}{l}2,676,017 \\
\text { prescriptions }\end{array}$ & $\begin{array}{l}37 \text { suicide deaths } \\
1598 \text { suicide } \\
\text { attempts }\end{array}$ & $\begin{array}{l}\text { p49,550 } \\
\text { prescriptions }\end{array}$ & $\begin{array}{l}29 \text { suicide } \\
1534 \text { suicide } \\
\text { attempts }\end{array}$ \\
\hline $\begin{array}{l}\text { Coupland et } \\
\text { al.(106) } \\
2011\end{array}$ & $\begin{array}{l}70891 \text { patients } \\
69255\end{array}$ & $\begin{array}{l}17 \text { suicide deaths } \\
178 \text { suicide } \\
\text { attempts }\end{array}$ & $\begin{array}{l}170863 \text { patients } \\
167507\end{array}$ & $\begin{array}{l}7 \text { suicide deaths } \\
150 \text { suicide } \\
\text { attempts }\end{array}$ \\
\hline
\end{tabular}

MDD=Major Depressive Disorder

3.4.3.1 Completed suicide with Selective Serotonin Reuptake Inhibitors in observational studies

The Risk Ratio of completed suicide in older depressed people exposed to SSRI compared to no treatment was $1.06(95 \% \mathrm{Cl} 0.68-1.66 ; p=0.79$; Figure 3.4$)$ indicating no statistically significant change in risk of suicide with treatment of major depression in the elderly with SSRIs. Disparity between the two included studies' risk ratios is readily apparent with visual analysis of the forest plot and reinforced by the high $\mathrm{Chi}^{2}$ indicating the presence of statistical heterogeneity. Similarly, an $1^{2}$ of $93 \%$ suggests a high level of inconsistency as a result of heterogeneity between the two studies included in this meta-analysis.

The reason for such pronounced statistical heterogeneity is likely due to underlying differences in the severity of depression, varying doses of SSRI and different research methodologies used 
to collect outcome mortality data from coroners, doctors, hospital death certificates and social services between these included studies.

\begin{tabular}{|c|c|c|c|c|c|}
\hline Study or Subgroup & $\log$ [Risk Ratio] & SE & Weight & $\begin{array}{l}\text { Risk Ratio } \\
\text { IV, Fixed, } 95 \% \mathrm{Cl}\end{array}$ & $\begin{array}{l}\text { Risk Ratio } \\
\text { IV, Fixed, } 95 \% \mathrm{Cl}\end{array}$ \\
\hline Rahme 2008 & -0.446 & 0.264 & $75.0 \%$ & $0.64[0.38,1.07]$ & \\
\hline Coupland 2011 & 1.583 & 0.4576 & $25.0 \%$ & $4.87[1.99,11.94]$ & $\rightarrow-$ \\
\hline Total $(95 \% \mathrm{Cl})$ & & & $100.0 \%$ & $1.06[0.68,1.66]$ & \\
\hline \multicolumn{4}{|c|}{$\begin{array}{l}\text { Heterogeneity: } \mathrm{Chi}^{2}=14.75, \mathrm{df}=1(\mathrm{P}=0.0001) ; \mathrm{I}^{2}=93 \% \\
\text { Test for overall effect: } Z=0.27(\mathrm{P}=0.79)\end{array}$} & & $\begin{array}{ccccc} & 1 & 1 & 1 \\
0.01 & 0.1 & 1 & 10 & 100 \\
& \text { Decreased Risk } & \text { Increased Risk }\end{array}$ \\
\hline
\end{tabular}

\section{Figure 3.4 Meta-Analysis of Risk of suicide with SSRI in Observational Studies}

\subsubsection{Suicide attempt with Selective Serotonin Reuptake Inhibitors in included observational studies}

In the following meta-analysis, data on the risk of suicide attempt from three observational studies (104- 106) was combined to calculate the overall risk ratio of suicide attempt in older people with major depression treated with SSRI compared to no treatment. The calculated risk ratio was $1.18(95 \% \mathrm{Cl} 1.10-1.27 ; p<0.00001$; Figure 3.5$)$ indicating a statistically significant risk of suicide attempt with SSRI treatment compared to no treatment. Both visual and statistical analysis, however, also indicated the presence of significant statistical heterogeneity represented by the high $\mathrm{Chi}^{2}$ of 34.81 and very high $\mathrm{I}^{2}$ value of $94 \%$. All three studies used different strategies to collect data on suicide attempt from doctors, police, social services or hospital records. This significant heterogeneity could also relate to differences in mental health service models and unique demographic data, such as in US study. ${ }^{104}$

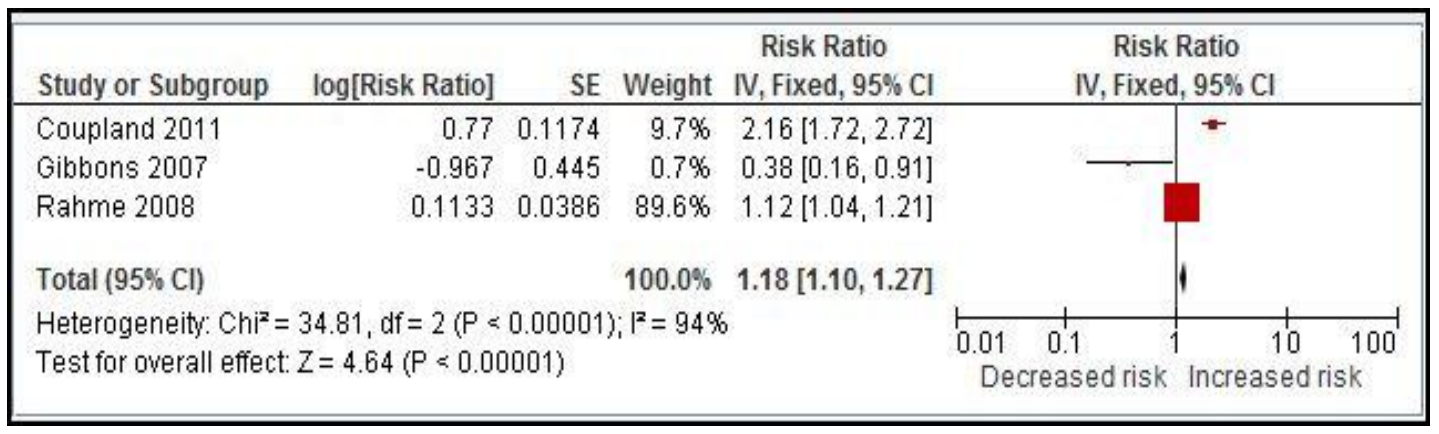

Figure 3.5 Meta-Analysis of Risk of Suicide attempt with SSRI Treatment in Observational Studies 


\section{CHAPTER FOUR: DISCUSSION}

\subsection{Major findings from the Systematic Review}

This systematic review investigated the available evidence informing the risk of suicide, suicide attempt and emergent suicidal ideation in both RCTs and observational studies on SSRI treatment for older people with major depression. The study identified and included eight RCTs investigating SSRI treatment for depression in the elderly that reported on suicide risk in safety report. The total number of participants in experimental studies in this review was low, consisting of only 2455 elderly patients participating in eight RCTs. No trials were located that matched the eligibility criteria for this review that compared SSRIs to MAOls. Meta-analyses of two placebo controlled RCTs $(97,108)$ detected an OR of emergent or worsening of suicidal ideation in older depressed people on SSRI treatment compared to placebo during the 9 weeks treatment of $0.52(95 \% \mathrm{Cl} 0.14-1.94$; Figure 3.2). Although this finding was not statistically significant, the outcome may have some clinical importance. This finding highlighted higher risk of suicidality in untreated older people with major depression. There was no difference in the risk of suicide attempt between SSRIs and TCAs in four RCTs (99,101- 103) (Figure 3.3). The relative risk of suicide attempt in elderly depressed patients treated with SSRIs compared to TCAs with the absolute risk of $0.7 \%$ in both groups. This finding supports the study by Khan et al. (112), who reported that the risk of suicidality when treated with SSRIs and TCAs was similar. Khan et al.(112) also reported the rate of suicide in antidepressant RCTs as 0.66, 40 times higher than general international population risk of suicide estimated as 0.0166 . In this review, only one RCT by Kasper et al. (98) reported one suicide event in each group, both SSRI and placebo, which occurred after the trial period. Since these events did not occur during the period of the controlled study, this data was not included in the meta-analysis.

Considering similar issues to this review, the US FDA in 2004 issued black box warnings of increased suicidal ideation and suicidal behaviour in short-term use of all antidepressants in children and youth. (55) The findings in the adult population were conflicting. $(57,61)$ In the elderly population, antidepressant treatment was considered favorable to protect against suicidality. (23) These authors concluded that antidepressant treatment reduced the risk of suicidal behaviour or ideation in older people over 65 years of age based on subgroup analysis of a total of 99231 adult patients from 372 antidepressant RCTs.(23)

In this systematic review, male to female participant ratio was low. The average male to female ratio in all included RCTs was 1:3. Sampling bias may have resulted in less male participants included across the experimental studies. It is well established that the suicide rate is higher in 
older males compared to females.(111) The higher risk male population was under-represented across almost all included RCTs. According to the Australian Bureau of Statistics (2) more female patients aged 16-85 suffer depression compared to their male counterparts, as a result more female patients may participate in RCTs than males. Paroxetine was the most common SSRI used among those RCTs represented in four experimental studies (100-103). The SSRI starting dose used in the included RCTs was in line with the manufacturer's recommended lowest effective dose. The dose escalation method was used in four RCTs which compared SSRIs with TCAs. (97, 101-103) This approach was supported by Preskorn et al. (113) who stated that some patients will benefit from a dose escalation. In 2005, Berney et al. (114) argued that a flat dose-response curve is a class phenomenon for SSRIs in fixed dose RCTs and these authors questioned the benefit of increasing SSRI dose in patients who failed to respond to minimum effective dose.(114) $\mathrm{A}$ flat dose response curve refers to the phenomenon where the response is not better on average in patients receiving a higher than minimally effective dose. Bollini et al. (115) reported that clinicians use a low dose of antidepressants to trade off a slightly reduced probability of improvement for a higher one of avoiding adverse reactions.

At the same time, this systematic review revealed a significant dropout rate of $24 \%$ in the SSRI group across the included experimental studies. This rate was similar to the report by Daly et al. (64) where the antidepressant discontinuation rate in SSRI treatment in adults aged 18-75 years was $28 \%$ in the first month. This high dropout rate may be due to side effects of antidepressant medication such as agitation and restlessness and may also be linked to future non-compliance with medication and poor response to the antidepressant; all of these factors may lead to worsening of depression. Overall, the side effects of SSRIs may significantly contribute to poor compliance with medications and worsening of underlying depression, hence predisposing the increased risk of suicidality in older people with major depression.

Though still the best method for finding a causal link regarding an adverse outcome, experimental studies were not primarily designed to study harm. The apparent methodological and clinical similarity across RCTs without statistically significant heterogeneity may minimise bias in interpreting an association between the risk of suicidality and SSRI treatment in elderly patients. As RCTs are designed for a short-term treatment effect, this result does not negate the possible relationship between SSRI treatment and increased suicidal ideation in older people with longer term use.

Inclusion of five observational studies involving 362,158 patients exposed to SSRIs for 2.5-12 years allowed this systematic review to consider long-term outcomes of SSRI treatment 
including risk of suicide and suicide attempts. $66,104-107)$ These studies did not report on emergent or worsening of suicidal ideation. The most common co-morbid medical condition was cardiovascular disease in the observed population. Two studies reported the concurrent use of benzodiazepines in $20-76 \%$ of the study population. A meta-analysis of three observational studies (104-106) involving 117,308 elderly depressed patients demonstrated some evidence of increased risk of suicide attempt in elderly patients with major depression exposed to longer term SSRI treatment. The calculated risk ratio was $1.18(95 \% \mathrm{Cl} 1.10-1.27$; Figure 3.5). In terms of risk of completed suicide risk, a meta-analysis of two observational studies (105, 106) resulted in an $\mathrm{OR}$ of $1.06(95 \% \mathrm{Cl} 0.68-1.66)$ that was not statistically significant. The validity of the meta-analysis of results from observational studies on these associations may be compromised by heterogeneity between studies. Differences emerge in baseline demographic data including male to female ratio, military veterans ${ }^{(104)}$ versus the civilian population ${ }^{(66,105-}$ 107), and sources of suicide-related events data collection.

Other possible factors contributing to increased risk of suicide in SSRI exposed elderly patients may include poly-pharmacy. Elderly depressed patients are usually on poly-pharmacy rather than SSRI mono-therapy; the effect of other medications may have an impact on the adverse effects attributable to SSRls and other drug interactions.(116) Carlsten et al.(59) reported that a current prescription for a hypnotic on its own was associated with a four-fold increase in suicide risk in the adjusted model. This systematic review found between 20 to $70 \%$ of patients concurrently used benzodiazepines along with SSRIs in two observational studies by Rahme et al.(105) and Coupland et al.(106). Additional contributing factors may include lack of clinical monitoring or poor compliance with treatment. Despite such limitations the results are clinically important enough for clinicians to be mindful of the potential risk of suicide and suicide attempt in older people exposed to longer term SSRI therapy.

\subsection{Diagnosis of major depression}

This systematic review focused on elderly people with major depression. As depression in late life may have diverse aetiologies and mode of presentation, many older people with clinically significant depression may not fulfill the DSM IV criteria(19) for major depression. Therefore, this may limit the ability to generalise the findings from this review to the wider elderly depressed population. Depression in old age is associated with more medical co-morbidities and vascular ischemic changes in the brain. The studies included in this systematic review indicated that the most common medical co-morbidity was cardiovascular disease in elderly depressed patients. Fiske et al. (31) reported that physical illnesses such as cancer, congestive heart failure or 
Parkinson's disease increase the risk of suicide late in life. Depression is the strongest risk factor for suicide, with up to a 32 -fold increase within the first three months of diagnosis. ${ }^{(117)}$ The black box warning initiated by the FDA (55) was based on the evidence from RCTs with an assumed high suicide rate in the initial 6-12 weeks of treatment. It was reported the risk of suicidality is higher prior to the commencement of antidepressant. ${ }^{(118)}$ In this systematic review, there is some evidence for the increased risk of suicide attempt in SSRI exposed elderly patients documented in the longer term observational studies.

\subsection{Comparison with findings from wider literature review}

\subsubsection{Adolescent studies}

The US FDA black box warning was based on research reporting the higher risk of suicidal behavior with SSRI treatment in the adolescent population. ${ }^{(55)}$ Several studies support evidence used by US FDA in 2004. Gunnell et al.(75) systematically reviewed 477 RCTs on SSRIs from pharmaceutical companies involving 40,000 individual patients including adolescents. Sixteen suicides, 172 episodes of self-harm and 177 episodes of emerging suicidal ideation were reported during the study period. Gunnell et al. (75) concluded there was weak evidence of increased risk of self-harm (OR 1.57, 0.99 to 2.55$)$ in adolescents treated with SSRls. Bridge et al. (119) conducted a meta-analysis of $27 \mathrm{SSRI}$ trials of pediatric participants suffering from depression and anxiety disorders. There was no report of completed suicides in these 27 clinical trials. The result showed increased risk of suicidality with SSRI treatment in both depression and anxiety disorders. The pooled risk differences in major depression was $0.9 \%$ $(\mathrm{Cl}-0.1$ to 1.3$)$ and for anxiety disorders the risk difference was $0.7 \%$ with $(\mathrm{Cl}-0.4-1.8)$. Vitiello and Swedo(120) conducted a RCT funded by the British Department of Health (which regulates the National Health Service) in 2004. The trial involved 4100 children aged 18 and younger who were randomly assigned to SSRI treatment or placebo. Suicidal behavior was noted in $2.7 \%$ of young people treated with SSRI compared to $2.5 \%$ in the placebo group. No participant committed suicide in the study.(120) Similarly, Hammad et al.(121) conducted a meta-analysis on 24 placebo controlled trials involving 4852 adolescents on SSRI treatment, reporting an overall risk ratio for suicidality associated with SSRI treatment in young people as $1.66(95 \% \mathrm{Cl}, 1.02-$ 2.68). In contrast, this review did not show an increased risk of suicidality in RCTs on SSRIs in the elderly. 


\subsubsection{Evidence from wider studies involving adults and older people}

The results from systematic reviews and observational studies on the risk of suicidality and SSRI treatment in adults or older people were mixed. In 2005, Fergusson et al.(76) reviewed 702 SSRI clinical trials involving 87650 adults and found a significant increase in suicide attempt with an OR of 2.28 (95\% Cl 1.14-4.55) in SSRI versus placebo groups. In contrast, Beasley et al. (67) in 2007 reported that placebo treated patients were 1.89 times more likely to experience suicide-related adverse events than Fluoxetine treated patients $(P=0.028)$ across all ages investigated. For the over 65 age group, placebo treated patients were 3.33 times at greater risk of committing suicide than Fluoxetine treated patients $(P=0.016)$.(66) The systematic review by Anstey and Brodaty(122) which comprised 22 double-blind SSRI trials conducted in elderly participants between 1987 and 1992 did not report on incidence of suicide attempt or completed suicide. In 2009, Stone et al. (23) conducted a meta-analysis of 372 antidepressant RCTs involving nearly 100,000 patients of all ages and concluded the rate of suicide ideation with SSRI treatment was less in older people over 65 years compared to placebo. In terms of evidence from observational studies, Juurlink et al (107) reported a five-fold increase in suicidal behavior in the early weeks of SSRI treatment in older people with depression.

Similarly, this systematic review found mixed results; in experimental studies there was a statistically insignificant increased risk of emergent suicidal ideation in the placebo treated group compared to SSRI. On the other hand, observational studies over the 2.5-12-year period showed higher risk of suicide attempt on longer term SSRI treatment compared to no treatment in older people.

\subsection{Limitations of the included studies}

Several limitations of studies investigating SSRIs and risk of suicide were identified during the conduct of this systematic review. This review included only eight RCTs that reported on suicide-related events. The absence of reporting on such events in RCTs does not necessarily mean no suicide-related events occurred in the 32 RCTs listed in Appendix IV. This may pose a potential reporting bias in this review. Lack of data informing suicide-related harm in those RCTs leaves any risk estimates in this review as potentially being either over or underestimates of the true risk.

The analysis of worsening or emergent suicidal ideation in this review was hindered by the fact that the observational studies $(66,104-107)$ did not report on this clinically important outcome. This absence may also pose potential reporting bias in this systematic review. Another potential bias relates to the measurement of the outcome of interest, or cause of death. In this systematic 
review, two included observational studies $(105,107)$ relied on the coroner's report for completed suicide data. The confirmation of a sudden death as suicide usually depended on the coroner's reports. Coronial definitions of suicide and suicide attempt can differ, thus leading to bias or inconsistency in statistical reporting. Although it is the most reliable method for confirming suicide, many cases may have been missed. For example, in sub-intentional suicide cases, elderly depressed patients may stop taking medications for their co-morbid illness deliberately and later died from such medical conditions.

The combined quality of the SSRI-related suicide risk data was significantly limited by variation in different reporting and data collection methods used in both experimental and observational studies selected for this systematic review. In the included RCTs, the rate of suicide-related incidents was obtained from safety reports that relied on passive reporting and surveillance without systematic harm monitoring. This could have mitigated the potential risk of increase in suicidality with the SSRI treatment. Information was lacking about the timing and context of the incident, and systematic clinical tools were not employed to assess and monitor the risk of suicide-related harm during SSRI trials.

Furthermore, the following factors may have contributed to heterogeneity among three observational studies involved in the meta-analysis. Consequently, bias was reported with confounding factors of varying degrees of depression severity in the study population, the studies' different time duration and different observational strategies.

The term suicidality - which covers suicidal behavior and thinking - is criticised for its lack of clinical utility. In this systematic review, the term suicide-related harm event was used to cover: 1) completed suicide; 2) suicide attempt/act; and 3) emergent or worsening of suicide ideation. These categories have different incidences and relationships, and covering them with one umbrella term of suicidality may be misleading. This binary outcome measure may have limitations in assessing suicidal ideation, preparatory suicidal behavior or attempted suicide as they are continuum in nature with the difference being the degree of suicide risk. Not enough is known about the relationship between suicide, suicide attempt, preparatory acts and suicidal ideation.

This systematic review did not include pharmaco-epidemiological and ecological studies due to time and resource factors. Chou et al.(92) stated that pharmaco-epidemiological and ecological studies are two useful sources of data for harm analysis. Similarly, Gibbons et al. (60) have recommended that researchers who study the relationship between suicide and medication treatment should use data from all available sources rather than relying only on spontaneous 
reports, for example data from ecology, large-scale medical claim data and pharmacoepidemiological studies. ${ }^{(60)}$ Ecological studies on SSRIs and suicide in the elderly have claimed that a higher SSRI prescription rate is associated with less suicides in elderly people.(35) Such studies have major limitations. Linking exposure to SSRI and the incidence of suicide without accounting for potentially lower, longer term oral medication adherence may lead to significant bias in interpretation. This severely limits the conclusions that are able to be drawn from the prescription rate as a marker for full SSRI treatment.

\subsection{Issues with study size}

All RCTs in this systematic review excluded patients at risk of suicide, and consequently the study samples may not truly represent the general older patient population with major depression. There are moral, ethical and methodological challenges in recruiting patients who are at risk of suicide in antidepressant clinical trials and these issues limit the study size and duration. However, as part of the assessment of drug safety, Meyer et al.(89) recommended the inclusion of patients at risk of suicide in pre-market clinical trials with proper precautions and appropriate monitoring. Randomised controlled trials are generally designed to study efficacy and tolerability of a drug, but not the risk of suicide-related harm. Gunnell et al.(75) stated that effective RCTs will require a sample population of up to two million participants to detect a $20 \%$ change in suicide risk.

In this systematic review, which looked at the incidence of suicide, attempted suicide and emergent or worsening of suicidal ideation in RCTs on SSRIs, the study population size was small. Only 2606 elderly patients were involved in eight SSRI RCTs. Of these patients 1372 were exposed to SSRI compared to 1234 elderly patients exposed to other antidepressants or placebo. The number of patients in each RCT in this review varied from 57 to 747 and only four out of eight experimental studies comprised over 300 patients in both arms. The total number of patients involved in the meta-analysis of RCTs in this systematic review is 1873. The duration of RCTs ranged from 6-9 weeks after SSRI initiation. Despite the small sample size, this review provides a snapshot of short-term suicide risk by SSRIs in selected RCTs. Compared to RCTs, this systematic review included five observational studies including 132,306 elderly patients who were exposed to SSRI treatment compared to no treatment over a ten-year period. The longitudinal course of major depression and relationship to risk of suicide is complex and complicated. Some older patients may be on antidepressant therapy for a short time only but for some, it may be for life. It is important for clinicians to review and rationalise the need for ongoing SSRI therapy in the elderly. 


\subsection{Study setting and funding}

The locations of the studies included in this systematic review are limited to Western cultural settings. Differences in models of mental health service delivery and unique characteristic of cohorts may have contributed to the significant heterogeneity among the included observational studies. All studies in this review were conducted in the USA, Canada and Europe therefore, the overall sample may not accurately represent the global elderly population. The results of clinical trials from less developed countries and reported in non-English languages were not included in this systematic review.

The RCTs in this systematic review were conducted between 1989 and 2005 with the source of funding in three experimental studies not reported. All observational studies disclosed their funding source and four out of five studies were funded by local governmental health and research authorities. According to the World Association of Medical Editors(123), scientific journals should publish all financial information and conflicts of interest. The absence of such material could well affect (or be seen to affect) how the research study was conducted or reported. Lexchin et al.(124) reported that systematic bias favours products that are made by the company funding the research. The studies sponsored by pharmaceutical companies were more likely to have outcomes favouring the sponsor than were studies where no commercial interest was evident (odds ratio 4.05; 95\% confidence interval 2.98 to 5.51). However, Lexchin et al.(124), also stated that no studies funded by the pharmaceutical industry were of poorer quality. Tallon et al. (125) reported that $55 \%$ of medical research was funded by pharmaceutical companies; research funded by industry tends to publish positive outcome studies. The majority of experimental studies were sponsored by pharmaceutical companies and therefore positive outcome publication bias has the potential to be a major limitation. Dorman et al.(126) stated that the sponsor's involvement in the design, conduct, management, analysis and publication of the RCTs in acute stroke between 1955 and 1995, was poorly reported. This poor reporting on conflict of interest may be associated with under-reporting of the negative outcomes and harms associated with the treatment.

\subsection{Search strategies and Data analysis}

Most of the SSRI trials were completed in the 1990s with very few more recent SSRI studies on the elderly population. Extensive multi-database literature searching including international clinical trials registers returned few publications relevant to this systematic review. Despite recommendations to search extensively for 'grey literature' sources to alleviate the risk of publication bias, this component of the search strategy yielded no relevant studies. The 
majority of the included experimental studies came from hand-searched reference lists. The report on the number of suicide-related events in this systematic review has to be viewed in the light of 32 excluded RCTs prior to critical analysis that did not report on suicide data. Overall low scores on the McHarm tool in both experimental and observational studies may indicate the need for better suicide-related harm monitoring and recording in clinical trials and observational studies.

\subsection{Statistical methods}

The analyses conducted in this systematic review encountered several pitfalls notably related to zero event analysis and the power of statistical testing. In this systematic review experimental studies had study arms with very few or zero suicide-related events (for example see Figure 3.3). In order to handle zero events in the included RCTs, the Peto method was employed for meta-analysis in this review. (96) The Peto method is known as a better method to estimate ORs when there are many trials with no events in one or both arms. It uses not only an inverse variance approach but also employs different weights and approximate method for estimating the log odds ratio. The approximation used in the computation of the log OR works well when intervention effects are small (ORs are close to one), events are rare, and the studies have similar numbers in experimental and control groups. However, the Peto method is criticised for its inbuilt mathematical assumption that every study is evaluating a universal treatment effect and the play of chance is the same in all studies. (96)

The included RCTs all reported small number of suicide-related events and the statistical power is too low to detect a difference in the incidence of completed suicide or attempted suicide between RCTs. The total patient number of all included 8 RCTs is 2634 , still low to have acceptable statistical power. For meta-analyses of observational studies, this review used the inverse variance statistical method to combine original effect estimates of suicide risk expressed as hazard ratios. To calculate the hazard ratio, the data from the long-term variable rate of suicide with SSRI treatment or no treatment was divided by the number of years of exposure. As a result, the hazard ratio relied on the incidence of harm at a given year compared to the longer time frame of the study rather than the absolute timing of the incident. Many factors may have an impact on the timing of the suicide-related event. For example, sudden cessation of SSRI treatment may trigger physiological withdrawal and rebound effects in addition to the recurrence of severe depression with worsening of suicidal ideation. The importance of recording the time of the suicide-related event must be emphasised in suiciderelated harm studies. It is a common assumption to use the hazard ratio interchangeably with 
the risk ratio in meta-analyses investigating rare events such as suicide. Such a practice may have important clinical implications in terms of misinterpretation of the results. ${ }^{(96)}$ Huang et al.(127) proposed that meta-analysis of adverse event data should be regarded as exploratory, rather than confirmatory and listed the pitfalls that could occur when conducting a systematic review on adverse events reported in RCTs. These authors mentioned that at a clinical trial level, these pitfalls include variation in the completeness of adverse event detection across trials and variation in reporting effort for unexpected adverse events. At the metaanalysis level the pitfalls include incomplete reporting on the adverse events, different summary statistics being reported, appropriate handling of zero events and potentially misleading results from statistical testing.(127)

\subsection{Implications for research}

Future studies should consider the need for a cost-benefit analysis to include a systematic suicide-related harm monitoring and reporting function in all clinical trials, particularly those funded by pharmaceutical companies. The quality of clinical trials may be improved by including both active and passive surveillance using clinical and research rating scales to accurately assess suicide-related harm in all clinical trials involving antidepressants and other psychotropic medications. Furthermore, all future trials on antidepressants, SSRIs or otherwise, should report on pre-defined suicide-related adverse outcomes. There is a need to develop an evidence-based valid and reliable systematic suicide-related harm assessment protocol to monitor suicide risk for older people who suffer from a major depression and are on antidepressant treatment.

\subsection{Implications for practice}

Routine assessment of suicide risk is highly recommended prior to the commencement, change in dose or cessation of any antidepressant medication in the elderly and youth alike in daily clinical practice. It is necessary to explore the need for primary care clinicians to use a systematic suicide harm monitoring tool for older people on both short-term and longer term SSRI treatment. In older people, the need for longer term antidepressant treatment must be clearly justified and regularly monitored for treatment side effects and suicidality as and when necessary. It should be accompanied by a regular clinical review process to balance benefit and risk associated with SSRI treatment. 


\subsection{Conclusion}

The study of SSRI treatment and risk of suicide is regarded as controversial. Experimental studies on suicide are confronted with ethical, political and methodological challenges and controversies. Though it appears that more research has been published on adolescent and youth populations on association between SSRI treatment and risk of suicide, the reports are conflicting. A few studies are available on the same subject with reference to the old age population; these studies reported a favourable effect of SSRI treatment for suicidal older patients. $(23,50)$ This systematic review explored the association between suicidality and SSRI treatment in older people with major depression. This study found some evidence which suggests increased risk of suicide attempt in older people with major depression who are on longer term SSRI treatment compared to no treatment. This is despite the limitations that have been documented regarding study design, collection and analysis of adverse events. The finding of an $18 \%$ increase in risk of suicide attempt on longer term 2.5 to 12 years SSRI exposure is not consistent with the previous notion of preventive effect of SSRI treatment in older patients against suicide. The finding of a $6 \%$ increase in the risk of completed suicide with SSRI treatment over 12 years was not statistically significant, however clinically important. There is significant heterogeneity among the included observational studies which increases the risk of bias in the meta-analysis. Nevertheless, the finding of this review raised important clinical implications on the need to systematically monitor the risk of suicide in elderly depressed patients on long-term SSRI treatment. 


\section{REFERENCES}

1. Australian Bureau of Statistics. "Causes of death, Australia, 2010". ABS, Canberra. 2012; Cat. No. 3303.0:Pages 21-2.

2. Australian Bureau of Statistics. Year Book Australia, 2009-2010, Mental Health. ABS, Canberra. 2007; Canberra (Cat. 1301.0).

3. Raymond J. Suicide in Later Life. Journal of Religious Gerontology. 2003 2003/04/15;13(3-4):117-28.

4. Sturgiss EA. Suicide in people over 65 years of age in the Australian Capital Territory. Journal of Forensic and Legal Medicine. 2009 Aug;16(6):338-9. PubMed PMID: 19573844. 5. Mann JJ. Drug Therapy: The Medical Management of Depression. N Engl J Med. 2005;353:1819-1834.

6. Knox KL, Conwell Y, Caine ED. If suicide is public problem, what are we doing to prevent it? American Journal of Public Health. 2004 Jan; 94(1):37-45.

7. Pridmore $S$, Walter G. Protest suicide. Australasian psychiatry : bulletin of Royal Australian and New Zealand College of Psychiatrists. 2012 Dec;20(6):533-4.

8. Kleespies PM, Hughes DH, Gallacher FP. Suicide in the medically and terminally ill: psychological and ethical considerations. Journal of Clinical Psychology. 2000 Sep;56(9):115371.

9. Ginn S, Price A, Rayner L, Owen GS, Hayes RD, Hotopf M, Lee W. Senior doctors' opinions of rational suicide. Journal of Medical Ethics. 2011 Dec;37(12):723-6.

10. Gerathy S. Upper House votes down voluntary euthanesia bill. Australian Broadcasting Corporation. 2013;May(23).

11. Szanto K, Prigerson HG, Reynolds CF. Suicide in the elderly. Clinical Neuroscience Research. 2001 11;1(5):366-76.

12. Carballo JJ, Akamnonu CP, Oquendo MA. Neurobiology of suicidal behavior. An integration of biological and clinical findings. Archives of Suicide Research : Official Journal of the International Academy for Suicide Research. 2008;12(2):93-110.

13. Lopez JF, Vazquez DM, Chalmers DT, Watson SJ. Regulation of 5-HT receptors and the hypothalamic-pituitary-adrenal axis. Implications for the neurobiology of suicide. Annals of the New York Academy of Sciences. 1997 Dec 29;836:106-34.

14. Mann JJ, Malone KM. Cerebrospinal fluid amines and higher-lethality suicide attempts in depressed inpatients. Biological Psychiatry. 1997 Jan 15;41(2):162-71. 
15. Arango V, Ernsberger P, Marzuk PM, Chen JS, Tierney H, Stanley M, Reis DJ, Mann JJ. Autoradiographic demonstration of increased serotonin $5-\mathrm{HT} 2$ and beta-adrenergic receptor binding sites in the brain of suicide victims. Archives of General Psychiatry. 1990 Nov;47(11):1038-47.

16. Hrdina PD, Demeter E, Vu TB, Sotonyi P, Palkovits M. 5-HT uptake sites and 5-HT2 receptors in brain of antidepressant-free suicide victims/depressives: increase in 5-HT2 sites in cortex and amygdala. Brain Research. 1993 Jun 18;614(1-2):37-44. PubMed PMID: 8348328. Epub 1993/06/18. eng.

17. Slater S VM, Davis J. Key neurochemical markers for the prevention of suicide. Trends in Analytical Chemistry 2009;28(9):1037-47.

18. Brent D, Melhem N, Turecki G. Pharmacogenomics of suicidal events.

Pharmacogenomics. 2010 Jun;11(6):793-807.

19. Association AP. Major depressive disorder. American Psychiatric Association

Diagnostic and Statistical Manuals of Mental Disorders 2000;Washington, DC (Text Rev (fourth edition)).

20. Conwell $\mathrm{Y}$, Rotenberg M, Caine ED. Completed suicide at age 50 and over. J Am Geriatr Soc. 1990 Jun;38(6):640-4.

21. Laughren T. Memorandum: overview for the December 13 meeting of

Psychopharmacologic Drugs Advisory Committee. US Food and Drug Administration. $2006 ; 4272(b)$.

22. Medical Encyclopaedia. suicide. US National ILibrary of Medicine 2013. (Internet) www.nlm.nih.gov/medlineplus/encyclopedia.html

23. Stone $M$, Laughren $T$, Jones ML, Levenson M, Holland PC, Hughes A, Hammad TA, Temple R, Rochester G. Risk of suicidality in clinical trials of antidepressants in adults: Analysis of proprietary data submitted to US Food and Drug Administration. BMJ: British Medical Journal. 2009;339:b2880.

24. Goldney RD, Wilson D, Grande ED, Fisher LJ, McFarlane AC. Suicidal ideation in a random community sample: attributable risk due to depression and psychosocial and traumatic events. Australian and New Zealand Journal of Psychiatry. 2000;34(1):98-106.

25. Beck AT, Kovacs M, Weissman A. Assessment of suicidal intention: the Scale for Suicide Ideation. J Consult Clin Psychol. 1979 Apr;47(2):343-52. 
26. Blair-West GW, Mellsop GW. Major depression: does a gender-based down-rating of suicide risk challenge its diagnostic validity? Australian \& New Zealand Journal of Psychiatry. 2001;35(3):322-8.

27. Coryell W, Young EA. Clinical predictors of suicide in primary major depressive disorder. The Journal of Clinical Psychiatry. 2005 Apr;66(4):412-7.

28. Sinyor M, Remington G. Is psychiatry ignoring suicide? The case for clozapine. Journal of Clinical Psychopharmacology. 2012 Jun;32(3):307-8.

29. Unutzer J, Tang L, Oishi S, Katon W, Williams JW, Jr., Hunkeler E, et al. Reducing suicidal ideation in depressed older primary care patients. J Am Geriatr Soc. 2006 Oct:54(10):1550-6.

30. Cattell H. Suicide in the elderly. Advances in Psychiatric Treatment. 2000 March 1, 2000;6(2):102-8.

31. Fiske A, O'Riley AA, Widoe RK. Physical Health and Suicide in Late Life: An Evaluative Review. Clinical Gerontologist. 2008;31(4):31-50.

32. David W. Crumpacker. Suicidality and antidepressants in the elderly. Baylor University Medical Center Proceedings. 2008;21(4):373-377.

33. Conwell Y. Suicide in Later Life: A Review and Recommendations for Prevention. Suicide and Life-Threatening Behavior. 2001;31:32-47.

34. Joiner TE, Jr., Brown JS, Wingate LR. The psychology and neurobiology of suicidal behavior. Annual Review of Psychology. 2005;56:287-314.

35. Isacsson G, Rich CL, Jureidini J, Raven M. The increased use of antidepressants has contributed to the worldwide reduction in suicide rates. The British Journal of Psychiatry. 2010 June 1, 2010;196(6):429-33.

36. Wessely S and Kerwin R. Suicide Risk and the SSRIs. JAMA : the Journal of the American Medical Association. 2004;292(3):379-381.

37. Fergusson D, Doucette S, Glass KC, Shapiro S, Healy D, Hebert P, Hutton B.

Association between suicide attempts and selective serotonin reuptake inhibitors: systematic review of randomised controlled trials. BMJ (Clinical research ed). 2005 Feb 19;330(7488):396. 38. Healy D, Langmaak C, Savage M. Suicide in the course of the treatment of depression. Journal of Psychopharmacology (Oxford, England). 1999;13(1):94-9.

39. NICE. Depression: the Treatment and Management of Depression in Adults (Update). NICE Clinical Guideline 902009; October (23): 24. 2009;90(23):24. 
40. Henry JA, Alexander CA, Sener EK. Relative mortality from overdose of antidepressants. BMJ (Clinical research ed). 1995 Jan 28;310(6974):221-4.

41. Mottram PG WK, Strobl JJ. Antidepressants for depressed elderly (Review). The Cochrane Library. 2009 (01).

42. Schneider LS. Pharmacologic considerations in the treatment of late-life depression American Journal of Geriatric Psychiatry 1996;4(4 (Suppl)):S51-S65.

43. Hall WD, Mant A, Mitchell PB, Rendle VA, Hickie IB, McManus P. Association between antidepressant prescribing and suicide in Australia, 1991-2000: trend analysis. BMJ (Clinical research ed). 2003 May 10;326(7397):1008.

44. Tedeschini E, Levkovitz Y, lovieno N, Ameral VE, Nelson JC, Papakostas GI. Efficacy of antidepressants for late-life depression: a meta-analysis and meta-regression of placebocontrolled randomized trials. The Journal of Clinical Psychiatry. 2011 Dec;72(12):1660-8.

45. Juurlink DN, Mamdani MM, Kopp A, Redelmeier DA. The Risk of Suicide With Selective Serotonin Reuptake Inhibitors in the Elderly. The American Journal of Psychiatry. 2006;163:813-21.

46. Perlis RH, Beasley CM, Jr., Wines JD, Jr., Tamura RN, Cusin C, Shear D, Amsterdam J, Quitkin F et al. Treatment-associated suicidal ideation and adverse effects in an open, multicenter trial of fluoxetine for major depressive episodes. Psychotherapy and Psychosomatics. 2007;76(1):40-6.

47. Szanto K, Mulsant BH, Houck PR, Dew MA, Dombrovski A, Pollock BG, et al. Emergence, persistence, and resolution of suicidal ideation during treatment of depression in old age. Journal of Affective Disorders. 2007 Feb;98(1-2):153-61.

48. Gaudiano BA, Andover MS, Miller IW. The emergence of suicidal ideation during the post-hospital treatment of depressed patients. Suicide \& Life-Threatening Behavior. 2008 Oct;38(5):539-51.

49. Martinez C, Rietbrock S, Wise L., Ashby D, Chick J, Moseley J, Evans S, Gunnell D. . Antidepressant treatment and the risk of fatal and non-fatal self harm in first episode depression: nested case-control study. BMJ, 2005;330:1-7.

50. Barbui C, Esposito E, Cipriani A. Selective serotonin reuptake inhibitors and risk of suicide: a systematic review of observational studies (Structured abstract). CMAJ: Canadian Medical Association Journal [Internet]. 2009; 180(3): 291-7.

51. Schneeweiss S, Patrick AR, Solomon D H. Mehta J, Dormuth C, Miller M, Lee JC, Wang PS. Variation in the Risk of Suicide Attempts and Completed Suicides by Antidepressant Agent in Adults. Archives of General Psychiatry. 2010;67(5) 497-506. 
52. Power AC, Cowen PJ. Fluoxetine and suicidal behaviour. Some clinical and theoretical aspects of a controversy. The British Journal of Psychiatry. 1992 December 1 , 1992;161(6):735-41.

53. Teicher MH, Glod C, Cole JO. Emergence of intense suicidal preoccupation during fluoxetine treatment. The American Journal of Psychiatry. 1990 Feb;147(2):207-10.

54. Jick H, Kaye JA, Jick SS. Antidepressants and the risk of suicidal behaviors. Journal of the American Medical Association. 2004;292(3):338-43.

55. US Food and Drug Administration. Public Health Advisory 2004. "Suicidality in Children and Adolescents Being Treated with Anti-depressant medications". FDA Online.

2004;http://www.fda.gov/Safety/MedWatch/Safetylnformation/SafetyAlertsforHumanMedicalPro ducts/ucm155488.htm (Last accessed 03/08/2013).

56. Hall WD, Lucke J. How have the selective serotonin reuptake inhibitor antidepressants affected suicide mortality? Australian and New Zealand Journal of Psychiatry. 2006;40(1112):941-50.

57. Moller HJ. Is there evidence for negative effects of antidepressants on suicidality in depressive patients? A systematic review. European Archives of Psychiatry and Clinical Neuroscience. 2006 Dec;256(8):476-96.

58. Gibbons RD, Brown CH, Hur K, Marcus SM, Bhaumik DK, Erkens JA, Herings RM, Mann JJ. Early evidence on the effects of regulators' suicidality warnings on SSRI prescriptions and suicide in children and adolescents. The American Journal of Psychiatry. 2007 Sep;164(9):1356-63.

59. Carlsten A, Waern M. Are sedatives and hypnotics associated with increased suicide risk of suicide in the elderly? BMC Geriatrics. 2009;9:20.

60. Gibbons RD, Mann JJ. Strategies for quantifying the relationship between medications and suicidal behaviour: what has been learned? Drug safety: an International Journal of Medical Toxicology and Drug Experience. 2011 May 1;34(5):375-95.

61. Beasley CM, Jr., Dornseif BE, Bosomworth JC, Sayler ME, Rampey AH, Jr., Heiligenstein $\mathrm{JH}$, et al. Fluoxetine and suicide: a meta-analysis of controlled trials of treatment for depression. BMJ (Clinical research ed). 1991 Sep 21;303(6804):685-92.

62. Tollefson GD, Bosomworth J C, Heiligenstein JH, Potvin, JH, Holman S. A Double-Blind, Placebo-Controlled Clinical Trial of Fluoxetine in Geriatric Patients With Major Depression. International Psychogeriatrics. 1995;7(1):89-105. 
63. Healy D, Whitaker C. Antidepressants and suicide: risk-benefit conundrums. Journal of Psychiatry \& Neuroscience. 2003 Sep;28(5):331-7.

64. Daly EJ, Trivedi MH, Fava M, Shelton R, Wisniewski SR, Morris DW, et al. The relationship between adverse events during selective serotonin reuptake inhibitor treatment for major depressive disorder and nonremission in the suicide assessment methodology study. Journal of Clinical Psychopharmacology. 2011 Feb;31(1):31-8.

65. Lapierre Y.D. Suicidality with selective serotonin reuptake inhibitors: Valid claim? Journal of Psychiatry and Neuroscience. 2003;28(5):340-8.

66. Barak Y, Olmer A, Aizenberg D. Antidepressants reduce the risk of suicide among elderly depressed patients. Neuropsychopharmacology : official publication of the American College of Neuropsychopharmacology. 2006;31(1):178-81.

67. Beasley CM, Jr., Ball SG, Nilsson ME, Polzer J, Tauscher-Wisniewski S, Plewes J, et al. Fluoxetine and adult suicidality revisited: an updated meta-analysis using expanded data sources from placebo-controlled trials. Journal of Clinical Psychopharmacology. 2007 Dec;27(6):682-6.

68. Gartlehner G, Thieda P, Hansen RA, Gaynes BN, DeVeaugh-Geiss A, Krebs EE, Lohr KN. Comparative risk for harms of second-generation antidepressants: A systematic review and meta-analysis. Drug Safety. 2008;31(10):851-65.

69. Isacsson G, Holmgren A, Ösby U, Ahlner J. Decrease in suicide among the individuals treated with antidepressants: a controlled study of antidepressants in suicide, Sweden 19952005. Acta Psychiatrica Scandinavica. 2009;120(1):37-44.

70. Chou R AN, Atkinsc D, Ismailad AS, Santaguidad P, Smithe DH, Whitlock E, Wilt TJ, Mohar D. AHRQ Series Paper 4: Assessing harms when comparing medical interventions: AHRQ and the Effective Health-Care Program. Journal of Clinical Epidemiology 2010;63:50212.

71. Ioannidis JP, Evans SJ, Gotzsche PC, O'Neill RT, Altman DG, Schulz K, et al. Better reporting of harms in randomized trials: an extension of the CONSORT statement. Annals of Internal Medicine. 2004 Nov 16;141(10):781-8.

72. Santaguida P RPD. McMaster Quality Assessment Scale of Harms (McHarm) for primary studies. Manual for use of the McHarm 2010;22(12):6.

73. American College of Neuropsychopharmacology (ACNP). Suicidal behaviour and psychotropic medication, Consensus statement by the ACNP Council 
neuropsychopharmacology : official publication of the American College of Neuropsychopharmacology. 1993;8(2):177-83.

74. Goldney RD. Suicide and antidepressants: what is the evidence? Australian and New Zealand Journal of Psychiatry. 2006;40(5):381-5.

75. Gunnell D, Saperia J, Ashby D. Selective serotonin reuptake inhibitors (SSRIs) and suicide in adults: meta-analysis of drug company data from placebo controlled, randomised controlled trials submitted to the MHRA's safety review. BMJ (Clinical research ed). 2005 Feb 19;330(7488):385. PubMed PMID: 15718537.

76. Fergusson D, Doucette S, Glass KC, Shapiro S, Healy D, Hebert P, Hutton B. Association between suicide attempts and selective serotonin reuptake inhibitors: systematic review of randomised controlled trials. BMJ (Clinical research ed). 2005;330:1-7.

77. March JS, Silva S, Petrycki S, Curry J, Wells K, Fairbank J, et al. The Treatment for Adolescents With Depression Study (TADS): long-term effectiveness and safety outcomes. Archives of General Psychiatry. 2007 Oct;64(10):1132-43.

78. Goldney RD. An historical note on suicide during the course of treatment for depression. Suicide \&Life-Threatening Behavior. 2007 Feb;37(1):116-7.

79. Nallamothu BK, Hayward RA, Bates ER. Beyond the Randomized Clinical Trial: The Role of Effectiveness Studies in Evaluating Cardiovascular Therapies. Circulation. 2008 September 16, 2008;118(12):1294-303.

80. Didham RC, McConnell DW, Blair HJ, Reith DM. Suicide and self-harm following prescription of SSRIs and other antidepressants: confounding by indication. British Journal of Clinical Pharmacology. 2005 Nov;60(5):519-25.

81. Coupland C, Dhiman P, Morriss R, Arthur A, Barton G, Hippisley-Cox J. Antidepressant use and risk of adverse outcomes in older people: population based cohort study. BMJ: British Medical Journal. 2011;343(7819):1-15.

82. Kalmar S, Szanto K, Rihmer Z, Mazundar S, Harrison K, Mann JJ. Antidepressant Prescription and Suicide Rates: Effect of Age and Gender. Suicide and Life-Threatening Behavior 2008;38(4):363-75.

83. Barbui C, Esposito E, Cipriani A. Selective serotonin reuptake inhibitors and risk of suicide: a systematic review of observational studies. CMAJ : Canadian Medical Association Journal. 2009 Feb 3;180(3):291-7. 
84. Gibbons RD, Brown CH, Hur K, Davis JM, Mann JJ. Suicidal thoughts and behavior with antidepressant treatment: Reanalysis of the randomized placebo-controlled studies of fluoxetine and venlafaxine. Archives of General Psychiatry. 2012;69(6):580-7.

85. Hammad TA, Laughren TP, Racoosin JA. Suicide rates in short-term randomized controlled trials of newer antidepressants. Journal of Clinical Psychopharmacology. 2006 Apr;26(2):203-7.

86. Healy D. Lines of evidence on the risks of suicide with selective serotonin reuptake inhibitors. Psychotherapy and Psychosomatics. 2003;72(2):71-9.

87. The Joanna Briggs Institute. Syatematic Review; Protocol; Effectiveness; Qualititave; Economics; and Methods. Joanna Briggs Institute Reviewer's Manual. 2011;2011 edition. 88. Golder S, Loke YK, Bland M. Meta-analyses of adverse effects data derived from randomised controlled trials as compared to observational studies: methodological overview. PLoS medicine. 2011 May;8(5):e1001026.

89. Meyer RE, Salzman C, Youngstrom EA, Clayton PJ, Goodwin FK, Mann JJ, et al. Suicidality and risk of suicide--definition, drug safety concerns, and a necessary target for drug development: a consensus statement. The Journal of Clinical Psychiatry. 2010 08/;71(8):e1e21.

90. Concato J. Observational Versus Experimental Studies: What's the Evidence for a Hierarchy? The Journal of the American Society for Experimental NeuroTherapeutics. 2004;1(3):341-7.

91. Montori VM, Swiontkowski MF, Cook DJ. Methodologic issues in systematic reviews and meta-analyses. Clinical Orthopaedics and Related Research. 2003 Aug(413):43-54.

92. Chou R, Helfand M. Challenges in systematic reviews that assess treatment harms. Annals of Internal Medicine. 2005 Jun 21;142(12 Pt 2):1090-9.

93. Aung EK, Aromataris E. The association between suicidality and treatment with Selective Serotonin Reuptake Inhibitors in older people with major depression: a systematic review. JBI Library of Systematic Reviews; [S.I.], v. 10, n. 56 Suppl, p. S313 - S324, dec. 2012. ISSN 1838-2142. Available at:

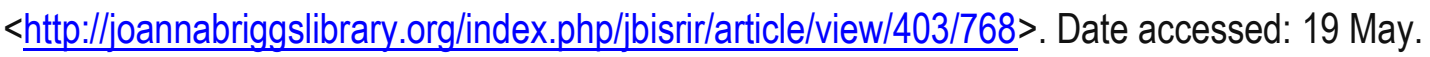
2014.

94. Endnote. Endnote X6. Thomson Reuters. 2012; http://endnote.com.

95. RevMan 5.1. Copenhagen. The Cochrane Collaboration, The Nordic Cochrane Centre. 2001; http://ims.cochrane.org/revman (Last accessed): 09/07/2012. 2012. 
96. Higgins J PT and Green S. Cochrane Handbook for Systematic Reviews of Interventions. The cochrane collaboration. 2011; Version 5.1.0(Chapter 9.4.4.2).

97. Tollefson GD, Bosomworth JC, Heiligenstein JH, Potvin JH, Holman S. A double-blind, placebo-controlled clinical trial of fluoxetine in geriatric patients with major depression. The Fluoxetine Collaborative Study Group. International Psychogeriatrics / IPA. 1995 Spring;7(1):89-104.

98. Kasper S, de Swart H, Friis Andersen H. Escitalopram in the treatment of depressed elderly patients. The American Journal of Gerriatric Psychiatry : official journal of the American Association for Geriatric Psychiatry. 2005 Oct;13(10):884-91.

99. Kyle CJ, Peterson HEH, Overø KF. Comparison of the tolerability and efficacy of Citalopram and Amitriptyline in elderly depressed patients treated in General Practice. Depression and Anxiety. 1998:8:147-53.

100. Geretsegger C, Bohmer F, Ludwig M. Paroxetine in the elderly depressed patient: Randomized comparison with fluoxetine of efficacy, cognitive and behavioural effects. International Clinical Psychopharmacology. 1994 //;9(1):25-9.

101. Guillibert E, Pelicier Y, Archambault JC, Chabannes JP, Clerc G, Desvilles M, et al. A double-blind, multicentre study of paroxetine versus clomipramine in depressed elderly patients. Acta Psychiatrica Scandinavica, Supplement. 1989 //;80(350):132-4.

102. Rouillon $\mathrm{F}$ et al A double-blind, multicenter study comparing increasing doses of paroxetine (20-50 mg) and clomipramine (50-150 mg) in elderly patients with major depression. World Congress of Biological Psychiatry. 1991;Poster.

103. Dorman T. Sleep and paroxetine: a comparison with mianserin in elderly depressed patients. International Clinical Psychopharmacology. 1992 Jun;6 Suppl 4:53-8.

104. Gibbons RD, Brown CH, Hur K, Marcus SM, Bhaumik DK, Mann JJ. Relationship between antidepressants and suicide attempts: an analysis of the Veterans Health Administration data sets. The American Journal of Psychiatry. 2007 Jul;164(7):1044-9.

105. Rahme E, Dasgupta K, Turecki G, Nedjar H, Galbaud du Fort G. Risks of suicide and poisoning among elderly patients prescribed selective serotonin reuptake inhibitors: a retrospective cohort study. The Journal of Clinical Psychiatry. 2008 Mar;69(3):349-57. 106. Coupland CA, Dhiman P, Barton G, Morriss R, Arthur A, Sach T, Hippisley-Cox J. A study of the safety and harms of antidepressant drugs for older people: a cohort study using a large primary care database. Health Technology Assessment 2011;15(28). 
107. Juurlink DN, Mamdani MM, Kopp A, Redelmeier DA. The risk of suicide with selective serotonin reuptake inhibitors in the elderly. The American Journal of Psychiatry. 2006 May;163(5):813-21.

108. Nelson JC, Delucchi K, Schneider L. Suicidal thinking and behavior during treatment with sertraline in late-life depression. The American journal of geriatric psychiatry : official journal of the American Association for Geriatric Psychiatry. 2007 Jul;15(7):573-80.

109. Kasper S, Moller HJ, Montgomery SA, Zondag E. Antidepressant efficacy in relation to item analysis and severity of depression: a placebo-controlled trial of fluvoxamine versus imipramine. International Clinical Psychopharmacology. 1995 Jan;9 Suppl 4:3-12.

110. Schneider LS NJea. An 8-Week Multicenter, Parallel-Group, Double-Blind, PlaceboControlled Study of Sertraline in Elderly Outpatients With Major Depression. The American Journal of Psychiatry. 2003;160:1277-85.

111. Australian Bureau of Statistics. "Causes of death, Australia, 2010". ABS, . 2010; Canberra. 2012 (Cat. No. 3303.0):21-2.

112. Khan A, Khan S, Kolts R, Brown WA. Suicide rates in clinical trials of SSRIs, other antidepressants, and placebo: analysis of FDA reports. The American Journal of Psychiatry. 2003 Apr;160(4):790-2.

113. Preskorn SH. Flat dose-response curves for efficacy: what do they mean to the clinician? Journal of Psychiatric Practice. 2008 Jul;14(4):232-6.

114. Berney P. Dose-response relationship of recent antidepressants in the short-term treatment of depression. Dialogues in Clinical Neuroscience. 2005;7(3):249-62.

115. Bollini P, Pampallona S, Tibaldi G, Kupelnick B, Munizza C. Effectiveness of antidepressants. Meta-analysis of dose-effect relationships in randomised clinical trials. The British Journal of Psychiatry : the journal of mental science. 1999 Apr;174:297-303.

116. Morgan TK, Williamson M, Pirotta M, Stewart K, Myers SP, Barnes J. A national census of medicines use: a 24-hour snapshot of Australians aged 50 years and older. The Medical Journal of Australia. 2012 Jan 16;196(1):50-3.

117. Crump C, Sundquist K, Sundquist J, Winkleby MA. Sociodemographic, psychiatric and somatic risk factors for suicide: a Swedish national cohort study. Psychological Medicine. 2013;FirstView:1-11.

118. Simon GE, Savarino J, Operskalski B, Wang PS. Suicide risk during antidepressant treatment. The American Journal of Psychiatry. 2006 Jan;163(1):41-7. 
119. Bridge JA, lyengar S, Salary CB, Barbe RP, Birmaher B, Pincus HA et al. Clinical response and risk for reported suicidal ideation and suicide attempts in paediatric antidepressant treatment: a meta analysis of randomized controlled trials. JAMA - Journal of the American Medical Association. 2007;297:1683-96.

120. Vitiello B. and Swedo S. Antidepressant medications in Children. New England Journal of Medicine. 2004;4(350):1489-91.

121. Hammad TA LT, Racoosin J. Suicidality in paediatric patients treated with antidepressant drugs. Archives of General Psychiatry. 2006;63(3):332-9.

122. Anstey K, Brodaty H. Antidepressants and the elderly: Double-blind trials 1987-1992. International Journal of Geriatric Psychiatry. 1995;10(4):265-79.

123. World Association of Medical Editors Committees. Conflict of Interest in PeerReviewed Medical Journals. World Association of Medical Editors.

2009;http://www.wame.org/conflict-of-interest-in-peer-reviewed-medical-journals (Last accessed 27/01/2014).

124. Lexchin J, Bero LA, Djulbegovic B, Clark O. Pharmaceutical industry sponsorship and research outcome and quality: systematic review. BMJ (Clinical research ed). 2003 2003-05-29 17:48:55;326(7400):1167-70.

125. Tallon D, Chard J, Dieppe P. Relation between agendas of the research community and the research consumer. Lancet. 2000 Jun 10;355(9220):2037-40.

126. Dorman PJ, Counsell C, Sandercock P. Reports of randomized trilas in acute stroke, 1955 to 1995 . What proportions were commercially sponsored? Stroke. 1999 Oct; 30(10): 1995-8

127. Huang HY, Andrews E, Jones J, Skovron ML, Tilson H. Pitfalls in meta-analyses on adverse events reported from clinical trials. Pharmacoepidemiology and Drug Safety. 2011 Oct;20(10):1014-20. 


\section{APPENDICES}

\subsection{Appendix I}

\begin{tabular}{|c|c|}
\hline McMaster Quality Assessment Scale for Harms (McHarm) & Rating \\
\hline 1. Were the harms PRE-DEFINED using standardized or precise definitions? & $\begin{array}{l}\sim \text { Yes } \sim \text { No } \\
\sim \text { Unsure }\end{array}$ \\
\hline 2. Were SERIOUS events precisely defined? & $\begin{array}{l}\sim \text { Yes } \sim \text { No } \\
\sim \text { Unsure }\end{array}$ \\
\hline 3. Were SEVERE events precisely defined? & $\begin{array}{l}\sim \text { Yes } \sim \text { No } \\
\sim \text { Unsure }\end{array}$ \\
\hline $\begin{array}{l}\text { 4. Were the number of DEATHS in each study group specified OR were the reason(s) } \\
\text { for not specifying them given? }\end{array}$ & $\begin{array}{l}\sim \text { Yes } \sim \text { No } \\
\sim \text { Unsure }\end{array}$ \\
\hline 5. Was the mode of harms collection specified as ACTIVE? & $\begin{array}{l}\sim \text { Yes } \sim \text { No } \\
\sim \text { Unsure }\end{array}$ \\
\hline 6. Was the mode of harms collection specified as PASSIVE? & $\begin{array}{l}\sim \text { Yes } \sim \text { No } \\
\sim \text { Unsure }\end{array}$ \\
\hline 7. Did the study specify WHO collected the harms? & $\begin{array}{l}\sim \text { Yes } \sim \text { No } \\
\sim \text { Unsure }\end{array}$ \\
\hline $\begin{array}{l}\text { 8. Did the study specify the TRAINING or BACKGROUND of who ascertained the } \\
\text { harms? }\end{array}$ & $\begin{array}{l}\sim \text { Yes } \sim \text { No } \\
\sim \text { Unsure }\end{array}$ \\
\hline 9. Did the study specify the TIMING and FREQUENCY of collection of the harms? & $\begin{array}{l}\sim \text { Yes } \sim \text { No } \\
\sim \text { Unsure }\end{array}$ \\
\hline 10. Did the author(s) use STANDARD scale(s) or checklist(s) for harms collection? & $\begin{array}{l}\sim \text { Yes } \sim \text { No } \\
\sim \text { Unsure }\end{array}$ \\
\hline $\begin{array}{l}\text { 11. Did the authors specify if the harms reported encompass ALL the events collected } \\
\text { or a selected SAMPLE? }\end{array}$ & $\begin{array}{l}\sim \text { Yes } \sim \text { No } \\
\sim \text { Unsure }\end{array}$ \\
\hline $\begin{array}{l}\text { 12. Was the NUMBER of participants that withdrew or were lost to follow-up specified } \\
\text { for each study group? }\end{array}$ & $\begin{array}{l}\sim \text { Yes } \sim \text { No } \\
\sim \text { Unsure }\end{array}$ \\
\hline $\begin{array}{l}\text { 13. Was the TOTAL NUMBER of participants affected by harms specified for each } \\
\text { study arm? }\end{array}$ & $\begin{array}{l}\sim \text { Yes } \sim \text { No } \\
\sim \text { Unsure }\end{array}$ \\
\hline $\begin{array}{l}\text { 14. Did the author(s) specify the NUMBER for each TYPE of harmful event for each } \\
\text { study group? }\end{array}$ & $\begin{array}{l}\sim \text { Yes } \sim \text { No } \\
\sim \text { Unsure }\end{array}$ \\
\hline 15. Did the author(s) specify the type of analyses undertaken for harms data? & $\begin{array}{l}\sim \text { Yes } \sim \text { No } \\
\sim \text { Unsure }\end{array}$ \\
\hline
\end{tabular}




\subsection{Appendix II}

\section{Search strategy and search histories}

Database: PubMed, searched on date 27/11/2012- 139 hit (201 combined with 3/10. Number of potentially positive studies-7)

Search Keywords

1 "Elder" [All Fields]

2 "Aged" [All Fields]

3"Ageing" [All Fields]

4 "Senior" [All Fields]

5"Geriatric" [All Fields]

6 "Old" Adult" [All Fields]

7 "Old* patient" [All Fields]

8 "Old* people" [All Fields]

9 "Aged+" [Mesh Terms]

10 \#1 OR \#2 OR \#3 OR \#4 OR \#5 OR \#6 OR \#7 OR \#8 OR \#9

11 "depression" [All Fields]

12 "major depression"[All Fields]

13 "Depressed" [All Fields]

14 "Depressive Disorder, Major" [All Fields]

15 "Melancholia, involutional" [All Field]

16 “depressive disorder"[All Fields]

17 "Depressive disorder, major"[Mesh Terms]

18 \#11 OR \#12 OR \#13 OR \#14 OR \#15 OR \#16 OR \#17

19 "Placebo" [All Fields]

20 "SSRl" [All Fields]

21 "SSRIs" [All Fields]

22 "Fluoxetine" [All Fields]

23 "fluvoxamine" [All Fields]

24 "Sertraline"[All Fields]

25 "paroxetine"[All Fields]

26 "Citalopram"[All Fields]

27 "Escitalopram"[All Fields] 
28 "Serotonin uptake inhibitor"[All Fields]

29 "Serotonin reuptake inhibitors"[All Fields]

30 "Serotonin uptake inhibitors" [Mesh Terms]

31 \#19 OR \#20 OR \#21 OR \#22 OR \#23 OR \#24 OR \#25 OR \#26 OR \#27 OR \#28 OR \#29 OR

\#30

32 "suicide, completed"[All Fields]

33 "Suicidal" "AAll Fields]

34 "suicide, attempted"[All Fields]

35 "attempted suicide"[All Fields]

36 "emergent suicide behaviour"[All Fields]

37 "emergent suicide 67ehaviour"[All Fields]

38 "suicide risk"[All Fields]

39 "suicidal ideation"[All Fields]

40 " suicide"[Mesh Terms]

41 \#32 OR \#33 OR \#34 OR \#35 OR \#36 OR \#37 OR \#38 OR \#39 OR \#40

42 "randomized controlled trials"[All Fields]

43 "randomised controlled trials"[All Fields]

44 " randomized controlled trial"[All Fields]

45 "randomised controlled trial"[All Fields]

46 "prospective randomized controlled trial"[All Fields]

47 " prospective randomised controlled trial "[All Fields]

48 "randomized clinical trial"[All Fields]

49 "randomised clinical trial"[All Fields]

50 "clinical trial"[All Fields]

51 "clinical trials"[All Fields]

52 "observational study"[All Fields]

53 "observational studies"[All Fields]

54 "case-control study"[All Fields]

55 "case-control studies"[All Fields]

56 "case control study"[All Fields]

57 "cohort study"[All Fields]

58 "cohort studies"[All Fields]

59 "prospective study"[All Fields] 
60 "prospective studies"[All Fields]

61 \#42 OR \#43 OR \#44 OR \#45 OR \#46 OR \#47 OR \#48 OR \#49 OR \#50 OR \#51 OR \#52 OR \#53 OR \#54 OR \#55 OR \#56 OR \#57 OR \#58 OR \#59 OR \#60

62 \#10 AND \#18 AND \#31 AND \#41 AND \#61

63 Limit to English language

Database: CINAHL (Number of potentially relevant studies-237 searched 28/11/2012)

Search Keywords

1 TX "elder"

2 TX "aged"

3 TX "ageing"

4 TX "Senior"

5 TX "Geriatric"

6 TX "Old* people"

7 TX "Old* adult"

8 TX "Old* patient"

$9 \mathrm{MH}$ "Aged+"

$10 \mathrm{~S} 1$ or $\mathrm{S} 2$ or $\mathrm{S} 3$ or $\mathrm{S} 4$ or $\mathrm{S} 5$ or $\mathrm{S} 6$ or $\mathrm{S} 7$ or $\mathrm{S} 8$ or $\mathrm{S} 9$

11 TX "depression"

12 TX "major depression"

13 TX "depressed"

14 TX "depressive disorder, major"

15 TX "Melancholia, involutional"

16 TX "depressive disorder"

17 TX "Major depressive disorder"

$18 \mathrm{~S} 11$ or $\mathrm{S} 12$ or $\mathrm{S} 13$ or $\mathrm{S} 14$ or $\mathrm{S} 15$ or $\mathrm{S} 16$ or $\mathrm{S} 17$

19 TX "Placebo"

20 TX "SSRI"

21 TX "SSRIs"

22 TX "Fluoxetine"

23 TX "fluvoxamine"

24 TX "Sertraline"

25 TX "paroxetine"

26 TX "Citalopram" 
27 TX "Escitalopram"

28 TX "Serotonin uptake inhibitor"

29 TX "Serotonin reuptake inhibitors"

$30 \mathrm{MH}$ "Serotonin uptake inhibitors"

$31 \mathrm{~S} 19$ or $\mathrm{S} 20$ or $\mathrm{S} 21$ or $\mathrm{S} 22$ or $\mathrm{S} 23$ or $\mathrm{S} 24$ or $\mathrm{S} 25$ or S26 or S27 or S28 or S29 or S30

32 TX "suicide, completed"

33 TX "Suicidal*"

34 TX "suicide, attempted"

35 TX "attempted suicide"

36 TX "emergent suicide behaviour"

37 TX "emergent suicide behaviour"

38 TX "suicide risk"

39 TX "suicidal ideation"

$40 \mathrm{MH}$ " suicide"

$41 \mathrm{~S} 32$ or $\mathrm{S} 33$ or $\mathrm{S} 34$ or $\mathrm{S} 35$ or S36 or S37 or S38 or S39 or $\mathrm{S} 40$

42 TX "randomized controlled trials"

43 TX "randomised controlled trials"

44 TX "randomized controlled trial"

45 TX "randomised controlled trial"

46 TX "prospective randomized controlled trial"

47 TX " prospective randomised controlled trial "

48 TX "randomized clinical trial"

49 TX "randomised clinical trial"

50 TX "clinical trial"

51 TX "clinical trials"

52 TX "observational study"

53 TX "observational studies"

54 TX "case-control study"

55 TX "case-control studies"

56 TX "case control study"

57 TX "cohort study"

58 TX "cohort studies"

59 TX "prospective study" 
60 TX "prospective studies"

61 S42 or $\$ 43$ or $\$ 44$ or $S 45$ or $\$ 46$ or $\$ 47$ or $\$ 48$ or $\$ 49$ or $\$ 50$ or $\$ 51$ or $\$ 52$ or $\$ 53$ or $\$ 54$ or $\mathrm{S} 55$ or $\mathrm{S} 56$ or $\mathrm{S} 57$ or $\mathrm{S} 58$ or $\mathrm{S} 59$ or $\mathrm{S} 60$

62 S10 and S18 and S31 and S41 and S61

63 Limit to English language

Database: Psychlnfo (No. of potentially relevant studies-97 searched on 28/11/2012)

Search Keywords

1 TX "elder"

2 TX "aged"

3 TX "ageing"

4 TX "Senior"

5TX "Geriatric"

6 TX "Old" people"

7 TX "Old* adult"

8 TX "Old" patient"

$9 \mathrm{MJ}$ "Aged+"

$10 \mathrm{~S} 1$ or $\mathrm{S} 2$ or $\mathrm{S} 3$ or $\mathrm{S} 4$ or $\mathrm{S} 5$ or $\mathrm{S} 6$ or $\mathrm{S} 7$ or $\mathrm{S} 8$ or $\mathrm{S} 9$

11 TX "depression"

12 TX "major depression"

13 TX "depressed"

14 TX "depressive disorder, major"

15 TX "Melancholia, involutional"'

16 TX "depressive disorder"

$17 \mathrm{MJ}$ "Major depressive disorder"

$18 \mathrm{~S} 11$ or $S 12$ or $S 13$ or $S 14$ or $S 15$ or $S 16$ or $S 17$

19 TX "Placebo"

20 TX "SSRI"

21 TX "SSRIs"

22 TX "Fluoxetine"

23 TX "fluvoxamine"

24 TX "Sertraline"

25 TX "paroxetine"

26 TX "Citalopram" 
27 TX "Escitalopram"

28 TX "Serotonin uptake inhibitor"

29 TX "Serotonin reuptake inhibitors"

$30 \mathrm{MJ}$ "Serotonin uptake inhibitors"

$31 \mathrm{~S} 19$ or $\mathrm{S} 20$ or $\mathrm{S} 21$ or $\mathrm{S} 22$ or $\mathrm{S} 23$ or $\mathrm{S} 24$ or $\mathrm{S} 25$ or $\mathrm{S} 26$ or $\mathrm{S} 27$ or $\mathrm{S} 28$ or $\mathrm{S} 29$ or $\mathrm{S} 30$

32 TX "suicide, completed"

33 TX "Suicidal*"

34 TX "suicide, attempted"

35 TX "attempted suicide"

36 TX "emergent suicide behaviour"

37 TX "emergent suicide behaviour"

38 TX "suicide risk"

39 TX "suicidal ideation"

40 MJ "suicide"

$41 \mathrm{~S} 32$ or $\mathrm{S} 33$ or $\mathrm{S} 34$ or $\mathrm{S} 35$ or $\mathrm{S} 36$ or $\mathrm{S} 37$ or $\mathrm{S} 38$ or $\mathrm{S} 39$ or $\mathrm{S} 40$

42 TX "randomized controlled trials"

43 TX "randomised controlled trials"

44 TX " randomized controlled trial"

45 TX "randomised controlled trial"

46 TX "prospective randomized controlled trial"

47 TX " prospective randomised controlled trial "

48 TX "randomized clinical trial"

49 TX "randomised clinical trial"

50 TX "clinical trial"

51 TX "clinical trials"

52 TX "observational study"

53 TX "observational studies"

54 TX "case-control study"

55 TX "case-control studies"

56 TX "case control study"

57 TX "cohort study"

58 TX "cohort studies"

59 TX "prospective study" 
60 TX "prospective studies"

61 S42 or $\$ 43$ or $\$ 44$ or $\$ 45$ or $\$ 46$ or $\$ 47$ or $\$ 48$ or $\$ 49$ or $\$ 50$ or $\$ 51$ or $\$ 52$ or $\$ 53$ or $\$ 54$

or $\mathrm{S} 55$ or $\mathrm{S} 56$ or $\mathrm{S} 57$ or $\mathrm{S} 58$ or $\mathrm{S} 59$ or $\mathrm{S} 60$

62 S10 and S18 and S31 and S41 and S61

63 Limit to English language

Database: PsycARTICLES (No. of potentially relevant studies-136 searched on 28/11/2012)

Search Keywords

1 TX "elder"

2 TX "aged"

3 TX "ageing"

4 TX "Senior"

5 TX "Geriatric"

6 TX "Old* people"

7 TX "Old* adult"

8 TX "Old* patient"

$9 \mathrm{MH}$ "Aged+"

$10 \mathrm{~S} 1$ or $\mathrm{S} 2$ or $\mathrm{S} 3$ or $\mathrm{S} 4$ or $\mathrm{S} 5$ or $\mathrm{S} 6$ or $\mathrm{S} 7$ or $\mathrm{S} 8$ or $\mathrm{S} 9$

11 TX "depression"

12 TX "major depression"

13 TX "depressed"

14 TX "depressive disorder, major"

15 TX "Melancholia, involutional"'

16 TX "depressive disorder"

$17 \mathrm{MH}$ "Major depressive disorder"

$18 \mathrm{~S} 11$ or $\mathrm{S} 12$ or $\mathrm{S} 13$ or $\mathrm{S} 14$ or $\mathrm{S} 15$ or $\mathrm{S} 16$ or $\mathrm{S} 17$

19 TX "Placebo"

20 TX "SSRl"

21 TX "SSRIs"

22 TX "Fluoxetine"

23 TX "fluvoxamine"

24 TX "Sertraline"

25 TX "paroxetine"

26 TX "Citalopram" 
27 TX "Escitalopram"

28 TX "Serotonin uptake inhibitor"

29 TX "Serotonin reuptake inhibitors"

$30 \mathrm{MH}$ "Serotonin uptake inhibitors"

$31 \mathrm{~S} 19$ or $\mathrm{S} 20$ or $\mathrm{S} 21$ or $\mathrm{S} 22$ or $\mathrm{S} 23$ or S24 or S25 or S26 or S27 or S28 or S29 or S30

32 TX "suicide, completed"

33 TX "Suicidal*"

34 TX "suicide, attempted"

35 TX "attempted suicide"

36 TX "emergent suicide behaviour"

37 TX "emergent suicide behaviour"

38 TX "suicide risk"

39 TX "suicidal ideation"

$40 \mathrm{MH}$ " suicide"

41 S32 or S33 or S34 or S35 or S36 or S37 or S38 or S39 or S40

42 TX "randomized controlled trials"

43 TX "randomised controlled trials"

44 TX " randomized controlled trial"

45 TX "randomised controlled trial"

46 TX "prospective randomized controlled trial"

47 TX " prospective randomised controlled trial "

48 TX "randomized clinical trial"

49 TX "randomised clinical trial"

50 TX "clinical trial"

51 TX "clinical trials"

52 TX "observational study"

53 TX "observational studies"

54 TX "case-control study"

55 TX "case-control studies"

56 TX "case control study"

57 TX "cohort study"

58 TX "cohort studies"

59 TX "prospective study" 
60 TX "prospective studies"

61 S42 or S43 or S44 or S45 or S46 or S47 or S48 or S49 or S50 or S51 or S52 or S53 or S54 or $\mathrm{S} 55$ or $\mathrm{S} 56$ or $\mathrm{S} 57$ or $\mathrm{S} 58$ or $\mathrm{S} 59$ or $\mathrm{S} 60$

62 S10 and S18 and S31 and S41 and S61

63 Limit to English language

Database: Cochrane Central Trials Register (Potentially relevant studies-55 searched on

$\underline{04 / 10 / 2012)}$

Search Keywords

1 "depression"

2 "major depression"

3 "depressed"

4 "depressive disorder, major"

5 "Melancholia, involutional"'

6 "depressive disorder"

7 "depression"

$8 \# 1$ or \#2 or \#3 or \#4 or \#5 or \#6 or \#7

9 "elder"

10 "aged"

11 "ageing"

12 "Senior"

13 "Geriatric"

14 "Old* people"

15 "Old* adult"

16 "Old* patient"

17 "elder"

18 "Agedt"

$19 \# 9$ or $\# 10$ or $\# 11$ or\#12 or \#13 or \#14 or \#15 or \#16 or \#17 or \#18

20 "SSRl" or "SSRIs"

21 "serotonin uptake inhibitors" or serotonin reuptake inhibitors"

22 (fluoxetine or Fluvoxamine or sertraline or paroxetine or citalopram or escitalopram)

$23 \# 20$ or \#21 or \#22

24 (Suicide or suicidal ideation or suicide attempt or suicidal behaviour or suicide Risk)

25 "emergent suicide behaviour" or "emergent suicide behaviour" 
$26 \# 24$ or \#25

27 \#8 and \#19 and \#23 and \#26

28 Limits to English

Database: Science Direct 321 studies searched on 04/10/2012

Search Keywords

articles found for: (Randomized Controlled Trials as topic OR Randomised Controlled Trials as topic OR Double-Blind Method OR case -control studies OR cohort studies OR prospective studies) AND (Suicide Attempted* [tiab] OR Suicide/prevention \& control*[tiab] OR Suicidal ideation*[tiab] OR Suicide Risk Factors OR Suicide Prognosis OR suicide/psychology OR suicide, Attempted/psychology OR suicide attempted/statistics and numerical data) AND (Serotonin Uptake Inhibitors OR Serotonin Uptake Inhibitors/adverse effects*[tiab] OR Antidepressive agents OR Antidepressive agents/adverse effects OR Fluoxetine OR fluvoxamine OR Sertraline OR Paroxetine OR Citalopram OR Escitalopram) AND ( Depressive Disorder/drug therapy OR Depressive disorder/mortality OR depressive disorder Major/Epidemiology OR Depressive Disorder, Major/Psychology*[tiab]) AND (Adult OR Aged*[tiab] OR Aged OR Aged 80 and over OR Female OR Human OR Male OR Aging OR Randomized Controlled Trials as topic OR Double-Blind Method OR case -control studies, cohort studies OR prospective studies)

Database: ProQuest Dissertations and Theses Database 64 studies searched on 08/12/12 Search Keywords

articles found for: (Randomized Controlled Trials as topic OR Randomised Controlled Trials as topic OR Double-Blind Method OR case -control studies OR cohort studies OR prospective studies) AND (Suicide Attempted* [tiab] OR Suicide/prevention \& control*tiab] OR Suicidal ideation*[tiab] OR Suicide Risk Factors OR Suicide Prognosis OR suicide/psychology OR suicide, Attempted/psychology OR suicide attempted/statistics and numerical data) AND (Serotonin Uptake Inhibitors OR Serotonin Uptake Inhibitors/adverse effects*[tiab] OR Antidepressive agents OR Antidepressive agents/adverse effects OR Fluoxetine OR fluvoxamine OR Sertraline OR Paroxetine OR Citalopram OR Escitalopram) AND ( Depressive Disorder/drug therapy OR Depressive disorder/mortality OR depressive disorder Major/Epidemiology OR Depressive Disorder, Major/Psychology*[tiab]) AND (Adult OR Aged*[tiab] OR Aged OR Aged 80 and over OR Female OR Human OR Male OR Aging OR Randomized Controlled Trials as topic OR Double-Blind Method OR case -control studies, cohort studies OR prospective studies) 


\subsection{Appendix III}

\section{JBI Critical Appraisal Checklist for Randomised Control / Pseudo-randomised Trial}

Reviewer

Record Number

Author

Year

1. Was the assignment to treatment groups truly random?

2. Were participants blinded to treatment allocation?

3. Was allocation to treatment groups concealed from the allocator?

4. Were the outcomes of people who withdrew described and included in the analysis?

5. Were those assessing outcomes blind to the treatment allocation?

6. Were the control and treatment groups comparable at entry?

7. Were groups treated identically other than for the named interventions

8. Were outcomes measured in the same way for all groups?

9. Were outcomes measured in a reliable way?

10. Was appropriate statistical analysis used?

Yes

No

Unclear

Not Applicable

Overall appraisal:

Include

Exclude

Seek further info.

Comments (Including reason for exclusion) 


\title{
JBI Critical Appraisal Checklist for Comparable Cohort/ Case Control
}

\author{
Reviewer ............ Date \\ Author \\ Year \\ Record Number \\ Yes \\ No \\ Unclear Not Applicable \\ 1. Is sample representative of patients \\ in the population as a whole? \\ 2. Are the patients at a similar point in \\ the course of their condition/illness? \\ 3. Has bias been minimised in relation \\ to selection of cases and of \\ controls? \\ 4. Are confounding factors identified \\ and strategies to deal with them \\ stated? \\ 5. Are outcomes assessed using \\ objective criteria? \\ 6. Was follow up carried out over a \\ sufficient time period? \\ 7. Were the outcomes of people who \\ withdrew described and included in \\ the analysis? \\ 8. Were outcomes measured in a \\ reliable way? \\ 9. Was appropriate statistical analysis \\ used?
}

Overall appraisal: Include

Exclude

Seek further info.

Comments (Including reason for exciusion) 
JBI Data Extraction Form for

Experimental / Observational Studies

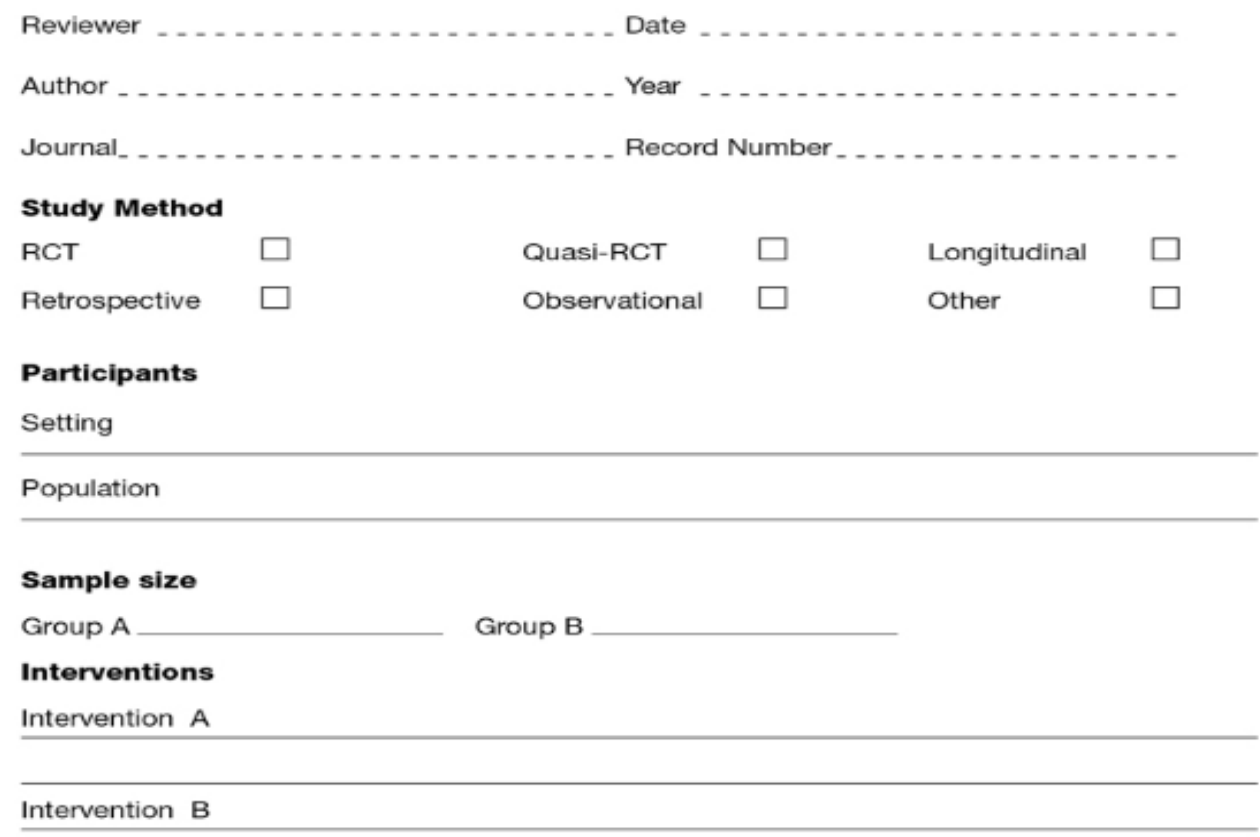

Authors Conclusions:

Reviewers Conclusions: 


\subsection{Appendix IV}

List of Excluded RCTs with no report on suicide/suicide attempt

\begin{tabular}{|c|c|c|c|}
\hline No. & Studies & Study type/Population & Note \\
\hline 1 & $\begin{array}{l}\text { Bondareff W, Alpert M et al. } \\
2000\end{array}$ & $\begin{array}{l}\text { RCT for } 10 \text { weeks } \\
\text { Sertraline/105 vs Nortriptyline/105 }\end{array}$ & $\begin{array}{l}20 \text { in sertraline } \\
\text { and } 19 \text { in } \\
\text { nortriptyline } \\
\text { withdrew due } \\
\text { to side effects } \\
\text { Efficacy, } \\
\text { remission } \\
\text { similar 53/74 in } \\
\text { sertraline, } \\
43 / 70 \\
\text { nortriptyline at } \\
\text { all points in } \\
\text { time }\end{array}$ \\
\hline 2 & Cohn CK et al. 1990 & $\begin{array}{l}\text { RCT for } 8 \text { weeks } \\
\text { Sertraline/161 vs Amitriptyline/ } 80\end{array}$ & $\begin{array}{l}\text { Similar } \\
\text { response on } \\
\text { HAMD. } \\
\text { Safety=Sertrali } \\
\text { ne } 30.5 \% \\
\text { Amitriptyline } \\
35 \% \text { withdrew }\end{array}$ \\
\hline 3 & Dalery J et al. 2001 & $\begin{array}{l}\text { RCT for } 6 \text { weeks, } 116 \text { patients }>60 \\
\text { Paroxetine/54/43 completed vs } \\
\text { Mianserin/62/53 completed }\end{array}$ & $\begin{array}{l}\text { Similar } \\
\text { efficacy, } 11.1 \% \\
\text { paroxetine and } \\
12.9 \% \\
\text { mianserin } \\
\text { withdrew due } \\
\text { to side effect }\end{array}$ \\
\hline
\end{tabular}




\begin{tabular}{|c|c|c|c|}
\hline 4 & De Ronchi D et al. 1998 & $\begin{array}{l}\text { RCT for } 10 \text { weeks, } 65 \text { patients }>60 \\
\text { Fluoxetine/32 vs Amitriptyline/33 }\end{array}$ & $\begin{array}{l}\text { Equally } \\
\text { effective }\end{array}$ \\
\hline 5 & Fairweather DB et al. 1993 & $\begin{array}{l}\text { RCT parallel group } 6 \text { weeks, } 66 \text { pts } \\
>60 \text {, Fluoxetine vs Amitriptyline }\end{array}$ & Similar efficacy \\
\hline 6 & Falk WE et al. 1989 & $\begin{array}{l}\text { RCT for } 7 \text { weeks, } 27 \text { patients }>62 \\
\text { Fluoxetine/14 vs Trazodone/13 }\end{array}$ & Similar efficacy \\
\hline 7 & Forlenza et al. 2000 & $\begin{array}{l}\text { RCT } \times 6 \text { weeks } \\
\text { Sertraline/28, imipramine/27 }\end{array}$ & $\begin{array}{l}\text { Outcome - } \\
\text { both } \\
\text { efficacious }\end{array}$ \\
\hline 8 & Karlsson I et al. 2000 & $\begin{array}{l}\text { RCT } 12 \text { weeks } \\
\text { Citalopram/157 vs Mianserin/163 }\end{array}$ & Dysthymia \\
\hline 9 & La Pia S et al. 1992 & $\begin{array}{l}\text { RCT } 6 \text { weeks } 20 / 20 \text { then } \\
\text { Fluoxetine/19 vs Mianserin/16 }\end{array}$ & $\begin{array}{l}\text { Similar efficacy } \\
\text { One } \\
\text { drop/failure to } \\
\text { follow up in Flu } \\
\text { three in Mian } \\
\text { due to s/e }\end{array}$ \\
\hline 10 & Mulsant BH et al. 1999 & $\begin{array}{l}\text { RCT for } 6 \text { weeks } \\
\text { Paroxetine/43-29 vs Nortirptyline/37-27 }\end{array}$ & $\begin{array}{l}14 \% \text { of Nor } \\
\text { and } 19 \% \text { of } \\
\text { Par } \\
\text { discontinued } \\
\text { due to s/e } \\
\text { Efficacy was } \\
\text { similar }\end{array}$ \\
\hline 11 & Mamo D et al. 2002 & $\begin{array}{l}\text { RCT for six weeks } \\
\text { Paroxetine/25 vs Nortriptyline/17 }\end{array}$ & $\begin{array}{l}\text { No significant } \\
\text { change in } \\
\text { postural sway }\end{array}$ \\
\hline
\end{tabular}




\begin{tabular}{|c|c|c|c|}
\hline & & & in both groups \\
\hline 12 & Phanjoo AL et al. 1991 & $\begin{array}{l}\text { Comparative study x } 6 \text { weeks } \\
\text { Fluvoxamine/7/25 vs } 4 / 25 \text { Mianserin }\end{array}$ & Similar efficacy \\
\hline 13 & Newhouse PA et al. 1992 & $\begin{array}{l}\text { RCT x } 12 \text { weeks, } 70-93 \text { years } \\
\text { Fluoxetine/33 vs Sertraline/42 }\end{array}$ & $\begin{array}{l}73 \% \text { vs } 71 \% \\
\text { responded }\end{array}$ \\
\hline 14 & Finkel SI et al. 1992 & $\begin{array}{l}\text { Comparative trial } 12 \text { weeks }>70 \\
\text { Sertraline/42 vs Nortriptyline/33 }\end{array}$ & $\begin{array}{l}\text { No significant } \\
\text { difference in } \\
\text { rate of adverse } \\
\text { events }\end{array}$ \\
\hline 15 & Rossini D et al. 2005 & $\begin{array}{l}\text { RCT for } 7 \text { weeks, } 93 \text { patients } \\
\text { Sertraline/45 vs fluvoxamine/39 }\end{array}$ & $\begin{array}{l}\text { Fluvoxamine - } \\
\text { faster speed of } \\
\text { response }\end{array}$ \\
\hline 16 & Schatzberg AF et al. 2002 & $\begin{array}{l}\text { RCT for } 6 \text { weeks, extended to } 12 \\
\text { weeks } \\
\text { Paroxetine/120 vs Mirtazapine/126 }\end{array}$ & $\begin{array}{l}\text { Primary- } \\
\text { efficacy= } \\
\text { Mirtazapine } \\
\text { faster onset at } \\
\text { one week, } \\
\text { better tolerable }\end{array}$ \\
\hline 17 & $\begin{array}{l}\text { Schone W, Ludwig M et al. } \\
1993\end{array}$ & $\begin{array}{l}\text { RCT for } 6 \text { weeks } \\
\text { Paroxetine/54 vs Fluoxetine/52 }\end{array}$ & $\begin{array}{l}\text { Efficacy } \\
\text { Paroxetine } \\
\text { more } \\
\text { favourable, } \\
\text { greater } \\
\text { cognitive } \\
\text { improvement in } \\
\text { paroextine }\end{array}$ \\
\hline 18 & Weber E et al. 2000 & $\begin{array}{l}\text { Double-blind RCT for } 12 \text { weeks } \\
\text { Nortriptyline/28 vs Paroxetine/34 }\end{array}$ & $\begin{array}{l}\text { Primary } \\
\text { outcome- } \\
\text { weight change, } \\
\text { no difference } \\
\text { between two } \\
\text { groups }\end{array}$ \\
\hline
\end{tabular}




\begin{tabular}{|c|c|c|c|}
\hline 19 & Weihs K et al. 2000 & $\begin{array}{l}\text { RCT for } 6 \text { weeks } \\
\text { Paroextine/52 vs Bupropion SR/48 }\end{array}$ & $\begin{array}{l}\text { Primary } \\
\text { outcome - Both } \\
\text { equally } \\
\text { efficacious }\end{array}$ \\
\hline 20 & Bruce ML et al. 2004 & Antidepressant & Meta-analysis \\
\hline 21 & Schatzberg A et al. 2006 & $\begin{array}{l}\text { RCT for } 8 \text { weeks, } 104 \text { patients } \\
\text { enlafaxine, Fluoxetine vs Placebo }\end{array}$ & $\begin{array}{l}\text { No significant } \\
\text { difference in } \\
\text { efficacy }\end{array}$ \\
\hline 22 & Banerjee S et al. 2011 & $\begin{array}{l}\text { RCT for } 13 \text { weeks, 111: 107: } 108 \\
\text { Placebo: Sertraline vs Mirtazapine }\end{array}$ & $\begin{array}{l}\text { Absence of } \\
\text { benefit } \\
\text { compared to } \\
\text { Placebo }\end{array}$ \\
\hline 23 & Evans M et al. 1997 & $\begin{array}{l}\text { RCT for } 8 \text { weeks, } 82 \text { physically ill } \\
\text { patients } \\
\text { Fluoxetine vs Placebo }\end{array}$ & $\begin{array}{l}\text { Fluoxetine } \\
\text { more } \\
\text { efficacious } \\
\text { than Placebo } \\
\text { Presence of } \\
\text { physical illness } \\
\text { did not reduce } \\
\text { the } \\
\text { effectiveness } \\
\text { of } \\
\text { antidepressant }\end{array}$ \\
\hline 24 & Klysner R et al. 2002 & $\begin{array}{l}230 \text { patients, RCT for } 8-48 \text { weeks } \\
\text { Citalopram vs Placebo }\end{array}$ & $\begin{array}{l}\text { Time to } \\
\text { recurrence was } \\
\text { more } \\
\text { favourable with } \\
\text { Citalopram, } \\
\text { well tolerated }\end{array}$ \\
\hline 25 & Rapaport MH et al. 2003 & $\begin{array}{l}\text { RCT for } 12 \text { weeks, } 319 \text { patients, } \\
\text { Paroxetine CR vs Placebo }\end{array}$ & $\begin{array}{l}\text { Paroxetine } \\
\text { more effective } \\
\text { than placebo }\end{array}$ \\
\hline 26 & Rapaport MH et al. 2009 & RCT for 10 weeks, 345 patients & Paroxetine low \\
\hline
\end{tabular}




\begin{tabular}{|c|c|c|c|}
\hline & & Paroxetine CR vs Placebo & $\begin{array}{l}\text { dose more } \\
\text { efficacious } \\
\text { than placebo, } \\
\text { well tolerated. }\end{array}$ \\
\hline 27 & Roose S et al. 2004 & $\begin{array}{l}\text { RCT for } 8 \text { weeks, } 174 \text { patients }>75 \\
\text { Citalopram vs Placebo }\end{array}$ & $\begin{array}{l}\text { Medication } \\
\text { was no more } \\
\text { effective than } \\
\text { placebo }\end{array}$ \\
\hline 28 & Wakelin et al. 1986 & $\begin{array}{l}\text { DB Placebo control trial } \\
\text { Fluvoxamine/33 vs imipramine/29 vs } \\
\text { placebo } 14 \\
4 \text { weeks data }\end{array}$ & $\begin{array}{l}\text { Outcome- } \\
\text { efficacy- } \\
\text { Fluvoxamine } \\
\text { and Imi } \\
\text { superior to } \\
\text { placebo after } \\
\text { week } 4\end{array}$ \\
\hline 29 & $\begin{array}{l}\text { Nyth AL, Gottfries CG et al. } \\
1992\end{array}$ & $\begin{array}{l}\text { RCT for } 6 \text { weeks, } 149 \text { patients }>65 \\
\text { Citalopram vs Placebo }\end{array}$ & $\begin{array}{l}\text { Citalopram } \\
\text { treated } \\
\text { patients } \\
\text { improved more } \\
\text { than placebo }\end{array}$ \\
\hline 30 & Reynolds CF et al. 2006 & $\begin{array}{l}\text { RCT for } 2 \text { years, } 116 \text { patients, mean } \\
\text { age was } 77 \text { years } \\
\text { Paroxetine } 63 \text { vs Interpersonal Therapy } \\
53\end{array}$ & $\begin{array}{l}\text { Outcome was } \\
\text { recurrence of } \\
\text { depression, no } \\
\text { data on } \\
\text { suicide. }\end{array}$ \\
\hline 31 & Szanto K et al. 2003, & $\begin{array}{l}\text { RCTs for } 12 \text { weeks, } 395 \text { elderly } \\
\text { Nortriptyline vs Paroxetine }\end{array}$ & $\begin{array}{l}\text { Aged mixed } 40 \\
\text { to } 65 \text { and over }\end{array}$ \\
\hline 32 & Szanto K et al. 2007 & $\begin{array}{l}\text { RCTs for } 12 \text { weeks, } 437 \text { elderly } \\
\text { Nortriptyline vs Paroxetine }\end{array}$ & $\begin{array}{l}\text { No primary } \\
\text { patient data } \\
\text { available }\end{array}$ \\
\hline
\end{tabular}

